\title{
Adrenal Involvement in Determining the Time of Onset of Puberty in the Rat
}

Marianne Gorski Firlit

Loyola University Chicago

Follow this and additional works at: https://ecommons.luc.edu/luc_diss

\section{Recommended Citation}

Firlit, Marianne Gorski, "Adrenal Involvement in Determining the Time of Onset of Puberty in the Rat" (1974). Dissertations. 1325.

https://ecommons.luc.edu/luc_diss/1325

This Dissertation is brought to you for free and open access by the Theses and Dissertations at Loyola eCommons. It has been accepted for inclusion in Dissertations by an authorized administrator of Loyola eCommons. For more information, please contact ecommons@luc.edu. (c) $($ ) $\Theta \Theta$

This work is licensed under a Creative Commons Attribution-Noncommercial-No Derivative Works 3.0 License. Copyright (c) 1974 Marianne Gorski Firlit 
ADRENAL INVOLVEMENT IN DETERMINING THE

TIME OF ONSET OF

PUBERTY IN THE RAT

by

Marlanne Gorski Firlit

Submitted as Partlal Fulfillment of the Requirements of the Doctor of Philosophy Degree in Physiology at the Stritch School of Medicine of Loyola University Maywood, lllinois

1974 


\section{ACKNOWLEDGEMENTS}

My gratitude goes to Irene E. Lawton, Ph.D. for her guidance and patience as my advisor during the years of my graduate training and to Walter C. Randall, Ph.D. and the Department of Physiology for presenting a unique and rewarding scientific challenge.

My thanks go to Method Duchon, who helped in the time consuming rat autopsies and who found these results exciting enough to pursue the concept in the male rat, and to Mrs. Mira Milosavljevic for her excellent histological preparation of the tissues.

My appreclation goes to my parents, Mr. and Mrs. James Gorski, for their constant encouragement and understanding during the years of my formal education, and to Robert S. Firlit, M.D., who spent many holidays and weekends helping autopsy rats, for his support, encouragement and interest in my work. 


\section{BIOGRAPHY}

Marlanne Gorski Firlit was born January 29, 1948 in Chicago, Illinois and was graduated from Lafayette Grammar School and Tuley High School, both in Chicago. In June of 1969 she received a Bachelor of Science degree in Biology from Loyola University of Chicago. In the Fall of that year she began her graduate training at Loyola University Stritch School of Medicine, Department of Physlology, with the support of the National Institutes of Health Research Training Grant. The work for this dissertation was begun in the Fall of 1970 under the guidance of Irene E. Lawton, Ph.D. In June of 1973 she was married to Robert S. Firlit, M.D. 


\section{ABSTRACT}

Previous investigators have presented data which suggest an interaction of the adrenal glands with the hypothalamic-pltuitary-ovarian axis in the adult rat. The question arises as to what role, if any, these secretions play in the first ovulation and in the developmental period preceding it. Therefore the role of the developing adrenal glands in the maturation of the hypothalamic-pituitary-ovarian axis in the rat was: investigated.

Female rats were received at 18 days of age, from ARS/SpragueDawley (Madison, Wisconsin), and housed two to three per cage under controlled lighting of 14 hours light and 10 hours dark. All animals were inspected daily from 30 days of age for vaginal opening.

In the first of four studies, the animals were bilaterally adrenalectomized, adrenal autotransplanted (adrenals removed and immediately placed subcutaneously) or laparotomized under ether anesthesia at 18,25 and 35 days of age. All adrenalectomized and adrenal autotransplanted animals were given a $1 \%$ saline drinking solution. Adrenalectomy at 18 and 25 but not 35 days of age delays puberty onset. Adrenal autotransplantation at 18 but not 25 days of age reverses the adrenalectorny-induced delay in puberty by supplying adrenal cortical hormones to the circulation. Adrenalectomy was also shown to affect the fine tuning of the cyclic reproductive processes by increasing the incidence of pseudopregnancy. 
In the second study this interaction period was more clearly defined. Animals were divided into controls and treatment groups: bilaterally adrenalectomized and sham-operated and were further divided according to the age and time at which surgery was performed. From this experiment it was established that a period of adrenalectomy-induced delay in puberty extends from 18 days of age to 1:00 AM on day 26 and a period of sham-induced advancement in puberty extends from 1:00 AM on day 26 to 30 days of age.

In the third study an attempt was made to isolate the substance(s) responsible for the interaction of the two systems. Adrenalectomized and control animals were given injections of progesterone, and/or corticosterone, ACTH or vehicle at various ages to determine the effect on vaginal opening. None of the hormones administered at the doses given were effective in mimicking the effects of the stress-induced advancement of puberty onset or reversing the adrenalectomy-induced delay in puberty onset, but this does not exclude the possibility of their interaction in the system.

In the fourth study the developmental changes in corticosterone output were examined. It was demonstrated that a circadian rhythm of corticosterone secretion is already present by 20 days of age with no change in this rhythm from day 20 through day 28.

The period of adrenalectomy-induced delay (18-26 days of age) and the sham-induced advancement (26-30 days of age) occur during the - late juvenile period when both the adrenal and reproductive systems are maturing. Whatever the factor(s) responsible for this interaction, estrogen, progesterone or corticosterone, it is clear that adrenals have an important role in determining the time of onset of puberty in the female rat. 


\section{TABLE OF CONTENTS}

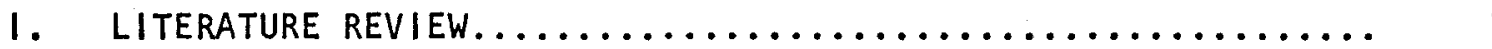

A. Brain-Pituitary-Ovarian Interactions...............

1. The rat estrous cycle: general description and discussion of hormonal regulation.............. I

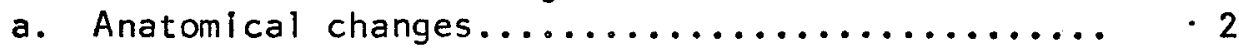

b. Hormonal changes and interactions............ 3

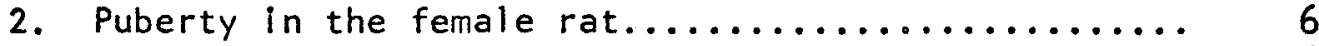

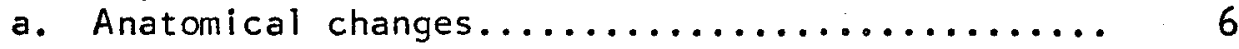

b. Hormonal changes and interactions............ 7

c. Neural control of puberty................. 13

d. External factors which influence the time of onset of puberty................... 15

B. Brain-Pituitary-Adrenal Interactions.............. 17

1. The adult adrenal gland: general description

and discussion of hormonal regulation........... 17

a. Anatomical description.................... 17

b. Hormonal changes and interactions............. 19

c. Regulation of corticosterone secretion......... 23

d. The influence of gonadal hormones upon adrenal cortical function................. 26

2. Developmental changes in adrenal morphology

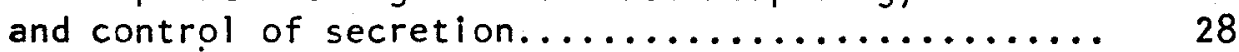

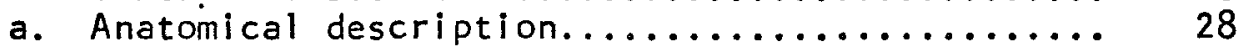

b. Hormonal changes and interactions........... 30

C. Adrenal - Ovarian Interactions.................. 33

1. Adrenal-ovarian interaction in the adult rat....... 33

2. Adrenal-ovarian interaction in the immature rat.... 38

D. Statement of Problem..................... 45

11. MATERIALS AND METHODS........................ 46

A. Animals and Housing...................... 46

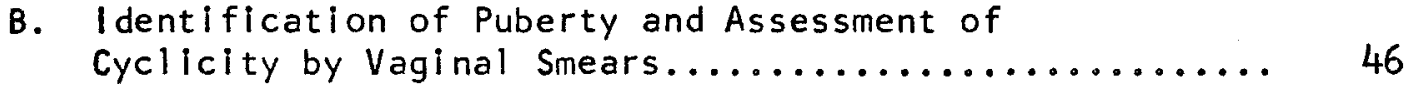


C. Treatments............................... 47

1. Laparotomy, adrenalectomy and adrenal

autotransplantation..................... 47

2. Hormone administration....................... 48

D. Autopsy Procedures............................. 48

1. Blood and tissue collection................... 48

2. Detection of ovulation and evaluation of cycle stage.. 49

E. Histology.............................. 50

F. Measurement of Corticosterone................... 50

111. RESULTS AND COMMENTS........................ 53

A. Study 1: Adrenal Involvement in Determining the Time of Onset of Puberty in the Rat................... 53

1. Experimental design...................... 53

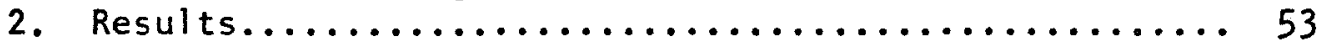

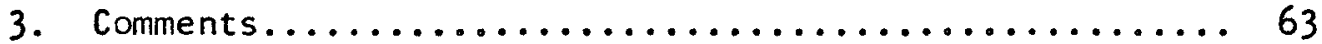

4. Conclusions................................ 66

B. Study II: Timing of the Prepuberal Adrenal-Ovarian

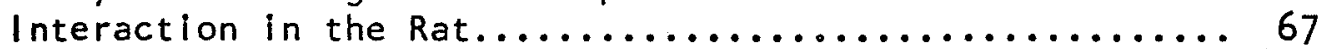

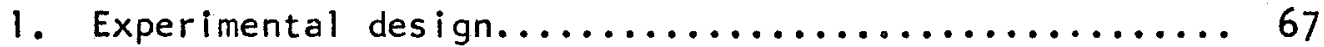

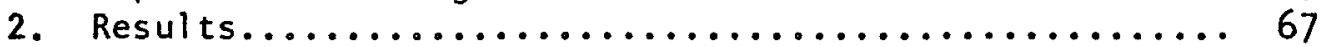

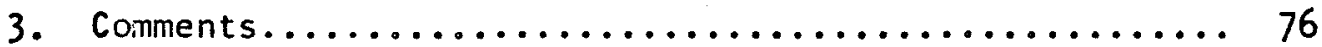

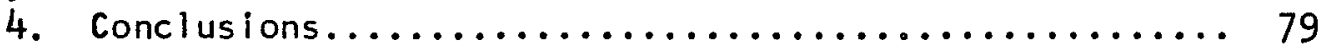

C. Study I11: Hormonal Effects on Vaginal Opening......... 81

1. Experimental design........................ 81

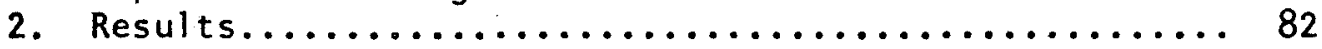

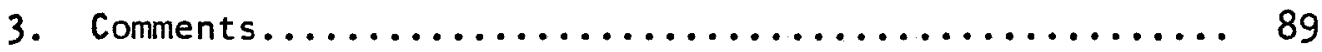

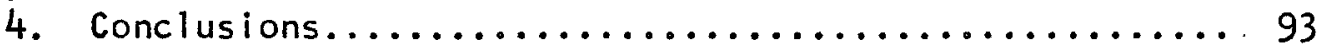

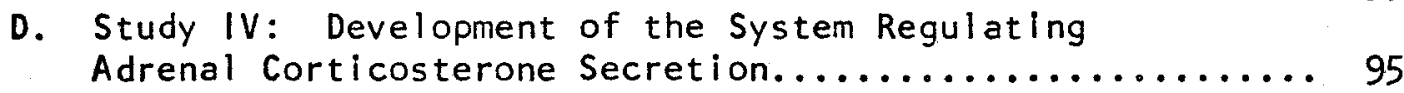

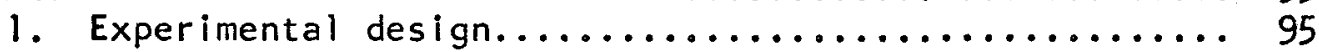

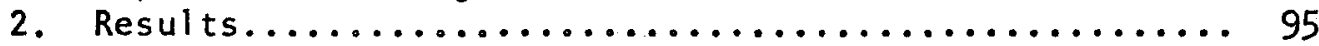

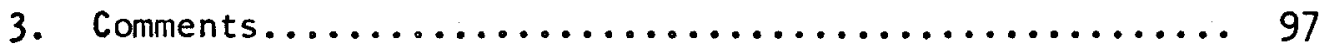

4. Conclusions.............................. 99

IV. DISCUSSION............................... 101

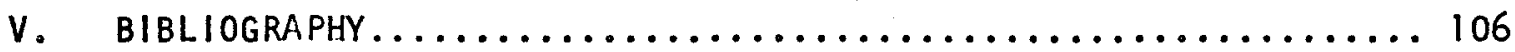




\section{LIST OF TABLES}

Tables

Page

1. Comparison of the Controls Receiving Tap Water

and those Receiving a $1 \%$ Salt Solution in Study $1 . . . . . .54$

11. Effect of Treatment on Body Weight and Specific

Gravity of Urine in Study $1 \ldots \ldots \ldots \ldots \ldots \ldots \ldots \ldots \ldots \ldots . \ldots \ldots$

111. Effect of Treatment on Puberty Onset and Cyclicity

in Study $1 . \ldots \ldots \ldots \ldots \ldots \ldots \ldots \ldots \ldots \ldots \ldots \ldots \ldots . \ldots . \ldots . \ldots$

IV. Comparison of Control Organ Weights During the

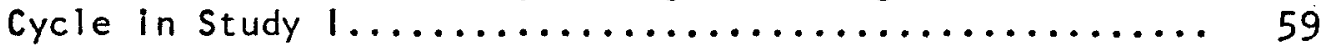

V. Effect of Treatment on Organ Weight in Study $1 \ldots \ldots \ldots 60$

VI. Effect of Treatment on Body Weight at Puberty in

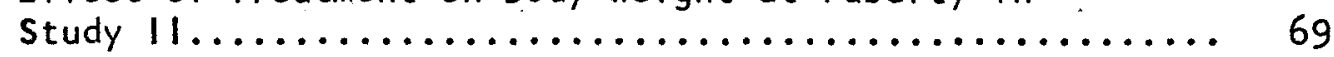

VII. Effect of Time of Year on Puberty Onset............ 70

VIII. Effect of Adrenalectomy and Laparotomy on Puberty

Onset in Study $11 \ldots \ldots \ldots \ldots \ldots \ldots \ldots \ldots \ldots \ldots \ldots \ldots \ldots \ldots$. 71

IX. Delineation of the Time Course of the Adrenalectomy-

induced Delay and the Sham-induced Advancement

Periods in study $11 \ldots \ldots \ldots \ldots \ldots \ldots \ldots \ldots \ldots \ldots . \ldots . \ldots . \ldots$

X. Effect of Treatment on Ovarian, Uteri.ne and Adrenal

We ights in Study $11 \ldots \ldots \ldots \ldots \ldots \ldots \ldots \ldots \ldots \ldots \ldots \ldots \ldots \ldots . \ldots . \ldots 4$

XI. Effect of Adrenalectomy and Laparotomy on Coincidence of First Estrus and Vaginal 0pening in Study $11 \ldots . . . . .77$

XI1. Effect of Hormone Treatment on Body Weight in Study $111 \ldots 83$

XIII. Effect of Hormone Treatment on Puberty Onset in

Study $111 \ldots \ldots \ldots \ldots \ldots \ldots \ldots \ldots \ldots \ldots \ldots \ldots \ldots \ldots . \ldots \ldots \ldots$ 
XIV. Effect of Hormone Treatment on Puberty Onset in Adrenalectomized Animals in Study $111 . . . \ldots \ldots \ldots \ldots . . . .66$

XV. Effect of Hormone Treatment on Organ Weights

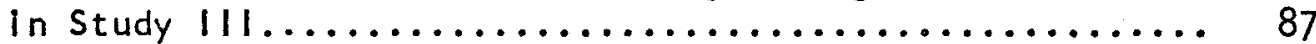

XVI. Effect of Hormone Treatments on Coincidence of First Estrus and Vaginal Opening in Study $111 \ldots . . . \ldots . .88$

XVII. Effect of Hormone Treatments on Coincidence of First Estrus and Vaginal Opening in Adrenalectomized

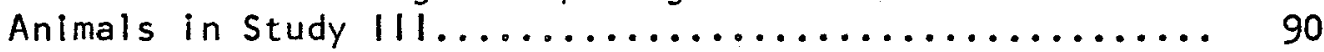

XVIII. Daily Varlations in Plasma Corticosterone in Adult Rats in Study IV....................... 96

XIX. Daily Variations in Plasma Corticosterone in Prepuberal Female Rats in Study IV.................. 98 


\section{LIST OF FIGURES}

Figures

Page

1. Biosynthesis of Active Adrenal Hormones............... 22

2. Ovarian Tissue.............................. 62

3. Adrenal Tissue............................... 64 
CHAPTER ।

\section{LITERATURE REVIEW}

The maturation and cyclic functioning of the reproductive system in the female has been investigated from many approaches, and yet remains a complex problem even in the advent of new techniques which have, in some cases, only confirmed hypotheses of pioneers in the field. The developmental process which culminates in puberty is a composite of interdependent systems: the central nervous system (CNS), the reproductive system, the adrenal system, and probably others. The purpose of this literature review is to explore the mechanics of puberty, which begin the "estrous cycle", and the ovary's interrelationship with the adrenal gland.

\section{A. Brain-Pituitary-Ovarian Interactions}

The chain of events which terminates in ovulation is dependent upon complex interactions of the CNS, pituitary and ovaries. These interactions, termed estrous cycle, are expressed in changes in organ cytology and weight, and hormone levels which maintain the cycle. The question arises: How do these complex interactions begin and why?... a formidable question which we can only begin to answer with the information available at the present time.

1. The Rat Estrous Cycle: General Description and Discussion of Hormonal Regulation. 


\section{a. Anatomical changes}

The classical description of the rat estrous cycle was published in 1922 by Long and Evans who correlated periodic anatomical changes of the reproductive tract with the different cell types from the vagina (122). They observed predominately cycles of either four or five days duration which was found by Astwood in 1939 to be mirrored by uterine weight and fluid changes (9). Ovarian follicle size changes during the estrous cycle were demonstrated by Boling et al. (25); a linear increase in volume of a given set of follicles occurs until ovulation, with corpora lutea formation following. Everett, in 1948, with the use of controlled lighting ( 14 hours of 1 ight and 10 hours of dark), described the cytological changes as a sequence exactly four or five days in length with ovulation occurring on the third night in rats with 4-day cycles and on the fourth night in five-day cycling rats (57).

The stages of the estrous cycle are defined as follows: Metestrus: vaginal smear is heavily leukocytic with occasional remnant clumps of cornified cells, maturation of primordial follicles begins in the ovary (118) and uterine weight is at its lowest $(163,176)$; Diestrus: vaginal smear is less dense with leukocytes predominating but nucleated and cornified epithelial cells appear, ovarian follicles are ripening (118) and uterine weight is still regressed $(163,176)$; Proestrus: vaginal smear shows the absence of leukocytes, numerous nucleated epithelial cell or cornified cells predominate, ovarian follicles are reaching maturity (118) and uterine weight is at its maximum $(163,176)$. Mating behavior occurs only on this day (216); Estrus: vaginal smear is characterized by a fully cornified smear, ovulation occurs, follicular 
granulosal cells proliferate forming the corpora lutea (25, 122), and uterine weight declines to a significantly lower weight than at proestrus $(163,176)$.

In the five-day rat a second day of diestrus occurs with the observable changes being much like that of the first day of diestrus but, with a possible increase in vaginal cornification (177). Estrus and proestrus follow as in the four-day rat.

b. Hormonal changes and interactions

The anatomical changes described are attributable to cyclic changes occurring in estrogen, progesterone, follicle stimulating hormone (FSH), luteinizing hormone $(L H)$ and prolactin. The first two of these hormones are predominately produced by the ovary. Allen and Doisy were the first to demonstrate that ovariectomy followed by administration of ovarian extract induces vaginal cornification and maintenance of uterine structures which normally atrophy (5). The follicular liquor of the follicle was further investigated and estrogenic compounds isolated (124). Estrogen secretion measured by ovarian vein collection, rises from very low levels at the beginning of the cycle to very high levels just prior to ovulation (177), proestrus, at which time uterine ballooning is correlated.

Following estrogen, progesterone from the corpus lutem was isolated (210) and identified (7). Progesterone secretion is low during the first part of the cycle and rises at the time of ovulation. Although, in the rat the sequence is unclear. Report that the progesterone rise follows the LH surge (177) is in conflict with the observation that ovarian progesterone does not increase until after the LH 
surge while peripheral plasma progesterone increases slightly; yet significantly before the onset of the LH surge $(15,61)$. The origin of this progesterone prior to the $L H$ surge is believed to be the adrenal gland (61) and will be discussed more fully (see section I.C. I.).

The ovary, once thought to be autonomous, is influenced by the pituitary gland. This was demonstrated by the facts that, one, injection of pituitary extract would suppress reproductive cyclicity (54); and two, hypophysectomy would result in atrophy of the reproductive system and cessation of estrous cycles. Injections of pituitary extracts resulted in reversal of the atrophy (193). Thus, substances in the pituitary affect the reproductive system although a full understanding of their function remains to unfold. Are FSH and LH different compounds which regulate different functions and are they separately controlled (181)? In the intact female either can cause ovulation in the mature follicle (89). Either FSH or LH can cause luteinization of follicles and increased progesterone secretion $(125,180)$, and both may be controlled by one releasing-factor (83). In the hypophysectomized female both LH and FSH are necessary for optimum estrogen secretion and follicle growth, but either hormone will cause ovulation once the animal is pretreated with both hormones (123). Whichever factor is responsible for ovulation, luteinization follows. Luteinization has also been shown to occur without ovulation, but only after experimental manipulation and not under normal conditions (181).

The term "luteotropic hormone" originally used by Astwood in 1941 for the hypophyseal hormone which maintains corpora lutea in rats is reserved for prolactin (10). Prolactin is necessary for pseudopregnancy 
and pregnancy to take place (81). Other studies have demonstrated that prolactin may increase progesterone secretion $(8,19)$, and yet be luteolytic at a different time in the cycle $(126,212)$. Serum prolactin levels, as LH and FSH, are elevated during the afternoon of proestrus in the rat $(70,146)$.

The feedback and interaction of these hormones has long been inferred. Pituitaries from gonadectomized rats have greater growth effects on ovaries of immature rats than pituitaries from intact rats which led to the demonstration of increased LH and FSH in ovariectomized animals $(53,55)$. These high gonadotropin (GTH) levels are inhibited by estrogenic compounds (137), but not by progesterone itself $(171,178)$. Low doses of estrogen lower plasma LH but not FSH, while high doses of estrogen lower both (153). Following estrogen treatment if a second steroid is given GTH levels are raised. Progesterone is capable of raising FSH or $\mathrm{LH}$, and estrogen of raising $\mathrm{LH}(29,199)$. This substantiated the theory that estrogen, in conjunction with some signal as to the time of day, stimulates the precisely timed (2-4pm) LH release (59) for ovulation in the rat (177). Additional support is lent by the advancement of ovulation, by one day in the five-day rat, when an injection of estrogen is given on the second day of the cycle (57). Progesterone, when given on the third day of a five-day cycle, advances estrus by one day also (56). Thus, these steroids can both facilitate and inhibit GTH release and have biphasic control over the pituitary.

How these interactions are mediated is explained by evidence that estrogen implants when placed in the anterior pituitary on day 2 of a five-day cycle advances estrus by one day but such implants are 
ineffective when placed in the hypothalamus $(206,207)$. Negative feedback effects of estrogen can be demonstrated by steroid implants into the median eminence and effecting an inhibition of the postcastration rise in pituitary and plasma LH $(101,161)$. Progesterone implanted into the same general region advanced the time of the critical period on the day of proestrus in the rat (111). LH and FSH appear to feedback on the brain as estrogen and progesterone. In the ovariectomized rat LH-releasing factors are nondetectable but following hypophysectomy plasma levels rise to detectable levels (144). LH implants in the median eminence lower high levels of LH seen following ovariectomy (40). This short loop feedback has also been demonstrated for FSH (97).

Thus, the chain of events terminating in ovulation is a complex interaction of differing hormones acting on the CNS and other structures exhibiting short and long loop feedbacks of biphasic actions. The next question arises: How do these complex interactions begin?

2. Puberty in the Female Rat.

Puberty, the attainment of sexual maturity, is a complex process which requires maturation and interaction not only of the gonads and reproductive tract, but also of the pituitary and neuroendocrine mechanisms which ultimately control gonadotropin secretion in the adult. a. Anatomical changes

Long and Evans in 1922 showed that the time of vaginal opening in the rat coincides with the occurrence of the first ovulation and the first psychic estrus (122). These two anatomical events which identify puberty are proceeded by other anatomical changes. Ovarian weight increases exponentially from the time of birth until puberty 
(178). Ovarian histology shows an "infantile" period (birth to 10 days of age) characterized by small follicles unresponsive to gonadotropins (94). This is followed by a "juvenile" condition ( 11 to 20 days of age) during which the follicles have antra (117), differentiation of the theca interna occurs (167) and the response to gonadotropins appears, according to some investigators (37). The appearance of interstitial cellis between $10-15$ days of age, representing a modification of thecal cells (203), occurs along with the growth of follicles which continues until the 21 st day. At this time many follicles have attained full growth and atresia is common. Atresia of large follicles continues and becomes more pronounced through the 29th day (42). This later period can be referred to as the "late juvenile" period which ends with the first ovulation (42), at about 40 days of age.

These changes in ovarian histology are accompanied by a gradual increase in uterine weight with a dramatic increase occurring at the time of puberty (178). Body weight increases from the time of birth until puberty with no change in rate around puberty rather an acceleration between 70 and 100 days of age (194).

b. Hormonal changes and interactions

A total understanding of the onset of puberty requires knowledge of the development of secretory patterns of both LH and FSH in the rat. In the female plasma LH starts out low, peaks at 10 to 12 days of age $\therefore$ and drops to low levels at 20 to 35 days of age, with a second peak at the time of the first ovulation $(72,151)$. This early plasma pattern is the same in the male in contrast to FSH patterns which are different in the male and female. FSH, in the female, rises to peak levels 
between 12 to 15 days of age; the male does not mirror this peak. Prior to the peak, FSH levels are low but are higher in the female than in the male. A second peak at ovulation is seen, of the same magnitude as the peaks that occur during the estrous cycle (113).

Regarding pituitary LH and FSH levels LH in the female reaches peak levels between 26 to 33 days of age while in the male levels continue to rise until 60 days of age (48). In the male pituitary FSH increases steadily from 10 to 40 days of age and then plateaus (114). In the female pituitary FSH increases from 10 to 20 days of age but then decreases between 20 and 40 days of age (115). The question remains: Are the changes in plasma levels due to increased pituitary secretion of the hormones or to changes in metabolic clearance?

Steroid hormones are undergoing changes in the first few weeks of life. Relatively high levels of testosterone have been observed in the plasma and testes of male rats 1 to 5 days of age (170). Testosterone secretion appears to peak between 17 to 20 days of age and then decreases until 35 days at which time a rise toward mature levels begins as puberty ( 65 days of age) is approached (140). Since LH levels are also high either prior to or during the peak in testosterone (140) the question arises as to the possible pituitary control of gonadal activity in the neonate. Low levels of LH and FSH increase strikingly following castration at 1 to 12 days of age (72); this rise is inhibited by $3 \mu \mathrm{g}$ testosterone propionate (73) suggesting that the testes exert an inhibitory effect on gonadotropin release. At 10 days of age the male pituitary responds with an increase in plasma FSH within two days following hemicastration while plasma LH levels did 
not increase until 10 days post-operatively (151). It appears that the early inhibitory effect of testicular steroids is due to their effect on the maturing hypothalamic-pituitary axis feedback system.

Steroid hormones in the female are also undergoing development during the first week of $1 \mathrm{ife}$. The presence of ovarian estrogen during the first week of postnatal 1 ife is demonstrated by: one, ovariectomy on day 1 causes a uterine weight decrease during the first ten days of life (13), and two, treatment of 2-to 5-day old animals with estradiol anti-serum results in an inhibition of the rate of uterine and ovarian weight gain (167). Thus, it can be concluded that estrogen probably locally secreted by ovarian thecal cells, stimulates granulosa cell proliferation and thus causes progressive uterine and follicular growth (167). Little is known of prepuberal progesterone secretion, but the appearance of cholesterol in the uterine epithelium suggests that progesterone secretion may occur as early as 20 days of age. This coincides with the time that follicles are beginning to undergo atresia and the granulosa cells temporarily contain histochemically demonstrable steroids $(4,42)$. The question then arises: if estrogen and progesterone are present and functioning, how do they interact in the feedback system on the hypothalamic-pituitary axis?

This feedback interaction which appears to be present in the male is not so obviously present in the female during the early stages of development. Castration of the female neonate ( 1 to 12 days of age) does not cause a rise in LH and FSH as in the male (72). Hemiovariectomy at 10 days of age does not induce an increase in plasma gonadotropin 
concentration until 25 days of age at which time the ovarian compensatory hypertrophy response is also evident for the first time (151). This suggests that the "infantile" and "juvenile" rat is unresponsive to steroid levels. Another indication that negative feedback is lacking is the inability of the brain to concentrate ${ }^{3}$ H-estrogen above blood levels in the hypothalamus until 25 - 30 days of age (117). It appears that during the "late juvenile" period these feedback interactions are mature. After 24 days of age ovariectomy is followed by a rise in plasma LH which can be inhibited by estradiol at doses 2 to 3 times smaller than that needed to depress the LH rise in the adult (162).

In the immature rat pregnant mare's serum (PMS) can cause the pituitary to release LH and FSH, at the critical period, two days following the injection (59). This can be consistently induced as early as 20 days of age (134). When progesterone is given on the second day after PMS, ovulations could be induced at 18 days of age, although ova counts were down. An increase in the incidence of ovulation and the number of ova per ovulation occurred following treatment of older animals (134). This implicates that both estrogen and progesterone can exert their stimulatory affects on pituitary function via the hypothalamus by the beginning of the "late juvenile" period.

Other changes in responsivity manifest themselves in this "late - juvenile" period. Low doses of estrogen administered between 26 and 30 days of age result in precocious vaginal opening, release of $\mathrm{LH}$, and, soon after, ovulation; this estrogen-induced precocious puberty cannot be induced prior to day 26 , as demonstrated by the observation 
that daily estrogen administration begun at 5 days of age results in the same age of onset of puberty (164). This is not to imply that estrogen has no effect on the system prior to this period. Estrogen may be involved in the maturation of the hypothalamic centers controlling the cyclic release of gonadotropin since rats treated with estradiol appear to undergo an accelerated period of rapid myelination in the hypothalamus which is greatest between 10 to 20 days of age (38). This precocious laying down of myelin sheath around nerve fibers may represent a mechanism by which early postnatal administration of estradiol accelerates functional brain maturation.

This developmental effect of steroids on the brain has been looked at for many years. In 1936 Pfeiffer published his now classic studies on the effects of secretions of the prepuberal ovary and testes to subsequent reproductive performance of rats. He observed that the ovaries, transplanted to adult male rats who were castrated at birth, showed normal follicular and corpora lutea development. Similarly, adult female rats ovariectomized at birth exhibited normal vaginal cycles when an ovary was transplanted into the eye. In contrast, when testes were implanted into newborn females the ovaries of these animals, when adult, contained only follicles. Persistent vaginal cornification, after a delayed vaginal opening without ovulation, was also induced. It was originally proposed by Pfeiffer that the mechanism - by which androgen produced this anovulatory persistent estrous condition was by masculinization of the adenohypophysis (154), but more recent studies have shown it to be the hypothalamus, the malfunction being the failure of the pituitary gland to release sufficient 
gonadotropin to cause ovulation (78). Thus, the ventromedial-arcuate nuclear region is capable of regulating tonic gonadotropin secretion. But, the preoptic area of the hypothalamus, which in the female but not in the male controls the release of the surge of gonadotropins, is incapable of effecting the surge release. When allowed to differentiate normally this area regulates the ovulatory surge but when allowed to differentiate in the presence of androgen it becomes refractory to both intrinsic and extrinsic activation and the tonic male pattern of gonadotropin secretion occurs in the female (154). This imprinting occurs within the first five days of 1 ife (77). More recent studies have shown that estrogen can also induce an anovulatory adult state. The characteristics of this state are not the same as the androgen-induced state but both are dose-dependent (78). Other substances as progesterone (46), desoxycorticosterone acetate (46), or gonadotropin (80), when given shortly after birth, can cause persistent estrus and/or anovulatory ovaries and thus caution must be used in drawing specific conclusions. It is safe to say that the postnatal delay in ovarian function and the early testicular function may be an important step in development of the hypothalamus of a normal female and normal male. Once the differentiation of the brain occurs and the hypothalamic portal system has developed well enough to transport releasing factors from the hypothalamus to the pituitary, (by the second day of life) (65), the developmental changes of hormonal secretion and interaction begins. This continues through the "infantile" and "juvenile" periods in the female so by the "late juvenile" period hormonal feedbacks are established. A question still remains unanswered: Why does a "late 
juvenile" animal whose ovaries are capable of being stimulated by gonadotropins, and whose pituitary can release a gonadotropin surge, undergo several cycles of follicular growth and atresia before the first estrus occurs? Investigators have looked for neural (see section A.2. c.) and hormonal triggers (which have been discussed above) neither of which have answered the question but, have contributed pieces to the complex developmental puzzle.

c. Neural control of puberty

Harris and Jacobsohn furnished the major stimulus for considering the role of the nervous system in relation to puberty. They demonstrated that immature rat hypophyses (12-16 days old) transplanted under the median eminence of hypophysectomized adult female rats not only restored vaginal cyclicity but also supported mating, pregnancy and delivery of normal young. Therefore the prepuberal period which follows the attainment of gonadal responsitivity to gonadotropins may result from the inactivity of hypothalamic mechanisms which regulate pituitary gonadal functions in adult animals. Evidence for this neural inhibition of gonadotropin was proposed by Donovan and Van der Werff ten Bosch who found that electrolytic lesions in the anterior: hypothalamus resulted in premature vaginal opening and ovulation (45). Lesions in the posterior hypothalamus have also resulted in precocious ovarian activity (174). Ventromedial-mammillary body region lesions are reported to produce a delay in maturation; however, these lesions were large and may have produced hypophysial atrophy. Attempts to 10calize and identify specific hypothalamic structures involved in the control of puberty onset have been filled with controversy. 
Extra hypothalamic structures such as the amygdaloid complex, other components of the 1 imbic system, and the pineal have also been implicated. Lesions in the amygdala at 18 to 20 days of age produce premature ovarian activation, uterine stimulation and vaginal opening, similar to lesions in the hypothalamus (50), while lesions in this same area at 4 days of age produce a delay in puberty (168). In contrast, lesions at 21 to 23 days of age had no effect on the day of vaginal opening (24). Lesions in the amygdala of the male had no effect on puberty when done at 4 days of age (169). Interruption of the stria terminalis, an amygdalo-hypothalamic tract, results in premature ovarian function, supporting the influence of the amygdaloid complex upon the hypothalamic control of gonadotropins release (51). This is also supported by the fact that stimulation of the amygdala resulted in a significant delay of vaginal opening and the first estrus (16). The precise role of the amygdaloid complex remains to be determined. Thus far it is possible to say that the amygdaloid complex has a definite influence on the neural control of puberty onset; this interaction changing as brain development continues.

The pineal has been implicated in the control of gonadal function and thus the onset of puberty. Pinealectomy increases ovarian weight in immature female rats operated at 26-30 days of age but not at 21 days of age (106) and melatonin, which is synthesized by the pineal gland, has been shown in small doses to depress growth of the immature rat ovary and delay vaginal opening (211). The role of the pineal is still speculative and conclusive evidence for its inhibitory effect upon gonadal function remains to be gathered. 
It is beyond dispute that the anterior hypothalamus and associated forebrain structures, when lesioned, produce sexual precocity in the rat $(24,45,168)$. It is interesting to note that the earlier placement of the lesions does not seem to cause earlier vaginal opening (46). Although electrical stimulation of the arcuate nuclear region, when performed at 27 days or later, advanced puberty, as did the anterior hypothalamus at 29 days or later, stimulation at younger ages was not successful (136). It is also of interest to point out that the structures implicated in control of the onset of puberty are those which control gonadotropin function in the adult. Much remains to be clarified, but it appears that the ovaries, reproductive tract, and pituitary are in a state of complete readiness to assume adult activities at approximately 25 days of age. This latent period may be occupied by processes involved with the functional maturation of neuroendocrine mechanism which control gonadotropin secretion. This latency may reflect a restraining or inhibitory influence of neural centers (37). d. External factors which influence the time of onset of puberty There are many external environmental factors which have been shown to influence the time of onset of puberty in the female rat. Early pituitary-ovarian function is induced by exposure to constant light instead of the normal light-dark cycle, while exposure to constant darkness induces a delay in puberty onset (64). Mild stimulation, $\therefore$ light and noise, and intense stimulation, placement in a shaking machine, delays vaginal opening, but is less effective the nearer they are applied to puberty (37). Handling, a mild stimulation, has varied effects upon puberty. In one experiment animals were roughly handled, 
which consisted of dropping them about a foot then catching them and letting them run on a bench and picking them up repeatedly, and then monitored for the time of onset of puberty. The handling was done daily from days $22,28,34$ and 40 until puberty onset, 41 days of age in this strain of rats. None of the groups showed any effect of handling upon the time of vaginal opening (128). In contrast, a more recent study demonstrated that pups who were handled from day 1 to 24 for 3 minutes each day, which consisted of removing the pup from the mother placing each pup into a one gallon container partially filled with shavings and then returning the pup to the mother, showed an advancement of puberty. It is interesting to note that this advancement only occurs if the animals are group-reared after weaning, that is, placed into group cages with 5 to 6 other rats (143). This may indicate that group weaning accentuates the effect of stimulation in infancy. Exposure to cold, which consisted of animals 22 to 34 days of age being placed into a refrigerator $\left(2\right.$ to $4^{\circ} \mathrm{C}$ ) for 45 minutes on three consecutive days in one group and another group subjected to 1 hour of refrigeration for three weeks resulted in a premature opening of the vagina in both of the groups (128).

Exposure to cold, handling, and other types of stimulation may act as a non-specific stress. Why other stressful stimulations as sham lesioning, at the same ages (24) do not act to alter puberty remains to be determined. Changes in lighting may act more directly on the timing mechanisms of development. The action of these non-specific stresses may be through ACTH and the adrenal gland causing a secondary stimulation of ovarian activity and gonadotropin output. This will be more 
fully discussed in the following sections.

\section{B. Brain-Pituitary-Adrenal Interactions}

The adrenal gland is a complex endocrine structure which is undergoing growth and development at the same time the reproductive system is experiencing maturation. While being dependent upon the pituitary and CNS for regulation the adrenal gland is influenced by other systems. These complex interactions, their development and control, is the subject of interest.

1. The Adult Adrenal Gland: General Description and Discussion of Hormonal Regulation.

a. Anatomical description

The adrenal gland is composed of two distinct endocrine tissues: the adrenal cortex and the adrenal medulla. These two parts have separate embryologic origins and fulfill different functions. The adrenal cortex is the site of the synthesis and secretion of certain steroids while the adrenal medulla, which is composed of postganglionic neurons of the sympathetic nervous system, synthesizes and secretes catecholamines (primarily epinephrine, but also some norepinephrine). Emphasis here will be placed upon the adrenal cortex.

The adrenal cortex is composed of large lipid-laden epithelial cells arranged in irregular strands around sinusoids. Three zones have been described: one, the zona glomerulosa, the thin outer layer composed of short loops and balls of cells irregularly arranged underneath the capsule; two, the zona fasciculata, the widest layer, consisting of radially orientated columns of cells and three, the zona reticularis, consisting of net-like cell cords bordering on the 
medulla (20). The cortex has an extremely rich vascular bed. Arterioles enter from the capsule and immediately break up into numerous long sinusoids, which run radially between the columns of cells (21).

Growth and maintenance of the adrenal cortex is dependent upon continued secretion of adrenal corticotrophic hormone (ACTH) by the pituitary. The zona glomerulosa is for the most part independent of ACTH secretion while the fasciculata and the reticularis atrophy most severely after hypophysectomy. Two months after hypophysectomy the zona fasciculata can scarcely be distinguished from the reticularis while the glomerulosa hypertrophies (43). The zona glomerulosa is not a conspicuous target organ of the anterior lobe of the pituitary, while the zona fasciculata and the zona reticularis appear to be completely dependent on the hypophysis.

The role of the adrenal cortex in the adaptation of the body to noxious agents or to environmental situations which create an unusual demand for energy has been explored by Selye $(184,185)$. In stress the adrenal undergoes morphological and cytochemical modifications which provide evidence of a rise in secretory activity. The zona glomerulosa fails to take any great part in these modifications. The zona fasciculata, on the other hand, is subject to increases in volume and alterations in lipid content and distribution. The three stages of the adaptation syndrome are: the immediate reaction to a stimulus is hypertrophy of the zona fasciculata with accompanying lipid depletion (the alarm reaction). During the "resistance" phase the lipid reaccumulates in the zona fasciculata and may be present in supranormal amounts. In the "exhaustion" phase, the zona fasciculata undergoes 
maximum hypertrophy and lipid depletion becomes extreme $(184,185)$. These histological changes induced by stress can be mimicked by the administration of ACTH (149).

The pituitary also undergoes histological changes. Following adrenalectomy the pituitary of these animals show an increase in number and size of the cells which are believed to secrete ACTH. These cells do not develop if cortisol, a steroid of the zona fasciculata, is given after adrenalectomy (186). The histological zonation of the cortex has led to the discussion of functional zonation. b. Hormonal changes and interactions

In 1855 Thomas Addison described the syndrome which bears his name, and attributed the life-maintaining function to the adrenal cortex (2). Brown-Séquard the next year performed the first adrenalectomies and verified the idea that the adrenals were essential for life (27). His findings were quickly challenged and the discussion continued until the end of the 19th century. The next two decades were spent on the question whether it is the adrenal cortex or the medulla that is essential for life. This was largely because the discovery of epinephrine about 1900 diverted attention from other adrenal secretions. In 1927 Zwemer initiated studies on the adrenal with a paper showing that the cortex was the life-maintaining portion of the gland (219). Due to poor techniques of adrenalectomy and lack of a good cortical extract the information accumulated prior to 1930 is difficult to interpret.

In 1930 Swingle and Pfeiffer, (196) and Hartman and Brownell first described methods based on lipid extraction procedures which 
produced extracts that would keep adrenalectomized animals and Addisonian patients alive indefinitely. Following the isolation of the whole extract laboratories of Pfeiffer, Reichstein and Kendall and others began work on the crystallization of a large number of steroids from cortical extract $(104,155,166)$. By 1932 work leading to the role of cortical steroids in electrolyte and water metabolism was begun. Loeb showed that sodium chloride alone would maintain an Addisonian patient (121). With the availability of crystalized steroids it was shown that desoxycorticosterone was the most potent cause of retention of sodium and the excretion of potassium (197). Most of the isolated steroids were shown to cause some sodium retention. Early workers noted changes in carbohydrate metabolism such as low blood sugar and low liver glycogen levels in adrenal insufficiency. The 11-oxygenated adrenal steroids were shown to have their effect on carbohydrate metabolism resulting in a sparing of glucose and an increase in glucose production (195). The glucocorticoids, which are activated during stress, may impair the immunologic response at each stage from the initial interaction and processing of the antigens by the cells of the reticuloendothelial system through antibody production (18). Glucocorticoids more recently have been shown to affect many other systems: muscle, blood, adipose tissue, and the central nervous system by controlling certain brain enzymes. The permissive actions of these hormones is impressive: enhanced cholinergic stimulation of the gastric secretion of hydrochloric acid, enhanced pressor effects of catecholamines (18), and enhanced release of thyroid stimulating hormone (TSH) via TSH releasing factor (12). Glucocorticoids 
have also been shown to be important in myelination of nerve fibers, and for surfactant development in the lungs, thus having an influence upon growth and maturation (18). The ability of the adrenal cortex to secrete sex steroids was also established and the physiological implications were studied by this time (121). They will be more fully discussed in a later section (I.C.).

Following the isolation and crystalization of these steroids came the identification of these compounds. The enzymatic pathways were then established. Pioneer work in the field of adrenal perfusion by 0 . Hector, and Pincus and Dorfman and their associates, since then expanded by others, led to the formation of a well documented scheme for the biosynthesis of corticosteroids (91) (Figure 1). The steroids are divided, according to activity, into mineralocorticoids, glucocorticoids, and sex hormones. The functional zonation of the secretion of these hormones has been established. The peripheral zona glomerulosa produces mostly mineralocorticoids, primarily aldosterone, and is affected little by ACTH. Yet the inner layers form glucocorticoids, 17-ketosteroids, progestins, and estrogens and are dependent on ACTH for growth and secretory stimulation.

The steroids of prime interest in research today on the rat are: 18-hydroxycorticosterone, 18-hydroxydeoxycorticosterone, corticosterone, and aldosterone. The first three steroids are produced by both capsular cells which are the cells of the zona glomerulosa, and decapsular cells which are cells of the zona fasciculata and zona reticularis. Aldosterone is produced by capsular cells only (88). Progesterones are also being produced by the rat adrenal (60), as are androgens (28). 


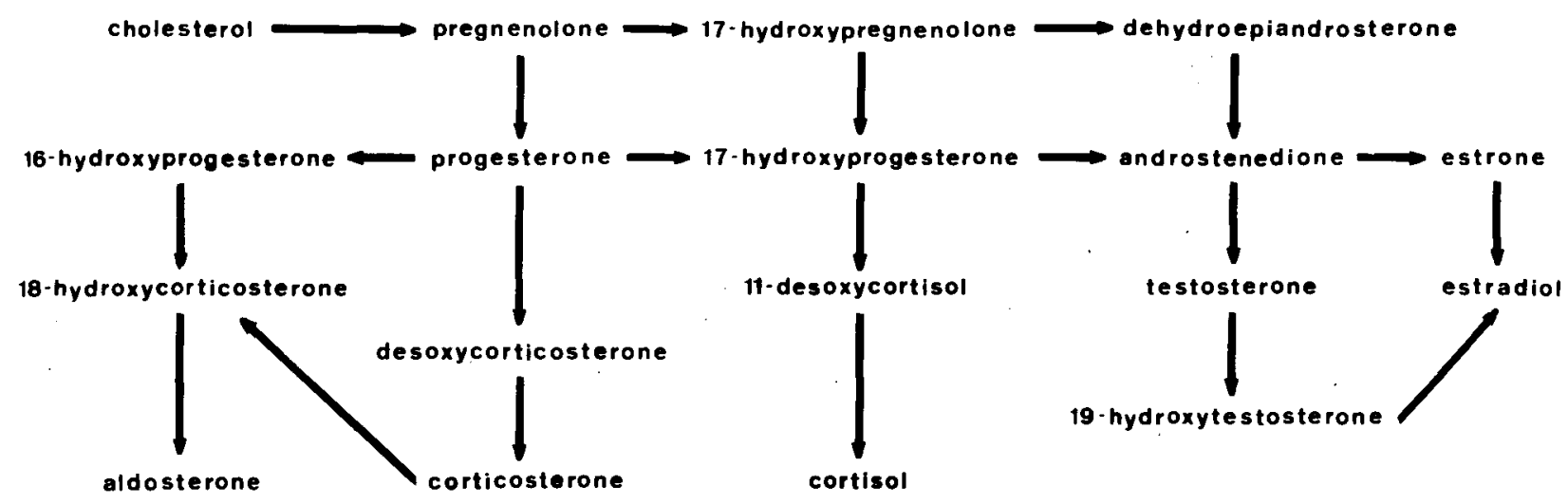

Figure 1

Biosynthesis of Active Adrenal Hormones. 
Much of the work in the rat has centered around the regulation of corticosterone, the predominant glucocorticoid.

c. Regulation of corticosterone secretion

A twenty-four hour, or circadian, rhythm in adrenocortical secretion of corticosterone, reflected by changes in plasma and adrenal corticosterone concentrations, has been demonstrated in the rat (36). Levels are higher in the female than in the male (107) but both males and females demonstrate lowest levels at approximately 3 AM hours and peak between 4 PM and 8 PM hours (36). These corticosterone secretions are controlled by ACTH, although it does affect other steroids in minor ways (88). The changes in ACTH are mediated by changes in corticotrophin releasing factor (CRF). Shapiro demonstrated that blood from stressed hypophysectomized animals contain a substance which produced ACTH release in recipient animals; this principle disappears after the administration of adrenal steroids (173). This proved to be CRF which more recently has been shown to have a diurnal rhythm which persists, although at a higher level following hypophysectomy. The level is influenced to some extent by ACTH and adrenal steroids but the diurnal rhythm is independent of hormonal feedback (183). Since the rhythm persists following adrenalectomy, the circadian periodicity of ACTH release appears to be induced by a periodic neural input into the system (198).

In addition to the circadian changes in corticosterone, stress can modify these levels. Stress has been defined by Ganong as "... the term used for those diverse, immensely dissimilar stimuli which have in common the experimentally proven property of stimulating ACTH secretion." (68) Blood levels of ACTH rise within three minutes in 
both normal and adrenalectomized animals following a stress (98). Ether anesthesia, administered as a standardized stress, produces high and more persistantly elevated plasma corticosterone concentrations in female rats than in males (see section I.B. 1.d.). Similar effects are obtained with ACTH (107).

Control of the stress-induced release of ACTH does not appear to be the same for the basal levels of ACTH. Slusher has shown that lesions in the periventricular zone and in the arcuate nucleus of the anterior hypothalamus are capable of inhibiting the diurnal rise without inhibiting the response to stress. Damaging the posterior tuber cinereum inhibited the acute rise in plasma corticosterone levels in response to stress but did not inhibit the usual diurnal rise (190). The feedback control of ACTH can be hormonally demonstrated by the fact that physiological plasma levels of corticosterone suppress not only the afternoon peak in corticosterone (217) but can suppress the pituitary-adrenal response to stress (218). These findings suggest that corticosterone feedback may play an important role in controlling stress and non-stress pituitary function. This is an area of controversy as to whether the stress system is an open loop or has a variable set point (213). The results of a study which determined the responsivity of the pituitary adrenal axis to a second stress during a period where the elevated corticosterone from the first stress is present, demonstrated that the second stress produced a response similar in magnitude to the first. From these results it would seem that physiological levels in plasma corticosterone do not modify the responsiveness of the adrenal system to stress (39). Adrenal steroids may modify CNS 
activity as demonstrated by electrophysiological studies (163). Implant studies have served to localize the action of corticoids. Implantation of cortisone into the basomedial hypothalamus of rats inhibits adrenal secretion at rest and prevents the increase caused by operative stress (52). Davidson and Feldman showed that cortisol implants in the median eminence or in the anterior medial hypothalamus abolish the compensatory hypertrophy response which usually occurs following unilateral adrenalectomy (41). Lèsions in various regions have confirmed the influence of areas on ACTH control. Median eminence lesions cause a block in ACTH secretion (133), as do lesions in the posterior and midcentral hypothalamus, and the basal tuberal region (189). Thus the hypothalamus acts as a funnel through which information collected from the periphery and from other nervous structures are transmitted to the pituitary. These other areas include the cerebral cortex, the midbrain and different areas of the limbic system (129). Although corticosteroids have been shown to feed back upon multiple sites in the brain, they can also inhibit the ACTH-releasing process by their action of the pituitary (74).

The question of whether or not increases in plasma levels of ACTH inhibit CRF release is unresolved. The adrenalectomized animal, with high initial levels of $A C T H$, still releases $A C T H$ after a stress (195). However, injection of ACTH into hypophysectomized adrenalectomized rats reduced the high level of hypothalamic CRF content to one eighth the levels found in hypophysectomized-adrenalectomized controls (182). Also, ACTH administration can decrease the rise in pituitary ACTH levels following adrenalectomy (116). Thus, there is evidence of 
an internal feedback loop for ACTH as demonstrated for LH and FSH although the physiological action is not clear.

The CNS plays an important role in the regulation of corticoid secretion and its rapid adjustment for the maintenance of homeostasis (214). The hypothalamus again appears as the focal point regulating information and controlling the synthesis and release of ACTH Via CRF, thus affecting adrenocortical secretion.

d. The influence of gonadal hormones upon adrenal cortical function

The reproductive system affects the level of adrenal steroids in the rat via the action of gonadal hormones on the hypothalamic-pituitaryaxis, the adrenal cortex and the liver. Since all plasma steroid concentrations are a balance between the output by the gland and the clearance by the liver, plasma concentrations alone are sometimes misleading. Biological half-life and secretion rates provide more clear information.

The effects of gonadal hormones upon the hypothalamic-pituitaryaxis has been demonstrated by Coyne and Kitay. Removal of the ovaries results in a decreased synthesis and release of ACTH (41), while orchiectomy results in elevated pituitary ACTH release (35). Testosterone inhibits (35) and estradiol stimulates (34) the secretion of ACTH by the pituitary gland. Therefore, gonadal hormones contribute to the control of the hypothalamic-hypophyseal adrenal system.

Reproductive hormones exert an effect on the level of adrenal hormones themselves. In female rats plasma corticosterone concentration not only undergoes a daily rhythm but is also affected by the different phases of the estrous cycle; levels are highest at proestrus with 
adrenal corticosterone concentrations following a similar pattern (165). As mentioned before, corticosterone levels are consistently higher in female rats than in male rats under resting conditions, and after stress and ACTH administration (107). Intact males given estradiol show no change in plasma steroid levels at rest but show enhanced responses to stress and ACTH (109). Administration of estradiol to intact females produces no change but ovariectomy results in decreased resting levels of corticosterone and a decreased response to stress and ACTH (109). No change in plasma levels occurs in the male following orchiectomy, but a decreased secretion rate of corticosterone occurs in both sexes following gonadectomy (168).

The effects of gonadal hormones on the levels of plasma corticosterone may be traced to their action on adrenal steroidogenes is and metabolism. Estradiol administration increased the $11-\beta$-hydroxylation of desoxycorticosterone to corticosterone (147), while orchiectomy stimulates and testosterone inhibits this secretory activity (109). Thus estradiol and orchiectomy may act to stimulate corticosterone synthesis. Changes are also going on in intra-adrenal metabolism of corticosterone. Adrenal tissue from gonadectomized rats convert exogenous corticosterone to $3-\beta$ and $5-\alpha$ tetrahydrocorticosterone and other A-ring reduced compounds. The activity of this enzyme, 5- $\alpha$ reductase, is enhanced by castration and inhibited by testosterone and estradiol. Intact rats of both sexes convert cholesterol predominantly to corticosterone and 18-hydroxy-11-desoxycorticosterone; following gonadectomy these levels are reduced with products of $5 \alpha$ reductase activity increased (109). These observations suggest that changes in reductase 
activity may be responsible for the decline in corticosterone secretion following gonadectomy. Control patterns of steroidogenesis are restored by hormone replacement (109).

Corticosterone-binding globulin levels and hepatic steroid metabolism are also affected by gonadal hormones. Gala and Westphal have reported a sex difference in the binding globulins; levels are twice as high in the female as in the male. These levels are unaffected by ovariectomy but are depressed following testosterone administration (67). The half-1ife of corticosterone is 20 minutes in the male and only 13 minutes in the female; estradiol administration and gonadectomy in the male shortened the half-life to female levels, while administration of testosterone or estrogen, or gonadectomy each prolong the half-life in the female (109). Hepatic reduction of corticosterone is also affected, the changes closely correlating with the changes in half-life (109).

Thus gonadal hormones influence adrenal function through a complex series of interactions at the different levels of the brain-pituitaryadrenal axis. The counterpart of this - the influence of adrenal hormones upon the brain-pituitary-ovarian axis - will be considered (see section C.).

2. Developmental Changes in Adrenal Morphology and Control of Secretion. a. Anatomical description

In the rat fetus of 16 days the adrenal glands consist of encapsulated masses of mesodermal tissue at the cephalic end of the kidney. Medial to these glands as well as occasionally within the glands are clusters of small basophilic cells, ectodermal in origin, which are 
prospective medullary tissue. On successive days the medullary tissue migrates toward the center of the gland and coalesces with the fetal cortical tissue. At fetal age of 16 days cortical tissue consists of two zones: a narrow layer immediately beneath the capsule consisting of small tightly packed cells, the zona glomerulosa and the zona fasciculata, composed of somewhat smaller cells organized into irregular cords. The cortex then grows, cell division occurring, and by the fetal age of 18 days three zones are distinguishable: a narrow zona glomerulosa, a broad fasciculata, and an equally broad reticularis (100). After birth the cells of the zona glomerulosa remain unchanged while those of the fasciculata and reticularis shrink considerably with the latter atrophying and gradually disappearing (202).

At birth the medulla is still incompletely organized, with the center of the gland consisting of strands of cortical cells intermixed with clumps of medullary cells. During the first week after birth the medullary cells become united and the cortical cells in the center shrink and disappear (202).

Thus after birth the cortex is separable into two zones and, by the second week, it has further differentiated into three zones. According to Howard, before the development of a distinct reticularis, a transitory juvenile cortex develops which is homologous to the mouse $X$ zone. This juvenile cortex gradually transforms into the adult reticularis zone and loses its distinctive character (96). This is occurring between three to five weeks of age. Other investigators do not have evidence for the existence of this transitory cellular condition (202). From cytochemical observations the growth and developmental 
changes of the adrenal are accompanied by development of steroid synthesis which exists as early as 16 days in the fetus $(100,202)$. b. Hormonal changes and interactions

Along with the morphological changes and zonation of the cortex is the development of steroid synthesis by the adrenal gland. Rat adrenals have been shown to contain corticosterone during the last five days of gestation (approximately 16 days in the fetus) (23). Corticosterone synthesis, as distinct from content, was shown to proceed from endogenous substrate in 21-to 22-day-old fetuses. Thus, by the time of birth, the enzymatic capacity for the synthesis of the steroid nucleus and of corticosteroids and aldosterone is present (22). Progesterone or estrogen secretion by the fetal adrenal has not been demonstrated (22), but androgen production has been demonstrated in 20-day old fetuses (71). The fetal rat adrenal differs from the human, who has a definite adrenal fetal zone producing $\mathrm{C}-19$ steroids (predominantly 17-ketosteroids) by producing predominantly corticosteroids $(28,139)$. The pattern in the human soon changes as ketosteroid production falls in the first week of life. Thus, it is evident that the fetal rat adrenal can readily synthesize corticosterone.

The next question is what if anything regulates this secretion. The presence of ACTH in the fetal pituitary has been postulated on the basis of (a) the stimulating influence of fetal pituitaries on the morphological differentiation of the adrenal tissue and (b) the ability of these pituitaries to increase the production of corticosterone by adult adrenal glands (139). Evidence also exists for a pituitary-adrenal interaction: adrenalectomy of mothers is followed by hypertrophy of 
the fetal adrenal gland (49). The ACTH for this hypertrophy may be from the fetal pituitary, the mother's pituitary or the placenta. The fetal pituitary is active because following unilateral adrenalectomy compensatory hypertrophy of the remaining fetal gland occurs (49); cortisone treatment or hypophysectomy of the fetus prevents this enlargement (150). Knobil and Briggs found that hypophysectomy of the mother prevents the fetal enlargement which normally follows adrenalectomy of the mother (110). Therefore, ACTH crosses the placenta and reaches the fetal adrenal and thus may affect its normal development. ACTH-like activity has also been found in the placental extracts (139), al though $i$ ts role in gestation remains to be determined. Therefore at birth we have evidence for ACTH production and corticoid synthesis and some indication of an interaction of the two.

The next questions to be considered are: When does the response to stress begin? and When does circadian periodicity start? The response to stress appears first. Gray has demonstrated that exposure of 2-day-old rats to ether resulted in small but reliable increments in corticosterone content of their plasma (79). Other authors have observed that the pituitary adrenocortical system is responsive to stress during fetal life followed by a period after birth in which the response to stress is absent $(93,139)$. CRF does increase in response to stress by the seventh day of postnatal life (93). In contrast, the adrenal does respond to exogenous ACTH as early as the second day of life (93). Allen and Kendall have claimed that the response to stress does not appear until 15 days of age, with response to ACTH present at 
birth (6). Thus, there seems to be a period of questionable duration during which the animal is refractory to stress although it is responsive to exogenous ACTH. The cause of this is yet to be determined but may lie in the hypothalamus since ACTH is present (93) and the adrenals are capable of responding to the hormone (6).

Following the response to stress the rhythm of the adrenal secretions begins. Circadian rhythm of corticosterone is present by 21 days of age, at which time the CRF rhythm is predominant for the first time (92). These circadian changes in plasma corticosterone levels have been reported as early as 18 days of age, attain an adult pattern by 26 days of age (159) and then remain the same until puberty in the female at which time the evening values become markedly elevated. This puberty-related change is not seen in the ovariectomized rat, although prior to this daily variations were the same (157). Other sex-related changes have also been shown: neonatal castration of males does not significantly alter adrenocortical levels but androgenized females show a significant decrease in adrenal plasma corticosterone levels when compared to normal females at 26 - 29 days of age (120). Ader has shown that this rhythm in corticosterone can appear as early as 16 days of age in both males and females, al though not consistently, when the animals are exposed to stress (electric shock) (3). Thus the response to stress can influence the onset of the circadian rhythm and gonadal hormones can influence the level.

As mentioned before, the interpretation of steroid levels is complex since plasma levels are a result of gland secretion rate and liver degradation rate. Thus, it is important to note that the liver 
undergoes development prior to puberty. Cortisol metabolizing enzymes, which sex hormones can influence the differentiation of, are undergoing development (44), as are the enzymes through which the glucocorticoid effects are mediated (188). There are also changes in steroid binding to serum proteins during maturation, which influence the availability of the hormone (156). All these factors which influence the net plasma levels of the hormones, along with the secretory capability of the gland, are maturing.

The adrenals' circadian rhythm and response to stress are both normally developed by 21 days of age, well before the onset of puberty in the female rat. Gonadal hormones can affect the development and normal function of the adrenal system. The next question: - does the counterpart exist - can the adrenal system affect the reproductive system?

c. Adrenal - Ovarian Interactions

As early as 1806 it was pointed out by Mekel that anatomical and certain pathological conditions suggested an intimate association of the adrenals with the gonads (131). In more recent years the existence of a functional relationship between the two organ systems has been demonstrated, with some indication that a developmental interaction may also exist. The adrenals can affect the reproductive system. The questions: How do they interact? and How does this interaction develop?

1. Adrenal - Ovarian Interation in the Adult Rat.

The first observation of an adrenal - ovarian interaction was of a suppression or irregular appearance of the estrous cycle following 
adrenalectomy in the female rat (131). Cory and Britton found that the estrous cycle, which disappeared following adrenalectomy, reappeared when the animals were maintained on adrenocortical extract (33). By 1937 it was demonstrated that adrenalectomized animals maintained in good health by the administration of sodium chloride experience normal estrous cycles (135), and have normal pituitary histology as well (132). Thus, it was shown that much of the early work attributed to the interaction of the adrenal with the ovary was due to the poor health of the animals. In 1946 a detailed study of the early history of this problem by Parkes was published. It was pointed out that the affect on the gonads may be secondary to a profound affect on the general metabolism caused by a lack of cortical hormones (152).

There still remained the evidence for the production of sex hormones by the adrenal. The first impressive indication that the adrenal contained appreciable amounts of substances with activity similar to that of gonadal hormones came with the demonstration that crude lipid extracts possessed both estrogenic and progestational activity in tests on ovariectomized rabbits (152). These results were later confirmed by the isolation of the androgens, estrogens and progestins from the secretory effluent of the adrenal gland (20). Recently it has been demonstrated that the adrenal gland contributes much of the total amount of plasma progesterone. The amount of progesterone contained in both adrenal glands was similar to or greater than that contained in both ovaries. After ether anesthesia the adrenal progesterone content increased by seventy-five per cent and the ovarian 
progesterone remains unchanged $(60)$. The secretion rates of progesterone also depend upon conditions. In undisturbed rats adrenal secretion rate is about one fifth that of ovarian secretion rate occurring at metestrus, while rats exposed to a mild stress for several days increase the adrenal secretion rate five-fold (60). A direct increase in progesterone secretion was demonstrated in ovariectomized animals given ACTH (62). Thus ACTH increases both corticosterone and progesterone secretion. It would therefore be expected that the circadian rhythm of progesterone would be the same as corticosterone when actually these rhythms have been shown to have a reciprocal relationship, progesterone being high during the early morning hours and low in the afternoon, the opposite being true for corticosterone. This may be explained by the use of progesterone as a precursor for corticosterone synthesis $(130)$.

The next question: Does this progesterone participate in the normal estrous cycle? Ovarian secretion of progesterone does not increase until plasma LH levels rise and the first rise in plasma LH occurs at 4 PM on the afternoon of proestrus. The gradual rise in peripheral plasma progesterone concentration at proestrus by 1 PM (at a time when normally plasma levels are at a nadir) could be due to increased adrenal secretion of progesterone $(62,130)$. The marked rise in progesterone following 4 PM is due to ovarian secretion. The stress of sham ovariectomy on the morning of proestrus will advance the time of the critical period for LH release (119). Interpretation of these findings may be that progesterone normally secreted by the adrenal plays a part in the initiation of the release of the ovulatory 
surge of LH.

Lordosis, which is usually induced experimentally by estrogen priming followed by progesterone (216), can be induced in ovariectomized rats primed with estrogen followed by ACTH (62), which induces progesterone secretion. The adrenals have been shown to participate in the timing of normal mating behavior. Acute adrenalectomy delayed the time of lordosis; sham ovariectomy and ovariectomy advanced this time; adrenalectomy plus ovariectomy blocked lordosis completely. Ovariectomy and sham ovariectomy, as deduced from barbital blockade, advanced the time of the LH discharge (148). Direct evidence for the stress advancement of the LH surge was demonstrated by Lawton (119). This stress induced advancement was abolished by adrenalectomy as was any detectable release of LH at proestrus but, in spite of this, ovulation did occur. Full ovulations were shown to occur after acute adrenalectomy $(119,148)$ while this has not been shown to be true after long-term adrenalectomy which results in a decreased number of ova ovulated and a decreased number of embryonic swellings. Mating behavior was shown not to be affected by long term adrenalectomy. The female seems to be able to reestablish normal mating behavior times (98) .

Stress, noise, light, pain and immobilization can disturb the estrous cycle, causing in some cases a persistent diestrous state (82) or, in others, prolonged cornification (86). Stress produces an increase in the number of cornified cells in the vaginal smears of ovariectomized rats; this disappears after adrenalectomy (175). According to Selye one of the first observations made in studies of the general 
adaptation syndrome was that animals subjected to prolonged intensive stress exhibited abnormal sexual behavior. He also reported that irregularities in the menstrual cycle, or complete cessation, may occur in women exposed to stress (175). Severe disease, psychic trauma, or change in environment may cause retarded ovulation and menstruation (145). Since stress can cause not only an increase in ACTH, but MSH (103), Growth Hormone (138), TSH (47) and Prolactin (145) as well, the adrenal cannot be inferred as the only cause for these stress results. It is interesting to note that stress does not induce an increase in LH (58).

The role of adrenal progesterone in the feedback system may be shown: ovariectomized plus adrenalectomized animals accumulate more radioactive progesterone in mesencephalic tissues than animals ónly ovariectomized. It can be concluded that progesterone from the adrenal may be accumulating in these tissues, accounting for the tissues increase in ability to uptake the labelled hormone after adrenalectomy (209)

The adrenal's involvement in pregnancy is also an area of controversy. Thoman recently demonstrated that adrenalectomy does not interfere with mating and impregnation and the ability to carry viable litters to term, although litter size was smaller, the pups weighed less, and had higher levels of plasma corticosterone than pups of non-adrenalectomized mothers. Lactation was sufficient to maintain the young (200). 0thers have supported the ability of adrenalectomized animals to become pregnant (98), and implicated the role of cor-. ticoids in parturition (1). 
Thus it appears that stress at proestrus advances the time of release of the ovulatory surge of $\mathrm{LH}$ (119) and the onset of mating behavior (148); adrenalectomy that morning prevents this advancement $(119,148)$ and also interferes with the release of the LH surge that day (119). Evidence which supports the role of adrenal progesterone in the events leading to LH release and ovulation (62) would lead to the conclusion that the adrenals are involved, although not indispensable, in the events of ovulation.

If the adrenals have a role in ovulation the next question is: What, if any, role do they play in the first ovulation --- puberty? 2. Adrenal - Ovarian Interaction in the Immature Rat.

The functional relationship between the adrenal cortex and gonadal development was originally indicated by the clinical observation that a disturbance in the adrenals results in changes in sexual development and function, such as virilism in the female (66). This interaction fits into the broad category of adrenogenital syndrome, conditions in which secretions of adrenal cortical cells lead to changes in sex characteristics. The syndrome is best defined biochemically as a consequence of overproduction of adrenal androgen as a result of an enzyme deficiency in the production of cortisol. Poor cortisol production leads to an excess of ACTH secretion, via feedback mechanisms, and this results in a over stimulation of the working biochemical pathways and an excess of androgens (216). As it might be expected, not all enzyme deficiencies have these characteristics, but, the most common one that does is the $c-21$ block (see Figure 1). This causes masculinization of the fetus or, in less severe cases, the 
characteristics do not manifest themselves until puberty. As mentioned previously 17- ketosteroid production is normally high after birth in the human and then falls and does not rise until shortly before puberty. The factors responsible for the increased secretion of sex hormones by the adrenal cortex during adolescence are not clear. The significance of the change, the adrenarche, to which the female pattern of body hair has been attributed, is not understood, yet it coincides with the puberal changes in gonadal activity (46). These puberal changes which are so intimately related led investigators to look at the role of the adrenal in normal maturation of the reproductive system.

In 1931 Cory and Britton used injections of adrenocortical extracts starting at 4 to 35 days of age and continuing for one to two weeks and observed a stimulatory effect on reproductive development. By 28 days of age treated female rats showed uterine hypertrophy, enlarged follicles, and corpora lutea. From this age onward accelerated maturation responses were elicited in all females. In the male spermatogenesis appeared at 35 days of age, slightly advanced over control. Thus, in the male and female adrenocortical extracts induced precocious sexual maturity. The pituitary of the females showed hypertrophy although no change in the adrenal glands appeared present. The authors concluded that the extract had more than one hormone, one which maintained adrenalectomized animals and the other a sex hormone (32). In 1932 Gaunt and Parkins published results which contradicted Cory and Britton, reporting that extracts from whole adrenal glands given to rats at 12 to 16 days of age for periods ranging from 16 to 37 days 
resulted in no indication of precocious sexual maturity (69). The effect of the adrenal cortex on the development of reproductive function still remains controversial today; the problems are much the same: different experiments with different doses given at different ages leading to differing results and interpretations.

With the advent of purified hormone preparations more definite results were obtained. In 1954 the administration of cortisone acetate to 23 day old female rats for two to four weeks resulted in an increased ovarian weight due to a greater number of follicles undergoing development. This was accompanied by an increased uterine weight and greater gonadotropic potency of the pituitaries of the treated animals (22). In 1952 Aterman and Greenberg had also brought about precocious sexual maturity in the male by the administration of cortisone (11). Moore showed that animals treated with cortisone as early as 12 days of age for 12 days showed enlarged ovaries due to increased follicle number and size (142). The mechanism of action of the corticoids may be due to increased sensitivity of the ovary to the stimulation of gonadotropins or an increased production of gonadotropins under the influence of cortisone administration.

If the administration of cortical extracts hasten development then adrenalectomy may also affect development. In 1940 Wade and Haselwood investigated the effect of adrenalectomy and/or ovariectomy on vaginal opening in the rat. Animals were treated between the ages of 27 to 40 days and were found to have a delay in vaginal opening of 1.7 days in adrenalectomized animals, 6.1 days in ovariectomized animals, 50.5 days in adrenalectomized-ovariectomized animals treated under 35 
days of age and 26.8 days in adrenalectomized-ovarlectomized animals treated over 35 days of age. This led them to conclude that adrenalectomy alone was ineffective but, along with ovariectomy, was very effective in delaying vaginal opening. Therefore, they assumed the adrenals produced estrogenic substances which are involved in maturation (204)

More recently adrenalectomy has been shown to affect the sensitivity of immature animals to gonadotropins. In adrenalectomized rats 23 to 31 days of age the response to PMS was found to be impaired but addltion of cortisone returned this response to normal (127). The interpretation of this decrease in responsivity is two-fold: (a) it may be due to the Increased ACTH levels which have been shown to impair the response to PMS (87) or (b) the presence of adrenocortical hormones in some way affects the cellular mechanisms leading to the ovarlan response to PMS. The nature of these posslble Interactions are unknown. A dependence of age to the response of PMS in adrenalectomized animals has been pointed out by Ramaley (158). Adrenalectomy affected the response to both an ovulatory dose and a non-ovulatory dose of PMS given early, at 22 days of age, or late 27 days of age, causing a decreased uterine and ovarlan welght response. Vaginal opening was blocked by adrenalectomy at 21 days of age when elther dose of PMS was given at 22 days of age but was not blocked by adrenalectomy at 26 days of age when the same doses were given at 27 days of age (158). Thus it would seem that adrenalectomy affects the ovarian response to PMS as well as the uterine and vaginal response. Here again the treatment age and dose are shown to be critical. Adrenalectomy has also been 
shown to inhibit the response to chorionic gonadotropin, cortisone and hydrocortisone partially restore the response (17).

The affect of ACTH on the response to PMS in the immature rat has been investigated by Hagino et al. (87). ACTH in high doses was shown to inhibit the response to PMS while low doses doubled the average number of ova per rat. The inhibitory action of ACTH was demonstrated only in the intact rat. Adrenalectomized animals at 27 days showed normal responses to high doses of PMS with and without ACTH. Thus, the inhibitory action of high doses of ACTH is mediated through the adrenal. The next consideration is where the inhibition is taking place. Since injection of HCG restored ovulation in spite of large doses of ACTH the response of the ovary to exogenous $\mathrm{LH}-1 \mathrm{ike}$ activity, (HCG), was not blocked by ACTH (87). ACTH has even been shown to augment the ovarian weight response to HCG, suggesting a facilitation of luteinization which occurs following HCG (26). This suggests that the hypothalamus may be the site of action of the ACTHadrenal-mediated inhibition of the response to PMS rather than the ovary itself. Attempts to override the ACTH block by stimulation of the preoptic area or the ventromedial-arcuate complex were negative. Hypothalamic placement of corticosterone or systemic injections demonstrated no block to PMS in inducing ovulation. Interestingly, dexamethasone injected into the medial preoptic area, or less effectively into the ventromedial arcuate complex, blocked ovulation and also inhibited corticosterone production via decreased ACTH secretion (87). This seems contradictory at first, but the mechanism of action of dexamethasone is unclear. Implantation of cortisol acetate in the medial basal 
hypothalamus of immature rats apart from inhibiting pituitary adrenal function inhibits estrous cycling and ovulation. ACTH in doses producing slight to marked hypertrophy of the adrenal did not influence the changes produced by cortisol implants. Thus cortisol may have a direct suppressive effect on gonadotropin secretion at the hypothalamic pituitary level (192). High doses of ACTH inhibit PMS action as do centrally placed cortisol and dexamethasone but low doses of ACTH facilitate the action of PMS. As discussed before (see section 1.A. 2.b.) progesterone can facilitate the action of low doses of PMS and cause ovulation (134). Recently deoxycorticosterone or corticosterone, but not cortisone, were shown to have the same facilitory action on PMS activity (215).

Therefore, high doses of ACTH cause an adrenal-mediated central inhibition of ovulation mimicked by centrally placed dexamethasone or cortisol. Low doses of ACTH, which cause a less marked increase in adrenal secretions, and exogenous corticoid extracts or corticoids facilitate ovulation and maturation. Adrenalectomy, the complete lack of corticoids, decreases the sensitivity of immature rat to gonadotropins.

Another consideration is the extra - adrenal effect of ACTH. Kar et al. demonstrated that ACTH exerts a stimulatory effect on gonadotropin secretion in both intact and adrenalectomized rats causing an increased ovarian weight and increased follicle maturation (102). This is in contrast to findings that doses of ACTH sufficient to induce slight to severe adrenal hypertrophy in no way. prevented the reproductive atrophy resulting from intrahypothalamic implantation of 
cortisol (215). This stimulatory effect of ACTH demonstrated by Kar et al. is also in contrast to the inhibitory action of ACTH in both intact and adrenalectomized mice $(30,99)$. ACTH can inhibit sexual maturation in mice (99). The action differences in these species may in part be due to differences in steroid hormone production by the adrenals. It can be recalled that the mouse has a distinct $X$ zone whose counterpart is questionable in the rat and may account for differing effects of ACTH stimulation.

As pointed out before (see section I.A. 2.d.) external factors can influence the time of onset of puberty. Different stresses: handling, cold, light, noise, have been shown to advance, delay, or have no effect on the onset of puberty. The action of these nonspecific stresses may be through ACTH stimulation of the adrenal gland. From the previous discussion of the action of different levels of ACTH and corticoids on maturation it might be expected that dissimilar stress would produce very different levels of ACTH stimulation resulting in various effects on maturation also.

All of the studies point to an interaction of the adrenal system in the maturing of the pituitary - ovarian axis. The definition of this interaction is difficult due to the complex interpretation of the action of the many hormones added in attempts to test the system. PMS, which has been widely used, not only affects the ovary but in immature rats can augment the concentration of progesterone in adrenal vein blood 16 days after the initial treatment (17). It can also be pointed out that many of the exogenously given hormones used to test the system may be undergoing degradation or other changes before 
exerting their effect at the tissue level, which presents another problem in coming to concrete conclusions from exogenous hormone treatments.

The question remains: what is the adrenal's involvement in determining the time of onset of puberty in the female rat? D. Statement of Problem

Previous investigators have presented data which suggest the interaction of the adrenal gland with the hypothalamic - pituitary ovarian axis in the adult rat. They suggest that the adrenal secretions have a role in the regulation of the LH surge, ovulation and mating behavior $(61,119,148)$. The adrenals appear to not only be involved in the adult reproductive system but may be involved as well in the maturation of the brain - pituitary - ovarian axis, and the sensitivity of the maturing system to gonadotropins $(32,204)$.

While the reproductive system is undergoing maturation the adrenal system is also undergoing development during the prepuberal period. The purpose of this dissertation research is to elucidate the interaction of these two developing systems and to describe the time course of the interaction. 


\section{CHAPTER II}

\section{MATERIALS AND METHODS}

\section{A. Animals and Housing}

ARS/Sprague-Dawley female rats from Madison, Wisconsin were received at 18 days of age and housed two to three per metal cage. The animals, originally born and raised under constant light, were put under controlled lighting of 14 hours light (5 AM to 7 PM) and 10 hours dark upon arrival. The temperature was maintained $24^{\circ} \pm 1^{\circ} \mathrm{C}$ and the relative humidity, al though not controlled, was kept above $40 \%$. Rockland/Teklad's mouse breeder diet was fed to all rats to minimize variations in natural plant estrogenic contamination in the food (119). Tap water and food were available to all rats ad libitum except for adrenalectomized and adrenal autotransplanted animals for which a $1 \%$ saline solution was substituted for tap water.

\section{B. Identification of Puberty and Assessment of Cyclicity by Vaginal}

\section{Smears}

Vaginal canalization, which is completed at about the time of the first ovulation in the rat, is frequently taken as an index of puberty (46). In this experiment all rats were examined daily in the morning ( 7 AM - $10 A M)$ from 30 days of age to minimize any effect of handling. The examination consisted of gently removing the animal 
from her cage and placing her on the back, spreading her hind feet and visually examining the vaginal membrane, and then returning her to her cage. When the membrane was gone, vaginal opening was complete and a vaginal smear was obtained by saline lavage. This consisted of handling the rat in much the same way, washing the vagina with a small amount of saline in an eye dropper and placing the sample on a glass slide. The wet, unstained smear was then microscopically examined, the cell types present identified, and the stage of the cycle determined in the manner first described by Long and Evans (122) which was discussed in section 1.A.1..

\section{c. Treatments}

1. Laparotomy, Adrenalectomy and Adrenal Autotransplantation Laparotomy (Sham-operation), adrenalectomy, and adrenal autotransplantation were all performed under ether anesthesia. Bilateral longitudinal flank incisions of approximately 2 centimeters in length were made subcostally in all procedures. Adrenals were removed carefully; ligation of adrenal vessels was not necessary. The laparotomized animals underwent the same trauma of locating the adrenals but the adrenals were left in situ. In the adrenal-autotransplanted animals the adrenals were removed as in the adrenalectomized animals and were immediately placed subcutaneously, through the same incision, in the axillary region. In all procedures the muscle was closed with two interrupted simple sutures and the skin was closed with two to three small metal clips. Insignificant blood loss occurred, and the animals, after having recovered from the anesthesia, were returned to their cages. 
2. Hormone Administration

All hormones and vehicles were administered at the times specified by subcutaneous injection in the posterior neck region.

D. Autopsy Procedures

1. Blood and Tissue Collection

Animals were autopsied at different ages depending upon the experimental design. Those animals not used for blood collection were weighed and sacrificed under ether anesthesia; in most cases the left adrenal and ovary, and uterus were removed, trimmed and weighed. Dry uterine (uterine tissue wrapped in tin foil and placed in an oven at $45-50^{\circ} \mathrm{C}$ for 24 hours), and thymus weights were taken in some cases. Specific gravity of the urine was also determined by placing the rat over an American Optical Total Solids meter and coaxing her to urinate by passing an ether soaked cotton ball past her nose. Not all rats responded positively.

Those animals used for blood collection were removed from their cages and within 30 seconds were guillotined, trunk blood collected into heparinized test tubes (179), placed on ice and then spun down in a refrigerated centrifuge at $0^{\circ} \mathrm{C}$ for $5-7$ minutes. The plasma was removed and quick frozen by immersing the tube in acetone and dry ice. The plasma samples were later used for chemical determination. The animals were then immediately examined for uterine state and the presence or absence of a swollen ampulla on the oviduct, an indication of ovulation. Vaginal smears and adrenal weights were also taken.

The mean and standard error of the mean was calculated for the data and comparisons were made by Student's t-test using a PDP-12 
computer. $P$ values less than 0.05 were considered to be significant. 2. Detection of Ovulation and Evaluation of Cycle Stage

All left ovaries and oviducts were routinely checked for ovulation by placing the whole ovary with oviduct under the dissecting microscope. The ovaries were examined for stimulated follicles or fresh corpora lutea and the oviducts were examined for the presence of a swollen ampullar segment. When a swelling was present, the ampulla was isolated with probes, a small nick made with iridectomy scissors and the eggs expressed into the surrounding saline drop and counted. The ovary was then weighed; the right ovary and oviduct were processed for histological examination.

Evaluation of cycle stage involved classification of uterine state as being ballooned and fluid filled or small with little or no fluid, determination of cell types in the vaginal smear, and presence or absence of ova in the oviduct from fresh ovaries and/or after histological examination of the ovaries and oviducts. If the animals were autopsied after they had begun to cycle the smear history was used to determine the stage of the cycle also. Thus, the cycle stages were as follows: Metestrus: vaginal smear heavily leukocytic, small uterus, no fresh ova; Diestrus: vaginal smear less dense with leukocytes predominating but nucleated and cornified epithelial cells present, uterus small, no fresh ova; Proestrus: vaginal smear predominantly nucleated and cornified cells, uterus ballooned and fluid filled, no fresh ova; Estrus: vaginal smear fully cornified, small uterus, fresh ova in oviduct. Histological evaluation of the ovary was used to confirm the cycle stage in questionable cases along with smear 
histories.

E. Histology

Representative ovaries and adrenals were fixed in Bouins solution and sectioned and stained with hematoxylin and eosin. Serial sections of the ovaries were examined for the presence or absence of fresh or old ova in the oviduct, the presence of fresh corpora lutea, normal luteinization and follicular growth. If the cycle stage of the animals was questionable, the ovarian histology was used to confirm the stage of the cycle. Adrenals were examined for any changes in cell layer size in the control or transplanted animals, and to confirm the degeneration of the medulla in the transplanted animals. F. Measurement of Corticosterone

of the numerous studies and variations of the method of silber et al. (187) which have appeared, in the literature, the method described by Guillemin, Clayton, Lipscomb and Smith (84) was chosen not only because it is well validated (85) but the procedure was written with such detail that someone unfamiliar with the technique could understand and develop the method. The technique also required the purchase of only a small amount of equipment and thus was another point in its favor. After using different grades of reagents the following were found to give the lowest blanks and were used for the assays:

Chloroform Harleco, fluorometric grade

$2,2,4-t$ rimethylpentane (isooctane)

Sulfuric acid, Matheson, Coleman and Bell, fluorometric grade Sodium hydroxide, $0.1 \mathrm{~N}$ Harleco

In the procedure a $0.5 \mathrm{ml}$ sample of plasma was placed in a $15 \mathrm{ml}$ 
centrifuge tube with $2.0 \mathrm{ml}$ of double distilled deionized water to which $4.0 \mathrm{ml}$ of isooctane was added. This was mixed on a vortex mixer for 15 seconds, the isooctane layer discarded and $2.0 \mathrm{ml}$ of double distilled deionized water added. The aqueous defatted samples were then extracted with $5.0 \mathrm{ml}$ of chloroform mixed for 30 seconds and centrifuged for 3 minutes. The remaining acidic and phenolic impurities were then removed by $0.5 \mathrm{ml}$ of $\mathrm{NaOH}$ mixed for 5 seconds to avoid loss of corticoid and centrifuged for 3 minutes. Then $4.0 \mathrm{ml}$ of the chloroform extract was transferred to another centrifuge tube containing $1.2 \mathrm{ml}$ of $30 \mathrm{~N}$ sulfuric acid, the tubes shaken for 30 seconds and centrifuged for 3 minutes. One $\mathrm{ml}$ of the extract was then transferred to the fluorometer tubes and read 30 to 40 minutes after the addition of the sulfuric acid. The standard used was Corticosterone (Calbiochem, A Grade). The fluorescence was measured on a Turner Model 110 Fluorometer using primary filters $2 \mathrm{~A}$ and $47 \mathrm{~B}$ for an excitation of $436 \mathrm{~m} \mu$ and a secondary filter, $2 \mathrm{~A}-12$ for an emitted wave length of $530 \mathrm{m \mu}$. Care was taken in washing all glassware. It was first rinsed after use and soaked overnight in dichromate acid cleaning solution, rinsed and soaked 2-3 hours in Actionox (Scientific Products), rinsed 10 times in tap water, and 10 times in distilled water, oven dried and covered until use.

The sensitivity of the assay was such that values down to $4.0 \mathrm{\mu g} /$ $100 \mathrm{ml}$ could be routinely measured and at times values as low as $2.5 \mu \mathrm{g} /$ $100 \mathrm{ml}$ could be detected. This compares well with values in the $1 \mathrm{i}$ terature $(85,157)$ and is well below the background fluorescence found in place of adrenalectomized animals in other studies $(6.0 \pm .07 \mu \mathrm{g} / 100 \mathrm{ml})$ 
and in our own $(6.5 \pm 0.9 \mu \mathrm{g} / 100 \mathrm{ml})$. Accuracy was determined by running 8 separate assays of some pooled plasma from donors yielding a mean \pm sem of $35.6 \pm 1.1 \mu \mathrm{g} / 100 \mathrm{ml}$ of plasma.

In all assays two standard curves were run along with the unknowns, one at the start of the assay and the other at the end. Two plasma pool samples were run with each assay to check the assay and the standards against the previous assays. In all cases at least doubles were run on all experimental unpooled samples except in plasma from very young animals when $0.5 \mathrm{ml}$ could not be collected. 


\section{CHAPTER III}

\section{RESULTS AND COMMENTS}

\section{A. Study 1: Adrenal Involvement in Determining the Time of Onset of Puberty in the Rat}

\section{Experimental Design}

Animals in this study were divided into 4 treatment groups: sham-operated, bilaterally adrenalectomized, adrenal autotransplanted and untreated controls. These groups were further subdivided into the age 18,25 and 35 days of age at which the surgery was performed. Vaginal smears were taken daily from puberty until autopsy; the latter was performed at proestrus or estrus between the ages of 60-65 days at which time completeness of adrenalectomy and the condition of the transplants were visually assessed. Body, left adrenal, left ovary, uterine (wet and dry), and thymus weights were taken as were ova counts in estrous rats. Specific gravity was also recorded when possible. Adrenalectomized and transplanted rats were given saline to drink; 10 controls were also given saline to rule out any effect of salt.

\section{Results}

The overall conditions of the animals was excellent; they survived the surgery without complications. The control animals receiving a $1 \%$ saline solution did not differ from the controls receiving tap water (Table 1) and thus are grouped together. Specific 
TABLE I

Comparison of the Controls receiving Tap water and those receiving a $1 \%$ salt solution in Study 1 .

\begin{tabular}{|c|c|c|c|c|}
\hline & Controls Tap & Water & Controls $1 \%$ & Saline \\
\hline Puberty Onset (days) & $38.3 \pm 0.3$ & $(34)^{+}$ & $36.9 \pm 0.7$ & $(10)$ \\
\hline Body Weight $(G)$ & $189.3 \pm 2.6$ & $(34)$ & $183.3 \pm 3.9$ & $(10)$ \\
\hline Mean Cycle Length (days) & $4.77 \pm 0.09$ & $(34)$ & $5.06 \pm .17$ & $(10)$ \\
\hline Mean PSP per rat & $0.15 \pm .09$ & $(34)$ & $0.20 \pm .13$ & $(10)$ \\
\hline $\begin{array}{l}\text { Specific Gravity of } \\
\text { Urine }\end{array}$ & $1.031 \pm .003$ & (19) & $1.030 \pm .004$ & $(8)$ \\
\hline Adrenal Welght (mg) & $26.8 \pm 0.8$ & $(25)$ & $24.0 \pm 1.1$ & $(8)$ \\
\hline Thymus Weight (mg) & $402.0 \pm 14$ & $(25)$ & $428.0 \pm 20.0$ & $(8)$ \\
\hline Ovary Weight (mg) & $41.3 \pm 1.0$ & $(32)$ & $37.1 \pm 1.9$ & ( 8$)$ \\
\hline
\end{tabular}

tMean \pm SEM (number of animals)

All animals autopsied at $60-65$ days of age 
gravities of urine (Table II) from the sham, adrenalectomized, and transplanted animals were similar except for the group transplanted at 25 days of age which was significantly different from the controls $(p<0.05)$ but not from the sham group. Body weights (Table II) at autopsy in the groups adrenalectomized at 18 days of age were lower than in the shams $(p<0.25)$, and the groups adrenalectomized or receiving transplants at 25 days weighed slightly less $(p<0.05)$ than their respective sham controls. Body weights in other experimental groups were not significantly different from the sham or control animals.

The mean age of onset of puberty is summarized in Table 111. Puberty onset was not altered by laparotomy at any age, whereas adrenalectomy at 18 or 25 days of age incurred highly significant delays $(p<0.00005)$. Adrenal autotransplantation at 18 days decreased the adrenalectomy-induced delay; puberty onset occurred earlier than in the adrenalectomy group $(p<0.01)$ but later than in the sham controls $(p<0.005)$. However, in the group receiving transplants at 25 days of age, puberty occurred at approximately the same age in those which were adrenalectomized and was delayed when compared with the shams $(p<0.002)$. Puberty onset in the animals adrenalectomized or adrenal autotransplanted at 35 days of age was similar to that in their respective còntrols.

Following the onset of puberty cyclicity of the animals was assessed. Most animals demonstrated normal estrous cycles: 14/18, $11 / 14$ and $25 / 27$ in the groups adrenalectomized at 18,25 and 35 days of age respectively and $18 / 19$ in the groups transplanted at 25 days of 


\section{TABLE | |}

Effect of Treatment on Body Welght and Specific Gravity of Urine in Study 1

Treatment Group*

Control

18 days

Sham

Adrx

Adr AT

25 days tw

Sham

Adrx

Adr AT

35 days $* *$

Sham

Adrx

Adr AT
Body Weight (G)

$187.7 \pm 2.2(44)^{+}$

$189.3+2.0(28)$

$180.3 \pm 2.9(18)$

$184.6 \pm 3.9(15)$

$1.028 \pm .006(5)$

$1.025 \pm .002(5)$

$1.026 \pm .002(4)$
Specific Gravity

$1.031 \pm .004 \quad(27)$
$185.7 \pm 3.7(16)$

$172.0 \pm 5.1(14)$

$176.3 \pm 3.8(19)$
$1.028 \pm .002(8)$

$1.021 \pm .003(6)$

$1.021 \pm .002(10)$

tMean \pm SEM (number of animals)

*All groups autopsied at $60-65$ days of age

*:Treatment age; $A d r x=$ bilaterally adrenalectomized

Adr $A T=$ adrenals removed and autotransplanted subcutaneously

$180.0+2.9(22)$

$182.6 \pm 3.1 \quad(27)$

$194.8 \pm 3.5$ (12)
$1.025+.003(9)$

$1.028 \pm .002(16)$ 
TABLE \|\|

Effect of treatment on puberty onset and cyclicity in Study 1

\begin{tabular}{|c|c|c|c|}
\hline Treatment Group* & $\begin{array}{l}\text { Puberty Onset } \\
\text { (days) }\end{array}$ & $\begin{array}{c}\text { Mean Cycle Length } \\
\text { (days) }\end{array}$ & $\begin{array}{l}\text { Mean PSPriwix } \\
\text { per rat }\end{array}$ \\
\hline Control & $37.9 \pm .3 \quad(44)$ & $4.9 \pm .1 \quad(44)$ & $.16 \pm .06(44)$ \\
\hline \multicolumn{4}{|l|}{18 days $* x$} \\
\hline $\begin{array}{l}\text { Sham } \\
\text { Adrx } \\
\text { Adr AT }\end{array}$ & $\begin{array}{l}37.7 \pm .4(28) \\
44.4 \pm .8(18) \\
40.1 \pm .6(15)\end{array}$ & $\begin{array}{ll}4.9 \pm .1 & (28) \\
5.3 \pm .2 & (14) \\
5.1 \pm .1 & (15)\end{array}$ & $\begin{array}{l}.04 \pm .04 \\
.50 \pm .15 \\
.13 \pm .09\end{array}$ \\
\hline \multicolumn{4}{|l|}{25 days irk } \\
\hline $\begin{array}{l}\text { Sham } \\
\text { Adrx } \\
\text { Adr AT }\end{array}$ & $\begin{array}{l}36.7 \pm .9(16) \\
43.6 \pm .9(14) \\
41.1 \pm .9(19)\end{array}$ & $\begin{array}{ll}5.2 \pm .1 & (16) \\
5.0 \pm .2 & (11) \\
4.9 \pm .1 & (18)\end{array}$ & $\begin{array}{l}.25 \pm .11(16) \\
.28 \pm .13(14) \\
.16 \pm .09(19)\end{array}$ \\
\hline \multicolumn{4}{|l|}{35 days $w$} \\
\hline $\begin{array}{l}\text { Sham } \\
\text { Adrx } \\
\text { Adr AT }\end{array}$ & $\begin{array}{ll}38.0 \pm .4 & (22) \\
39.2 \pm .5 & (27) \\
39.4 \pm .7 & (12)\end{array}$ & $\begin{array}{ll}4.9 \pm .1 & (22) \\
4.9 \pm .1 & (25) \\
4.9 \pm .1 & (12)\end{array}$ & $\begin{array}{l}.14 \pm .07(22) \\
.48 \pm .12(27) \\
.33 \pm .14(12)\end{array}$ \\
\hline
\end{tabular}

tMean \pm SEM (number of animals)

*All groups autopsied at 60-65 days of age

*istreatment age; $A d r x=$ bilaterally adrenalectomized

Adr $A T=$ adrenals removed and autotransplanted subcutaneously

*is:Pseudopregnancy 
age; all other animals demonstrated normal cycles. The acyclic animals in the above groups were pseudopregnant from the time of puberty until the time of autopsy. Cyclic animals in all groups had similar mean cycle lengths (Table 111 ); the group adrenalectomized at 18 days of age had a slightly longer mean cycle length when compared to controls $(p<0.025)$ but not when compared to the shams. Although mean cycle length was similar in all groups those animals adrenalectomized at 18 and 35 days of age showed a higher number of pseudopregnancy episodes per rat than their respective sham groups $(p<0.002)$ or controls $(p<0.025)$. Incidence of pseudopregnancy in the sham groups was comparable to that in the controls and transplant groups.

Organ weights were first tested for variation during the cycle; the results are reported in Table IV. Ovarian weights were not shown to vary significantly during the cycle but adrenal weights were significantly higher $(p<0.025)$ in metestrous and diestrous animals. Thymus weights were considerably smaller $(p<0.025)$ in metestrous and diestrous animals. Thus, adrenal and thymus weights, which showed no difference at proestrus and estrus, are grouped together when reported. Uterine weights showed variation throughout the cycle and are reported separately.

- Ovarian weights of the sham animals (Table V) were not dif... ferent from those of the controls; ovarian weights in the experimental groups were not different from those of their respective sham or control animals except for the group adrenalectomized at 25 days of age which was lower than those of the controls $(p<0.0001)$ but, not of 
TABLE IV

Comparison of Control Organ Weights during the cycle in Study 1

\begin{tabular}{c} 
Proestrus $\quad$ Estrus $\quad \begin{array}{c}\text { Metestrus } \& \\
\text { Diestrus }\end{array}$ \\
\hline
\end{tabular}

Ovarian weight (mg) $40.4 \pm 1.1$ (18) $39.8 \pm 1.6$ (15) $41.8 \pm 3.0$ ( 7)

Adrenal weight $(\mathrm{mg}) \quad 25.8 \pm 0.8(18) \quad 26.5 \pm 1.1(15) \quad 31.9 \pm 1.9$ ( 7)

Thymus welght (mg) $404 \pm 18 \quad$ (18) $413 \pm 14 \quad$ (15) $343.5 \pm 23 \quad$ ( 7)

Uterine weight

Wet $(\mathrm{mg})$

$349.1 \pm 13.3(18) \quad 285.7 \pm 9.6(15) \quad 256.1 \pm 21.3(7)$

Uterine weight

Dry (mg)

$63.6 \pm 1.9(18) \quad 55.3 \pm 1.5(15) \quad 48.8 \pm 3.3(7)$

tMean \pm SEM (number of animals)

All groups autopsied at $60-65$ days of age 
Effect of Treatment on Organ Weight in Study 1

\begin{tabular}{|c|c|c|c|c|c|c|c|}
\hline Treatment Group' & $\begin{array}{l}\text { Ovarian } \\
\text { Wt. (mg) }\end{array}$ & $\begin{array}{l}\text { Thymus } \\
\text { Wt. (mg) }\end{array}$ & $\begin{array}{l}\text { Uterine } \\
\text { Wet Wt. } \\
\text { Estrus }\end{array}$ & $\begin{array}{l}\text { Uterine } \\
\text { Dry Wt. } \\
\text { Estrus }\end{array}$ & $\begin{array}{l}\text { Uterine } \\
\text { Wet Wt. } \\
\text { Proestrus }\end{array}$ & $\begin{array}{l}\text { Uterine } \\
\text { Dry Wt. } \\
\text { Proestrus }\end{array}$ & $\begin{array}{l}\text { Adrenal } \\
W t . \quad(m g)\end{array}$ \\
\hline Control & $40.4 \pm .9(40)^{+}$ & $408 \pm 12(33)$ & (15) $286 \pm 10$ & $55 \pm 2$ & (18) $349 \pm 13$ & $64 \pm 2$ & $26.1 \pm 0.7 \quad(33)$ \\
\hline 18 days & & & & & & & \\
\hline $\begin{array}{l}\text { Sham } \\
\text { Adrx } \\
\text { Adr AT }\end{array}$ & $\begin{array}{ll}40.1 \pm 1.5 & (24) \\
36.6 \pm 1.9 & (13) \\
42.7 \pm 1.6 & (15)\end{array}$ & $\begin{array}{ll}409 \pm 14 & (24) \\
613 \pm 40 & (11) \\
422 \pm 44 & (7)\end{array}$ & $\begin{array}{c}\text { (10) } 292 \pm 10 \\
\cdots \\
\cdots\end{array}$ & $\begin{array}{c}56 \pm 2 \\
-- \\
--\end{array}$ & $\begin{array}{c}(14) 380 \pm 11 \\
(8) 335 \pm 22 \\
-\end{array}$ & $\begin{array}{c}68 \pm 2 \\
63 \pm 7 \\
--\end{array}$ & $\begin{array}{c}26.5 \pm 0.9 \cdot(24) \\
= \\
-\end{array}$ \\
\hline $\begin{array}{l}25 \text { days } \\
\text { Sham } \\
\text { Adrx } \\
\text { Adr AT }\end{array}$ & $\begin{array}{ll}37.6 \pm 1.6 & (14) \\
32.6 \pm 2.4 & (14) \\
38.5 \pm 1.9 & (15)\end{array}$ & $\begin{array}{ll}398+20 & (14) \\
584+42 & (12) \\
406 \pm 17 & (15)\end{array}$ & $\begin{array}{c}(6) 279+21 \\
(6) 258 \pm 17\end{array}$ & $\begin{array}{l}-- \\
54 \pm 4 \\
50 \pm 3\end{array}$ & $\begin{array}{l}(10) 381+48 \\
(6) 325 \pm 15 \\
\text { (9) } 290 \pm 13\end{array}$ & $\begin{array}{l}62 \pm 3 \\
59 \pm 2 \\
50 \pm 4\end{array}$ & $\begin{array}{c}27.8 \pm 0.9(14) \\
- \\
\cdots\end{array}$ \\
\hline $\begin{array}{l}35 \text { days } \\
\text { Sham } \\
\text { Adrx } \\
\text { Adr AT }\end{array}$ & $\begin{array}{lr}37.9 \pm 1.2 & (20) \\
38.6 \pm 1.1 & (20) \\
37.2 \pm 3.2 & (8)\end{array}$ & $\begin{array}{l}406 \pm 17(15) \\
516 \pm 23(18) \\
546 \pm 32(8)\end{array}$ & 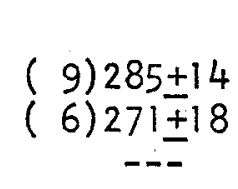 & $\begin{array}{c}56 \pm 3 \\
48 \pm 5 \\
=-\end{array}$ & $\begin{array}{l}(7) 372 \pm 17 \\
(12) 360 \pm 16 \\
(6) 375 \pm 29\end{array}$ & $\begin{array}{l}71 \pm 3 \\
67 \pm 6 \\
68 \pm 4\end{array}$ & 26. $\frac{6 \pm 1.0(16)}{-}$ \\
\hline
\end{tabular}

tMean \pm SEM (number of animals

*All groups autopsied at 60-65 days of age

*itreatment age; Adrx = bilaterally adrenalectomized

Adr $A T=$ adrenals removed and autotransplanted subcutaneously 
the shams.

Histological examination of ovarian tissues revealed full ovulations had occurred in all groups of estrous animals and luteinization appeared normal. Examples of ovarian histology are presented in Figure 2 .

Uterine weights (Table $V$ ) when examined closely revealed some small differences. The estrous uterine wet weights were the same in all groups except for the group transplanted at 25 days of age which was significantly lighter than the controls $(p<0.001)$. Only 6 animals were available for comparison which weakens the significance, along with the fact that there are no sham controls for comparison which further weakens the significance. Proestrous uterine wet weights in the group adrenalectomized at 18 days of age was smaller than their respective sham group $(p<0.05)$ but was not different from the controls while the group transplanted at 25 days was lighter than the control $(p<0.01)$ but not different from the sham group. Proestrous uterine dry weights in the group transplanted at 25 days of age was significantly lighter than both the sham and control groups $(p<0.05$ and $<0.005$ respectively). The sham at 35 days of age was significantly $(p<0.05)$ greater than the control but was not different from the adrenalectomized or transplanted animals at the same age. Thus the only group to demonstrate consistent differences was the group transplanted at 25 days of age. This group did not reflect the proestrus increase in both uterine wet and dry weights seen in the control groups and mirrored by all other groups. Again, the comparison here is weakened by the low number of estrous animals. 

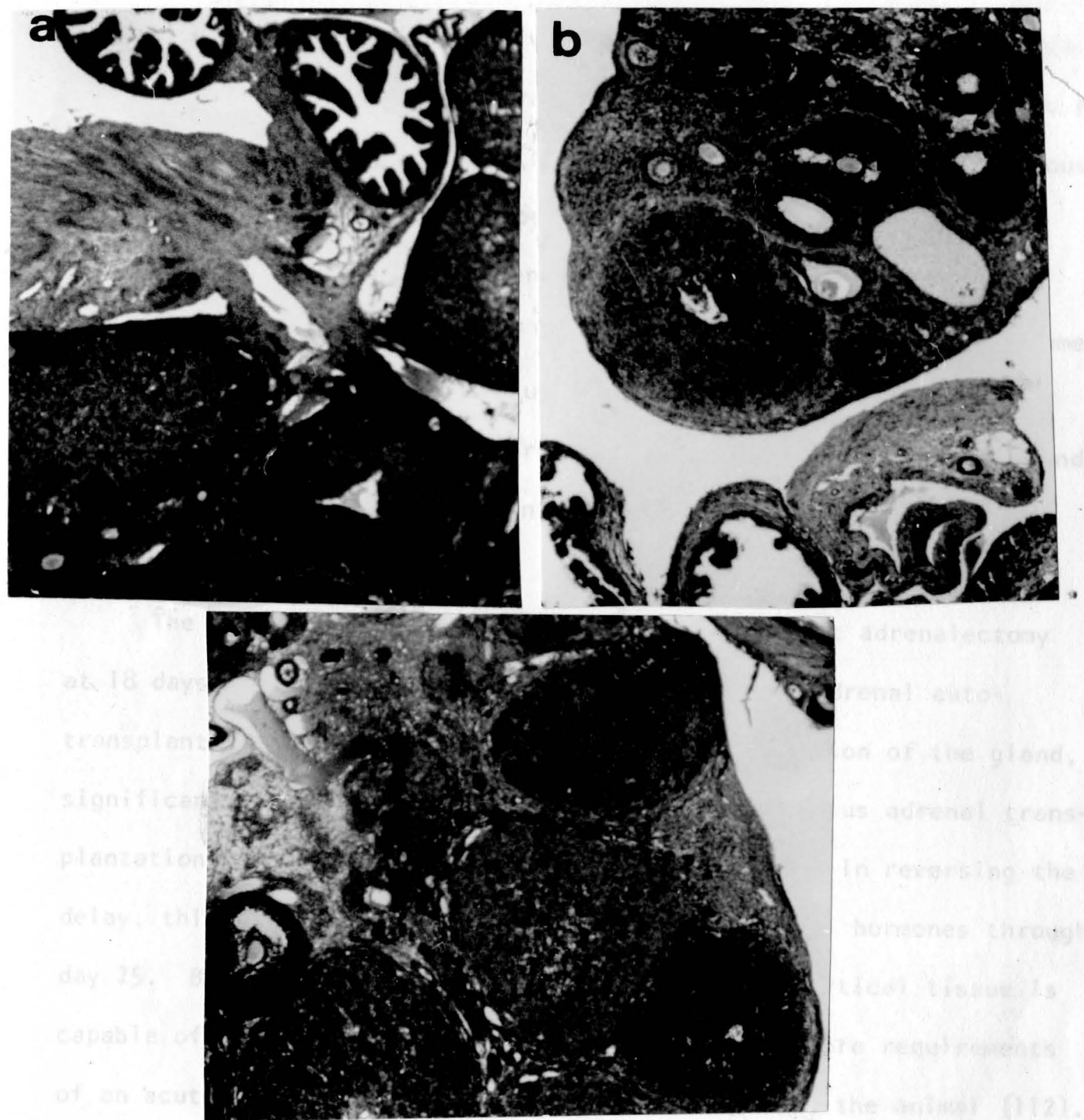

Figure 2

Ovarian Tissue

-a. control estrous ovary

b. 18 day old adrenalectomized estrous ovary

c. 25 day old adrenal-transplanted estrous ovary $\mathrm{X}=$ Corpus Iutem

$\mathrm{D}=$ Developing follicle 
Thymus weights (Table V) of cyclic estrous and proestrous animals were higher than their respective shams in all of the adrenalectomized groups and in the 35 day old transplant group $(p<0.00005)$ but in no other group. Adrenal weights (Table $V$ ) of the estrous and proestrous sham animals were not different from that of the controls. Histological examination of the adrenal transplants revealed medullary degeneration while the width of the cortical layers remained the same although the adrenal tissue assumed a lobular appearance due to the invasion of capsular stromal adrenal tissue. Examples of control and transplanted adrenals are presented in Figure 3.

\section{Comments}

The results of this experiment demonstrate that adrenalectomy at 18 days of age delayed the onset of puberty but adrenal autotransplantation, which denervated the medullary portion of the gland, significantly prevented'this delay. Adrenalectomy plus adrenal transplantation at 25 days of age was totally ineffective in reversing the delay; this substantiates a critical need for adrenal hormones through day 25. By the 5 th day after transplantation the cortical tissue is capable of secreting sufficient hormones to meet severe requirements of an acute stress in addition to the daily needs of the animal (112). Thus, in the 18 day transplant group hormones have reached adequate levels by day 23 but in the 25 -day transplant group these levels are not reached until day 30 . Since adrenalectomy at 35 days of age did not delay puberty it would appear that what ever adrenal factor is necessary for the maturation of the brain-pituitary-ovarian axis has already been released into the circulation. 

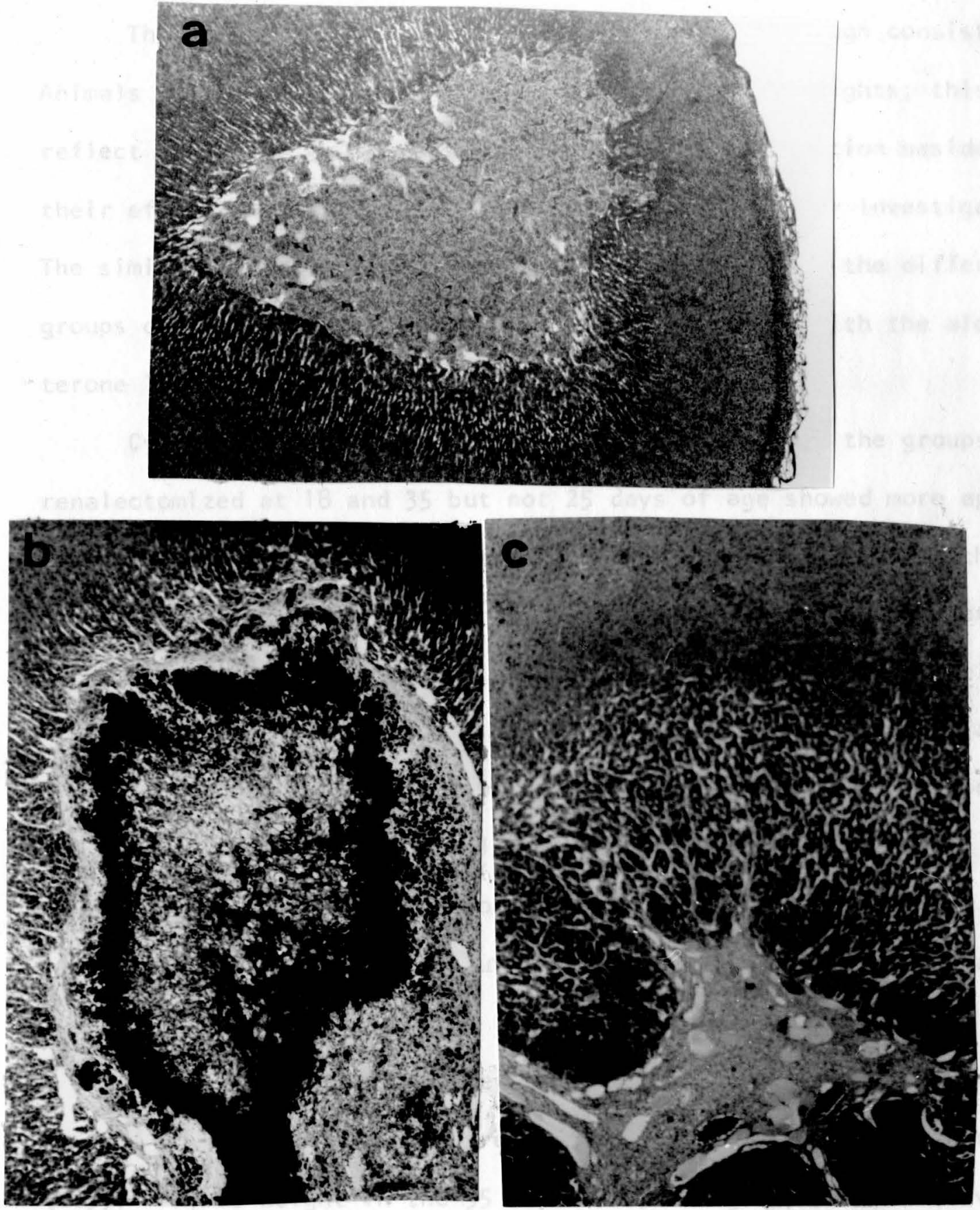

Figure 3

Adrenal Tissue

a. normal adrena!

b. 18 day old transplanted adrenál

c. 25 day old transplanted adrenal 
The differences in body weights were small although consistent. Animals in which puberty was delayed had lower body weights; this may reflect a generalized effect of the adrenals on maturation beside their effect on the reproductive system and was further investigated. The similarity of the specific gravity of the urine in the different groups demonstrated an ability of the animal to cope with the aldosterone loss and salt replacement.

Cycle length was similar in all groups, although the groups adrenalectomized at 18 and 35 but not 25 days of age showed more episodes of pseudopregnancy than the other groups. This suggests that the adrenals not only have a role in the development of reproductive mechanisms but also may play a role in maintaining normal cyclicity; however, this is not reflected in any consistent change in ovarian weight, number of ova per ovulation or vaginal cytology. The consistent difference from control in uterine weight seen in the 25 day transplant group, which does not demonstrate the proestrous rise in uterine weight, again points out a difference in the animals treated at 25 days of age.

The increase in thymus weight in the three adrenalectomized groups reflects the loss of adrenal hormones from the circulation (205). Thymus weight in the 35 day transplant group is also elevated because the thymus has not fully regressed following the increase due $\therefore$ to the temporary loss of adrenal hormones at the time of transplantation. The small cyclic changes in thymus weight may be due to the fact that corticosterone levels also undergo cyclic changes, highest levels being at proestrus dropping to low levels at estrus (165). The change 
in thymus weights follow this pattern, shifted by a few days.

Since adrenal transplantation reverses the adrenalectomy-induced delay in puberty, it would seem likely that the stimulatory factor or factors are from the cortex rather than from the medullary portion of the gland which was both denervated and degenerated. The factors remain to be investigated as well as the mechanisin by which they act. From this experiment it is clear that the adrenal cortex plays a role in determining the time of onset of puberty in the female rat.

4. Conclusions

1. Administration of salt does not effect the reproductive processes in the intact rat.

2. Adrenalectomy at 18 and 25 but not 35 days of age delays puberty onset.

3. Adrenal autotransplantation at 18 but not 25 days of age reverses the adrenalectomy-induced delay in puberty by supplying adrenal cortical hormones to the circulation.

4. Adrenalectomy affects the fine tuning of the cyclic reproductive processes by increasing the incidence of pseudopregnancy. 
in thymus weights follow this pattern, shifted by a few days.

Since adrenal transplantation reverses the adrenalectomy-induced delay in puberty, it would seem likely that the stimulatory factor or factors are from the cortex rather than from the medullary portion of the gland which was both denervated and degenerated. The factors remain to be investigated as well as the mechanism by which they act. From this experiment it is clear that the adrenal cortex plays a role in determining the time of onset of puberty in the female rat.

4. Conclusions

1. Administration of salt does not effect the reproductive processes in the intact rat.

2. Adrenalectomy at 18 and 25 but not 35 days of age delays puberty onset.

3. Adrenal autotransplantation at 18 but not 25 days of age reverses the adrenalectomy-induced delay in puberty by supplying adrenal cortical hormones to the circulation.

4. Adrenalectomy affects the fine tuning of the cyclic reproductive processes by increasing the incidence of pseudopregnancy. 
B. Study 11: Timing of the Prepuberal Adrenal-Ovarian Interaction in the Rat

1. Experimental Design

In the previous study puberty was significantly delayed by adrenalectomy at 18 or 25 but not 35 days of age; adrenal autotransplantation at 18 days of age prevented the delay but was ineffective at 25 days of age. Laparotomy at 18,25 and 35 days of age had no effect on puberty onset. The purpose of this study was to delineate the time course of this adrenal-ovarian interaction period.

Animals were divided into controls and 23 treatment groups: 10 bilaterally adrenalectomized and 13 sham-operated. These were further subdivided according to the age at which surgery was performed: adrenalectomy at 24 through 29 and at 31 days of age and laparotomy at 25 through 35 days of age; autopsies were performed at puberty onset. On days. 25 and 26 the sham and adrenalectomy groups were further subdivided into the time at which the procedures were performed: day $25,8: 00-9: 00 \mathrm{AM}$, and 9:30-10:30 PM; day 26, 1:002:00 AM and 8:00-9:00 AM (these animals were autopsied at 45 days of age for the data presented in Study IV). At vaginal opening body, left adrenal, left ovary and uterine weights were taken; ova counts were also obtained on estrous animals. Representative ovarian and adrenal tissues sectioned and stained with hematoxylin and eosin were examined histologically.

2. Results

Again, in this experiment the animals withstood the surgical procedures without complication and their condition remained excellent. 
Body weights presented in Table VI varied with the age of onset of puberty; the later an animal came into puberty the greater the body weight. In the sham. group these increases were significant $(p<0.05)$ at all ages. In the control and adrenalectomy groups they are significant until the 38-39 day groups are compared to the 40-42 day groups. A significant $(p<0.02)$ increment is again seen in the adrenalectomy groups between 43-44 day group and the 38-39 day group. At any age group the body weights of the adrenalectomized animals were not different from the respective sham or control groups. The sham when compared to the controls were significantly lighter at $34-35$ days of age $(p<0.005)$ and at $38-39$ days of age $(p<0.001)$.

The age of puberty onset remained constant regardless of time of year during which the studies were conducted: July 1971 and 1972 , $37.2 \pm 0.7$ and $37.7 \pm 0.6$ respectively and December $1971,37.4 \pm 0.4$ days of age. Table VII lists the mean age of onset of puberty and the date of the birth of the animals for the experiments run in the laboratory during the time the work for this thesis was completed. There does not seem to be a seasonal variation in puberty onset in our colony as has been noted by Ramaley (160). Therefore this was not taken into account when experiments are compared.

Puberty onset for all groups is summarized in Table VIII. Laparotomy at 25 and 31 through 35 days of age had no effect on puberty on... set but, when performed at 26 through 30 days of age puberty was significantly advanced. Adrenalectomy at 24 or 25 days of age significantly delayed puberty, but had no effect when performed at days 26 through 33. When adrenalectomy groups were compared to their respective shams 
TABLE VI

Effect of Treatment on Body Weight at Puberty in Study 11

\begin{tabular}{ccccc}
$\begin{array}{c}\text { Age at Puberty } \\
\text { Days } *\end{array}$ & \multicolumn{4}{c}{ Body Welght, $(G)$} \\
\hline $31-33$ & $88.2 \pm 1.7(9)^{+}$ & Adrenalectomy \\
$34-35$ & $104.1 \pm 1.8(11)$ & $95.1 \pm 1.7(20)$ & $100.0 \pm 2.2(12)$ \\
$36-37$ & $110.6 \pm 2.5(12)$ & $107.2 \pm 0.8(29)$ & $109.3 \pm 1.4(20)$ \\
$38-39$ & $119.2 \pm 2.5(13)$ & $110.4 \pm 1.0(47)$ & $113.8 \pm 1.5(17)$ \\
$40-42$ & $120.5 \pm 2.5(10)$ & $115.6 \pm 2.3(10)$ & $116.1 \pm 2.0(35)$ \\
$43-44$ & & & $119.4 \pm 2.7(7)$ \\
$45-49$ & & & $122.2 \pm 2.3(13)$
\end{tabular}

+Mean \pm SEM (number of animals)

*Autopsy at puberty onset 
TABLE VII

Effect of Time of year on Puberty Onset

Month of Birth of Control

January and February, 1971

April, 1971

June, 1971

August, 1971

November, 1971

November, 1971

March, 1972

June, 1972

July, 1972
Puberty Onset (days)

$38.1 \pm 0.4(28)^{+}$

$38.5 \pm 0.6(12)$

$37.2 \pm 0.7(10)$

$37.1 \pm 0.7$ ( 9 )

$37.5 \pm 0.8$ ( 8 )

$37.4 \pm 0.5(16)$

$38.3 \pm 0.9(10)$

$37.7 \pm 0.6(12)$

$37.2 \pm 0.7(12)$

${ }^{+}$Mean \pm SEM (number of animals) 


\section{TABLE VIII}

Effect of Adrenalectomy and Laparotomy on Puberty Onset in Study II

\begin{tabular}{|c|c|c|c|}
\hline Treatment Group & $\begin{array}{c}\text { Puberty Onset, } \\
\text { (days) }\end{array}$ & $\begin{array}{c}\text { P value } \\
\text { treatment } \\
\text { vs. control }\end{array}$ & $\begin{array}{c}\text { P value } \\
\text { sham vs. } \\
\text { adrenalectomy }\end{array}$ \\
\hline Control & $37.7 \pm 0.3(77)^{\mp}$ & $\overline{---}$ & -- \\
\hline Day 24-Adrx* & $44.0 \pm 1.0(10)$ & $<0.001$ & --- \\
\hline Day 25-Sham & $37.6 \pm 0.6(25)$ & N.S.S: & $<0.001$ \\
\hline Adrx & $42.7 \pm 0.7 \quad(26)$ & $<0.001$ & \\
\hline $\begin{array}{r}\text { Day 26-Sham } \\
\text { Adrx }\end{array}$ & $\begin{array}{l}35.7 \pm 0.7(15) \\
38.2 \pm 0.7(26)\end{array}$ & $\begin{array}{l}<0.001 \\
\text { N.S. }\end{array}$ & $<0.01$ \\
\hline $\begin{array}{r}\text { Day 27-Sham } \\
\text { Adrx }\end{array}$ & $\begin{array}{l}35.9 \pm 0.7(12) \\
38.9 \pm 0.8(14)\end{array}$ & $\begin{array}{l}<0.01 \\
\text { N.S. }\end{array}$ & $<0.01$ \\
\hline $\begin{array}{r}\text { Day 28-Sham } \\
\text { Adrx }\end{array}$ & $\begin{array}{l}35.4 \pm 0.6(21) \\
36.5 \pm 0.9(8)\end{array}$ & $\begin{array}{l}<0.001 \\
\text { N.S. }\end{array}$ & N.S. \\
\hline $\begin{array}{r}\text { Day 29-Sham } \\
\text { Adrx }\end{array}$ & $\begin{array}{l}35.4 \pm 0.8(12) \\
38.6 \pm 0.7(8)\end{array}$ & $\begin{array}{c}<0.005 \\
\text { N.S. }\end{array}$ & $<0.025$ \\
\hline Day 30-Sham & $36.2 \pm 0.5(12)$ & $<0.05$ & --- \\
\hline $\begin{array}{r}\text { Day 31-Sham } \\
\text { Adrx }\end{array}$ & $\begin{array}{l}37.0 \pm 0.8(12) \\
36.7 \pm 0.8(7)\end{array}$ & $\begin{array}{l}\text { N.S. } \\
\text { N.S. }\end{array}$ & N.S. \\
\hline Day 32-Sham & $37.8 \pm 0.8(12)$ & N.S. & \\
\hline $\begin{array}{r}\text { Day 33-Sham } \\
\text { Adrx }\end{array}$ & $\begin{array}{l}38.5 \pm 0.3(12) \\
39.0 \pm 1.2(7)\end{array}$ & $\begin{array}{l}\text { N.S. } \\
\text { N.S. }\end{array}$ & N.S. \\
\hline Day 34-Sham & $38.9 \pm 0.4(12)$ & N.S. & --- \\
\hline Day 35-Sham & $37.8 \pm 0.4(8)$ & N.S. & --- \\
\hline
\end{tabular}

${ }^{+}$Mean \pm SEM (number of animals per group)

*Age at treatment. Adrx = bilaterally adrenalectomized;

Sham $=$ ether and laparotomy stress; all treatments performed at 8:00-9:00 AM

*iNot significant $(p>0.05)$ 
all were significantly different except for the groups adrenalectomized. at 28,31 and 33 days of age.

Since adrenalectomy on or before, but not after 25 days of age delayed puberty and since laparotomy at 26 , but not 25 days of age advanced puberty this two day developmental period was more closely investigated. The results are summarized in Table IX. Adrenalectomy performed at 8:00-9:00 AM on day 25 delayed puberty onset. However, the delay decreased in magnitude as 8:00-9:00 AM on day 26 was approached. Puberty onset in the animals adrenalectomized at 8:009:00 AM on day 25 occurred significantly later than those adrenalectomized twenty-four hours later $(p<0.01)$ but did not differ from the intermediate groups. Puberty also occurred later in the groups adrenalectomized at $9: 30-10: 30 \mathrm{PM}$ on day 25 than in the group adrenalectomized at 8:00-9:00 AM $(p<0.005)$, but not 1:00-2:00 AM on day 26 . Puberty onset following, adrenalectomy at 8:00-9:00 AM on day 26 was not different from that in the controls or in the groups adrenalectomized at 1:00-2:00 AM on day 26. The sham procedure induced a significant advancement of puberty when performed at 1:00-2:00 AM or 8:00-9:00 AM on day 26 but not when done earlier (8:00-9:00 AM or 9:30-10:30 PM on day 25).

Although body weights increased progressively during the prepuberal period, ovarian, adrenal, and uterine weights were found to be comparable in animals who came into puberty early (34-37 days of age) or late (38-42 days of age). Organ weights for those groups with seven or more animals are summarized in Table $X$. Weights of the control estrous (first ovulation) ovaries were significantly 


\section{TABLE IX}

Delineation of the Time Course of the Adrenalectomy-induced delay and Sham-induced advancement periods in Study 11 .

\begin{tabular}{lccc}
\hline Treatment Group & $\begin{array}{c}\text { Puberty Onset, } \\
\text { (days) }\end{array}$ & $\begin{array}{c}\text { P value } \\
\text { treatment } \\
\text { vs. control }\end{array}$ & $\begin{array}{c}\text { P value } \\
\text { sham vs. } \\
\text { adrenalectomy }\end{array}$ \\
\hline Control & $37.7 \pm 0.3(77)^{+}$ & $\ldots$ & $\ldots$
\end{tabular}

Day 25 8:00-9:00AM

$\begin{array}{llll}\text { Sham* } & 37.6 \pm 0.6(21) & \text { N.S. } * 6 \% & <0.001 \\ \text { Adrx } & 42.7 \pm 0.7(26) & <0.001 & \end{array}$

Day 25 9:30-10:30PM

$\begin{array}{llll}\text { Sham } & 37.0 \pm 0.7(15) & \text { N.S. } & <0.001 \\ \text { Adrx } & 41.3 \pm 0.6(18) & <0.001 & \end{array}$

Day 26 1:00-2:00AM

$\begin{array}{llll}\text { Sham } & 35.7 \pm 0.7(14) & <0.005 & <0.001 \\ \text { Adrx } & 40.5 \pm 1.0(16) & <0.001 & \end{array}$

Day 26 8:00-9:00AM

$\begin{array}{llll}\text { Sham } & 35.7 \pm 0.7(15) & <0.001 & <0.01 \\ \text { Adrx } & 38.2 \pm 0.7(26) & \text { N.S. } & \end{array}$

tMean \pm SEM (number of animals per group)

*Age and time of treatment; Sham = ether and laparotomy stress;

Adrx = bilateral adrenalectomy.

$\because$ Not significant $(p>0.05)$ 


\section{TABLE $X$}

Effect of Treatment on Ovarian, Uterine and Adrenal Weights in Study 11.

\begin{tabular}{|c|c|c|c|}
\hline Treatment Group & $\begin{array}{l}\text { Ovarian } \\
\text { weight, (mg.) } \\
\text { (ova/oviduct) }\end{array}$ & $\begin{array}{l}\text { Uterine } \\
\text { weight, (mg.) }\end{array}$ & $\begin{array}{c}\text { Adrenal } \\
\text { weight, (mg.) }\end{array}$ \\
\hline \multirow[t]{2}{*}{ Control } & $\begin{array}{l}18.9 \pm 0.9 \\
(6.3 \pm 0.2)\end{array}$ & $148.0 \pm 4.6(19-E)$ & $16.5 \pm 0.8(12)$ \\
\hline & $12.8 \pm 1.2(7-P)^{+}$ & $168.9 \pm 11.3(7-P)$ & \\
\hline Sham day $25 \%$ & $----x$ & $\cdots$ & $18.9 \pm 1.2(8)$ \\
\hline Sham day 27 & $\begin{array}{l}19.7 \pm 1.3(10-E) \\
(6.0 \pm 0.3)\end{array}$ & $154.4 \pm 11.8(9-E)$ & $16.3 \pm 0.8(12)$ \\
\hline Sham day 28 & ---- & $---\quad---$ & $17.1 \pm 1.0(11)$ \\
\hline Sham day 29 & $\begin{array}{l}16.7 \pm 1.1(9-E) \\
(6.4 \pm .2)\end{array}$ & $149.9 \pm .4 .9(9-E)$ & $14.4 \pm 0.7(12)$ \\
\hline Sham day 30 & $\cdots$ & $\cdots \quad-\cdots$ & $18.9 \pm 1.1$ (11) \\
\hline Sham day 31 & $\begin{array}{l}16.1 \pm 1.4(7-E) \\
(5.9 \pm 0.5)\end{array}$ & $153.5 \pm 7.7(7-E)$ & $15.3 \pm 0.8(9)$ \\
\hline Sham day 32 & 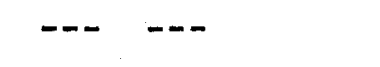 & $---\quad--$ & $17.5 \pm 0.8$ (9) \\
\hline Sham day 33 & $-\cdots \quad-\cdots$ & --- & $14.9 \pm 2.3(8)$ \\
\hline Sham day 34 & $\begin{array}{l}17.4 \pm 0.6(9-E) \\
(6.6 \pm .2)\end{array}$ & $159.1 \pm 11.4(9-E)$ & $17.5 \pm 0.8(12)$ \\
\hline Sham day 35 & ----- & --- & $17.7 \pm 1.2(8)$ \\
\hline Adrx days 24,25 & $(\overline{5} \cdot \overline{4} \pm \overline{3})(14-E)$ & $-\cdots$ & $\cdots$ \\
\hline $\begin{array}{c}\text { Adrx days } 26 \\
27 \text { and } 28\end{array}$ & $\begin{array}{l}15.4+1.1 \\
(5.4 \pm .3)\end{array} \quad(10-E)$ & $-\cdots \quad--$ & $-\cdots$ \\
\hline $\begin{array}{c}\text { Adrx days } 29, \\
31 \text { and } 33\end{array}$ & $\begin{array}{l}17.0 \pm 1.2(8-E) \\
(6.6 \pm 0.6)\end{array}$ & $---\cdots$ & $---\cdots$ \\
\hline
\end{tabular}

Hean \pm SEM (number of rats - cycle stage); $E=$ estrus, $P=$ proestrus; All animals autopsied at puberty onset.

$\therefore *$ Treatment age, Sham $=$ laparotomy and ether stress, Adrx = bilaterally adrenalectomized; treatment time 8:00-9:00 AM

**:Rats in these groups had less than 7 in this weight group and thus are not included. 
greater $(p<0.001)$ than those of the control proestrous ovaries (devoid of any corpora lutea); therefore proestrous and estrous are not conbined and only the weights of the estrous animals are reported because of their predominance. None of the sham animals' ovarian weights differed significantly from those of the controls. The adrenalectomized animals are grouped because of the low number of estrous animals in each group into those adrenalectomized at 26 through 28 days of age and those adrenalectomized at 29,31 and 33 days of age. Those adrenalectomized at 26-28 days of age had significantly lower ovarian weights when compared to controls $(p<0.02)$ whereas ovarian weights in those adrenalectomized at 29,31 and 33 days of age were comparable to those in the controls. The number of ova per oviduct, (Table $X)$ was lower $(p<0.01)$ in the animals adrenalectomized on or before day 28 than in the controls; in the other experimental groups ova counts were comparable to controls.

Uterine weights were not significantly greater at proestrus than at estrus in the controls and those in the estrous sham animals were not different from those in the control estrous group. Insufficient uterine weight data were collected for the adrenalectomized groups to make a valid comparison.

Adrenal weights in the control estrous and proestrous animals were not different and thus were pooled. There were no adrenal weight differences among the sham groups or between the shams and the controls.

Another comparison to be considered between animals treated at differing ages is the stage of the estrous cycle on the day of vaginal 
opening (Table $X I)$. To make group size more comparable the following divisions were made: sham day 25 , sham days $27-30$, sham days $31-35$, adrenalectomy days 24-25, adrenalectomy day 26 , and adrenalectomy days 27-33. The groups were classified as being in estrus, proestrus, or other (an undefinable stage of the cycle since no past cycle histories existed yet). In $30 / 46$ vaginal opening was coincident with the first estrus; the sham 25, sham 27-30, sham 31-35 and adrenalectomy 27-33 groups were not different in this respect. However, in the groups adrenalectomized at 24,25 , or 26 days of age significantly fewer animals were in estrus. Upon histological examination of ovaries from all groups no corpora lutea were observed in non-estrous animals indicating that ovulation did not occur prior to vaginal opening.

\section{Comments}

The above results clearly indicate there are two definable periods of prepuberal adrenal - gonadal interaction. One during which adrenalectomy delays and desynchronizes puberty and another during which sham surgery accelerates puberty. The sham induced advancement (day $261: 00-2: 00 A M$ to day 30$)$ is well defined while the period of adrenalectomy induced affects can be divided into an early period (prior to 25 days of age) during which adrenalectomy delays vaginal opening and decreases the number of animals ovulating on that day (and the number of ova per ovulation) and a later period (26 to 28 days of age) during which the effects of adrenalectomy are less profound resulting in a decreased ovarian weight due to a decreased number of ova, and corpora lutea per ovulation. Day 26 , the transitional day, has 


\section{TABLE XI}

Effect of Adrenalectomy and Laparotomy on Coincidence of First Estrus and Vaginal Opening in Study 11.

$\%$ Estrus $\frac{\text { Not Estrus }}{\% \text { Proestrus } \% \text { other }} \quad$ P value

Treatment Group

65.2

26.1

8.7

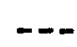

Sham $25 \%$

45.4

27.3

27.3

N.S. ${ }^{+}$

Sham 27-30

60.4

35.4

4.1

N.S.

Sham 31-35

55.4

26.8

17.8

N.S.

Adrx 24, 25*-

36.8

23.7

39.5

$<0.025$

Adrx 26

21.7

26.1

52.2

$<0.005$

Adrx 27-29, 31, 33 45.7

15.2

39.1

N.S.

$*$ Age at treatment, $A d r x=b i l a t e r a l l y$ adrenalectomized,

Sham = ether and laparotomy stress; treatments performed at 8:00-9:00 AM

*:Treatment performed at 9:30-10:30 PM also on day 25 .

${ }^{+}$Not significant $(p>0.05)$ 
characteristics of all periods: adrenalectomy resulting in a desynchrony of ovulation and vaginal opening, with and without a delay in vaginal opening and sham surgery advancing puberty.

Since adrenal autotransplantation reverses the adrenalectomy induced delay in puberty onset (Study 1), it would appear that the factor or factors are from the cortex. Progesterone is produced in the rat adrenal cortex in large amounts $(60)$ and its secretion is stimulated by ACTH (62) as is corticosterone secretion (213). Assuming that the adrenalectomy-induced delay and the sham-induced advancement of puberty is due to deficient and accelerated secretions respectively of the same factors, progesterone or corticosterone are likely candidates. The temporal proximity of the two periods points to one substance or two closely controlled substances. Circulating levels of both hormones would markedly decrease following adrenalectomy and increase during laparotomy stress. No effect of the stress procedures on adrenal weight was seen at the time of puberty but this does not negate the possibility of secretory changes at the time of the sham procedure.

Since body weight has been correlated with the age of onset of puberty in chronic under fed rats (105) the effect of adrenalectomy on body weight must be considered. In this study the body weight varied with the age of the animals so those reaching puberty - early weighed less and the converse. This was true for adrenalectomized animals which did not differ from the controls or shams at any age. The weight of the shams were slightly less in two groups when compared to controls supporting the fact that the attainment of a 
specific body weight is not as important as the maturation of the reproductive system itself. These results are in contrast to study 1 which showed that animals adrenalectomized at 18 or 25 days of age but not 35 days of age weighed less at 60-65 days of age indicating that a delay in puberty, via adrenalectomy may be involved in the long term weight gain of the animals. Uterine weight, which in the prepuberal control animals failed to demonstrate the normal proestrous rise may be due to deficiencies or imbalances at this young age in circulating hypophyseal and ovarian hormone levels was not affected by surgical procedures.

The question remains: What are the adrenal factors and how do they influence the reproductive system's development?

4. Conclusions

1. Puberty in this laboratory does not undergo a seasonal variation.

2. A period of adrenalectomy-induced delay in puberty onset in the female rat extends from 18 days of age to 1:00 AM at 26 days of age.

3. A period of sham-induced advancement in puberty onset extends from 1:00 AM on day 26 to 30 days of age in the female rat.

4. Adrenalectomy on or before day 28 decreases the number of ova per ovulation demonstrating the adrenals' effect on the sensitivity of the system to gonadotropins. 
5. Adrenalectomy on or before day 26 desynchronizes the two events of ovulation and vaginal opening; the first estrus occurring after vaginal opening instead of with it. This indicates that the adrenal may be responsible for synchronizing the timing mechanisms responsible for the first ovulation. 


\section{Study 111: Hormonal Effects on Vaginal Opening}

\section{Experimental Design}

In the previous studies puberty was delayed by adrenalectomy and advanced by laparotomy. Adrenal autotransplantation prevented the delay in puberty when done at 18 days of age but was ineffective when done at the end of the adrenalectomy - induced delay period. This period extends from 18 days of age until 26 days of age (at 1:00-2:00 AM), while the sham-induced advancement period begins at 1:00-2:00 AM on day 26 and extends until day 30.

While these studies were being carried out experiments were under way in attempts to identify the factor or factors responsible for the adrenals' effect on puberty onset. The hormones administered were: progesterone $(0.5 \mathrm{mg}$ Low dose, $\mathrm{L}$, and $1.0 \mathrm{mg} \mathrm{High} \mathrm{Dose,} \mathrm{H}$, in $0.1 \mathrm{cc}$ sesame seed oil) and corticosterone ( 5 gama in 0.1 cc $75 \%$ ethyl alcohol) because of their abundance in the adrenal cortex and their implications in the reproductive processes, and ACTH $(0.5 \mathrm{mg}$ Low dose, $\mathrm{L}$, and $1.25 \mathrm{mg} \mathrm{High} \mathrm{dose,} \mathrm{H}$, in $0.1 \mathrm{cc}$ water) in attempts to mimic any other factors which would increase as a result of stress beside progesterone and corticosterone. The vehicles, sesame seed oil and alcohol, $0.1 \mathrm{cc}$, were also administered as controls. The animals were divided into, untreated controls and 16 treatment groups according to the hormone (or vehicle) administered, the dose and the $\therefore$ ages at which they were given. Three treatment groups were injected at 19 through 22 days of age one receiving progesterone $-L$, one corticosterone and one ACTH-H. Seven groups were treated at 22 through 25 days of age each one with one of the following treatments: 
sesame seed oil, alcohol, Progesterone-L, Progesterone-H, Corticosterone, ACTH-L and ACTH-H. On days 25 through 28 four groups of animals were treated with one each of the following: sesame seed oil, alcohol, Progesterone-L and Corticosterone. Two separate groups were treated on day 25 only and received either Progesterone-L or ACTH-H. All injections were administered at 8:00-9:00 AM on the days specified and autopsies were performed at vaginal opening. Body, left adrenal, left ovary and uterine weights were obtained in most cases; ova counts were taken in estrous animals.

In another six groups of animals the hormone treatments were given in addition to adrenalectomy which was performed on day 25 . Injections were given on day 25 in attempts to replace hormones which the adrenalectomy had withdrawn from the circulation. Two groups received vehicles either alcohol or sesame seed oil and the other four groups received the following hormones: Progesterone-L, Corticosterone, Progesterone-H (two injections, one at the usual 8:009:00 AM and the other at 8:00-9:00 PM) and Progesterone-H plus Corticosterone. These animals were autopsied at puberty onset as above. 2. Results

The animals remained healthy. Body weights as in Study 11 were taken at puberty onset and thus varied with the age of the animal. Because of the many different treatment groups and lower group number, - this parameter is difficult to compare according to age but can be compared disregarding the age of puberty, since puberty did not differ from control in any group. This data is presented in Table XII. Body weight of any of the treatment groups did not differ from control. 
TABLE XI I

Effect of Hormone Treatment on Body Weight in Study 111 .

\begin{tabular}{llc}
\hline Treatment Group & Body Weight, $(G)$ & P Value Hormone \\
\hline
\end{tabular}

Control

$113.6 \pm 1.5(46)^{+}$

Injection days 19-22

$\begin{array}{lll}\text { Progesterone L } & 111.0 \pm 2.7(14) & \text { N.S. } \\ \text { Corticosterone } & 110.4 \pm 2.8(15) & \text { N.S. } \\ \text { ACTH-H } & 111.7 \pm 2.7(15) & \text { N.S. }\end{array}$

Injection days 22-25

\begin{tabular}{lll}
011 & $119.6 \pm 3.6(6)$ & N.S. \\
Alcohol & $111.9 \pm 1.9(6)$ & N.S. \\
Progesterone-L & $113.8 \pm 2.5(17)$ & N.S. \\
Progesterone-H & $120.2 \pm 8.3(17)$ & N.S. \\
Corticosterone & $110.1 \pm 2.1(18)$ & N.S. \\
ACTH-L & $109.9 \pm 2.0(16)$ & N.S. \\
ACTH-H & $113.3 \pm 2.5(17)$ & N.S. \\
Injection days 25-28 & $117.0 \pm 5.8(5)$ & N.S. \\
\hline $\begin{array}{l}\text { Oil } \\
\text { Alcohol }\end{array}$ & $111.3 \pm 3.2(10)$ & N.S. \\
Progesterone-L & $110.5 \pm 6.0(10)$ & N.S. \\
Corticosterone & $109.4 \pm 2.9(10)$ & N.S. \\
Injection day 25 & $116.6 \pm 2.7(9)$ & N.S. \\
Progesterone-L & $115.0 \pm 3.8(7)$ & N.S. \\
ACTH-H & &
\end{tabular}

${ }^{+}$Mean \pm SEM (number of animals)

All animals autopsied at puberty onset. 
Puberty onset (Table XIII) also did not differ from control in any of the treatment groups injected with either the hormones or vehicles at any of the ages. One group treated at 22 through 25 days of age with Progesterone- $L$ was advanced when compared to the oil control group but was not different from the control group.

The animals adrenalectomized on day 25 and also received hormone treatment (or vehicle) on day 25 (Table XIV) came into puberty at the same age as the untreated adrenalectomized animals but significantly later than the untreated controls. None of the hormone-treated adrenalectomized animals were different from their respective vehicle treated adrenalectomized animals. Thus, none of the hormone treatments affected the age of onset of puberty nor were they successful in reversing the adrenalectomy-induced delay in puberty onset.

The data for organ weights are presented in Table XV. Animals (of 6 or more) are grouped as in Study 11 . Ovarian and uterine weights are presented for estrous or proestrous animals separately and adrenal weights for estrous and proestrous animals are grouped together. When ovarlan weights were compared, either estrous or proestrous, between the controls and treatment groups no differences were demonstrable. The same was true for the comparisons of uterine weight. Adrenal weight comparisons where possible showed no differences. The number of ova per oviduct was the same for all animals including the treated - adrenalectomized animals.

Another consideration is the stage of the cycle at the time of vaginal opening (Table XVI). In the control animals $65 \%$ are in estrus at vaginal opening. These animals injected at days 19 through 22,25 
TABLE XIII

Effect of Hormone Treatment on Puberty Onset in Study 111 .

\begin{tabular}{|c|c|c|c|}
\hline Treatment Group & $\begin{array}{l}\text { Puberty onset, } \\
\text { (days) }\end{array}$ & $\begin{array}{c}\text { P Value } \\
\text { Hormone Treatment } \\
\text { vs. Control }\end{array}$ & $\begin{array}{c}\text { P Value } \\
\text { Hormone Treat } \\
\text { vs. Vehicle }\end{array}$ \\
\hline Control. & $37.7 \pm 0.3(77)^{+}$ & & \\
\hline \multicolumn{4}{|c|}{ Injection days $19-22$} \\
\hline Progesterone $L$ & $37.1 \pm 0.7(14)$ & N.S. & --- \\
\hline Corticosterone & $37.6 \pm 0.6(15)$ & N.S. & --- \\
\hline ACTH H & $38.7 \pm 0.5 \quad(15)$ & N.S. & $-\cdots$ \\
\hline \multicolumn{4}{|c|}{ Injection days 22-25 } \\
\hline Sesame seed oil & $39.0 \pm .7(6)$ & N.S. & $-\infty$ \\
\hline Alcohol $75 \%$ & $37.1 \pm .7(6)$ & N.S. & -- \\
\hline Progesterone L & $37.1 \pm 0.4(17)$ & N.S. & $<0.05$ \\
\hline Progesterone $H$ & $38.9 \pm 0.9(13)$ & N.S. & N.S. \\
\hline Corticosterone & $37.3 \pm 0.6(18)$ & N.S. & N.S. \\
\hline ACTH L & $37.9 \pm .7(16)$ & N.S. & -- \\
\hline ACTH H & $38.0 \pm 0.6(17)$ & N.S. & --- \\
\hline \multicolumn{4}{|c|}{ Injection days 25-28 } \\
\hline Sesame seed oil & $37.8 \pm 0.7(5)$ & N.S. & --- \\
\hline Alcohol $75 \%$ & $37.8 \pm 0.7(10)$ & N.S。 & $-\infty$ \\
\hline Progesterone $L$ & $37.4 \pm 1.0 \quad(10)$ & N.S. & N.S. \\
\hline Corticosterone & $37.3 \pm 0.6(10)$ & N.S. & N.S. \\
\hline \multicolumn{4}{|l|}{ Injection Day 25} \\
\hline Progesterone $L$ & $38.4 \pm 0.9 .(9)$ & N.S. & -- \\
\hline ACTH H & $37.7 \pm 1.1(7)$ & N.S. & --- \\
\hline
\end{tabular}

${ }^{+}$Mean \pm SEM (number of animals)

All animals autopsied at puberty onset. 
TABLE XIV

Effect of Hormone Treatment on Puberty Onset in Adrenalectomized Animals in Study 111.

\begin{tabular}{|c|c|c|c|c|}
\hline Treatment Group & $\begin{array}{l}\text { Puberty Onset } \\
\text { (days) }\end{array}$ & $\begin{array}{c}\text { P Value } \\
\text { Hormone Treatment } \\
\text { vs. Control }\end{array}$ & $\begin{array}{c}\text { P Value } \\
\text { Hormone Treatment } \\
\text { vs. Vehicle }\end{array}$ & $\begin{array}{l}\text { P Value } \\
\text { Hormone Treatment } \\
\text { vs. adrenalectomized }\end{array}$ \\
\hline Control & $37.7 \pm 0.3(77)^{+}$ & & & \\
\hline Adrx Day 25 & $43.6 \pm 0.9(14)$ & & & \\
\hline \multicolumn{5}{|l|}{ Injections on day 25} \\
\hline $\begin{array}{l}\text { Adrx + Sesame seed } \\
\text { oil }\end{array}$ & $42.6 \pm 1.2^{\circ}(5)$ & $<0.001$ & -- & N.S. \\
\hline Adrx + Alcohol $75 \%$ & $44.4 \pm 0.2(5)$ & $<0.001$ & -- & N.S. \\
\hline Adrx + Progesterone $L$ & $43.2 \pm 0.6(10)$ & $<0.001$ & N.S. & N.S. \\
\hline Adrx + Corticosterone & $42.1 \pm 1.0(8)$ & $<0.001$ & N.S. & N.S. \\
\hline $\begin{array}{l}\text { Adrx + Progesterone } H \\
\quad(2 \text { times })\end{array}$ & $42.1 \pm 1.3(10)$ & $<0.001$ & -- & N.S. \\
\hline $\begin{array}{c}\text { Adrx + Corticosterone } \\
+ \text { Progesterone } H\end{array}$ & $42.1 \pm 1.0(9)$ & $<0.001$ & -- & N.S. \\
\hline
\end{tabular}

${ }^{+}$Mean \pm SEM (number of animals)

All animals autopsied at puberty onset. 
TABLE XV

Effect of Hormone Treatment on Organ Weights in Study 111.

\begin{tabular}{|c|c|c|c|}
\hline Treatment Group & $\begin{array}{l}\text { Ovarian wt. (mg) } \\
\text { (ova/ovary) }\end{array}$ & $\begin{array}{l}\text { Uterine Wet } \\
\text { weight (mg) }\end{array}$ & $\begin{array}{l}\text { Adrenal } \\
\text { weight (mg) }\end{array}$ \\
\hline Control & $\begin{array}{l}12.8 \pm 1.2(7-P)^{+} \\
18.9 \pm 0.9(14-E) \\
(6.3 \pm 0.2)\end{array}$ & 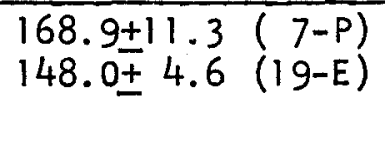 & $16.6 \pm 0.8(12)$ \\
\hline
\end{tabular}

Injection days 19-22

\begin{tabular}{lll}
\hline Progesterone L & $19.0 \pm 2.1(7-E)$ & $153.3 \pm 6.1(7-E)$ \\
& $(6.4 \pm 0.3)$ & \\
Corticosterone & $15.0 \pm 1.1(7-P)$ & $187.6 \pm 16.3(7-P)$ \\
& $19.6 \pm 2.7(6-E)$ & $148.1 \pm 7.1(6-E)$ \\
& $(5.6 \pm 0.4)$ \\
& $13.0 \pm 1.2(6-P)$ & $179.8 \pm 15.7(6-P)$ \\
ACTH-H & $19.9 \pm 1.2(6-E)$ & $162.2 \pm 16.2(6-E)$ \\
& $(6.7 \pm 0.6)$
\end{tabular}

Injection days 22-25

\begin{tabular}{|c|c|c|c|}
\hline Proges terone-H & $14.5 \pm 2.4(6-P)$ & -- & -- \\
\hline Corticosterone & $\begin{array}{l}18.7 \pm 0.7(8-E) \\
(6.2 \pm 0.4)\end{array}$ & $147.2 \pm 5.1(8-E)$ & $16.5 \pm 0.7(7)$ \\
\hline ACTH-L & $\begin{array}{l}16.9 \pm 1.0 \\
(6.6 \pm 0.7)\end{array}(7-E)$ & $163.5 \pm 8.4(7-E)$ & --- \\
\hline ACTH-H & $13.5 \pm 1.1(9-P)$ & $192.4 \pm 15.0(7-P)$ & $16.0 \pm 0.9(7)$ \\
\hline \multicolumn{4}{|c|}{ Injection days $25-28$} \\
\hline Proges terone-L & $\begin{array}{l}18.8 \pm 1.2(7-E) \\
(6.3 \pm 0.5)\end{array}$ & $150.6 \pm 6.6(6-E)$ & --- \\
\hline Alcohol & $\begin{array}{l}18.6 \pm 1.5(8-E) \\
(6.4 \pm 0.5)\end{array}$ & $155.7 \pm 3.4(7-E)$ & \\
\hline
\end{tabular}

Adrenalectomy day 25 injection day 25

Progesterone $L$

$$
(6.2 \pm 0.7)(6)
$$

Corticosterone $\quad(6.0 \pm .4)(6) \quad \cdot 146.5 \pm 4.4(6-E)$

${ }^{+}$Mean \pm SEM (number of animals)

$E=$ Estrus, $P=$ Proestrus

All animals autopsied at puberty onset 
TABLE XVI

Effect of Hormone Treatments on Coincidence of First Estrus and Vaginal Opening in Study 111.

\begin{tabular}{|c|c|c|c|c|}
\hline \multirow[b]{2}{*}{ Treatment Group } & \multirow[b]{2}{*}{$\%$ Estrus } & \multicolumn{2}{|c|}{ Not Estrus } & \multirow{2}{*}{$\begin{array}{l}\text { P Value } \\
\text { vs. Control }\end{array}$} \\
\hline & & $\%$ Proestrus & $\%$ other & \\
\hline Control & 65 & 26 & 9 & . . \\
\hline \multicolumn{5}{|c|}{ Injection days 19-22 } \\
\hline Progesterone $-\mathrm{L}$ & 50 & 36 & 14 & N.S. \\
\hline Corticosterone & 40 & 47 & 13 & N.S. \\
\hline ACTH-H & 40 & 40 & 20 & N.S. \\
\hline \multicolumn{5}{|c|}{ Injection days $22-25$} \\
\hline 011 & 83 & 17 & 0 & \\
\hline Alcohol & 17 & 66 & 17 & $<0.025$ \\
\hline Progesterone-L & 18 & 53 & 29 & $<0.05$ \\
\hline Progesterone-H & 23 & 46 & 31 & $<0.001$ \\
\hline Corticosterone & 61 & 39 & 0 & N.S. \\
\hline ACTH-L & 37 & 37 & 25 & N.S. \\
\hline ACTH-H & 35 & 53 & 12 & N.S. \\
\hline \multicolumn{5}{|c|}{ Injection days $25-28$} \\
\hline $0 i 1$ & 60 & 0 & 40 & N.S. \\
\hline Alcohol & 80 & 0 & 20 & N.S. \\
\hline Progesterone-L & 70 & 20 & 10 & N.S. \\
\hline Corticosterone & 50 & 20 & 30 & N.S. \\
\hline \multicolumn{5}{|l|}{ Injection day 25} \\
\hline Progesterone-L & 44 & 44 & 11 & N.S. \\
\hline ACTH-H & 42 & 42 & 14 & N.S. \\
\hline
\end{tabular}


through 28 , and day 25 with any of the hormones or vehicles were not different from the controls in this respect. The only differences existed in the groups injected at 22 through 25 days of age. Those receiving injections of oil, ACTH, or corticosterone were not different from controls but, those injected with progesterone, both high and low doses, and alcohol had significantly fewer estrous animals at vaginal opening when compared to controls. This was also true when the Progesterone $-\mathrm{L}$ and $-H$ were compared to the vehicle controls (oil treated animals $)(p<0.025$ and $<0.05$ respectively). When corticosterone is added to the vehicle, alcohol, the effect of the alcohol is reversed and the majority of the animals came into puberty at estrus.

When the same parameter is considered in the adrenalectomized animals (Table $\mathrm{XI}$ ) adrenalectomy decreases the number of estrous animals at vaginal opening. Injections on the day of adrenalectomy, day 25, reverses this adrenalectomy effect, and vaginal opening and the first estrous occurs at the same time, as in the controls (Table XVII). This is true for injections of Progesterone- $L$, Corticosterone, and Corticosterone plus Progersterone-H but not Progesterone-H (administered twice). Only five animals are in the vehicle treatment groups which are too low to be compared.

\section{Comments}

The injections given were kept within the physiological range rather than a pharmacological range and the lack of any change in body weight in any of the groups indicates that the attempts were successful. The lack of any change in puberty onset does not negate the possibility that any of the hormones; progesterone, corticosterone or ACTH has any 
TABLE XVII

Effect of Hormone Treatments on Coincidence of First Estrus and Vaginal Opening in Adrenalectomized Animals in Study 111.

Treatment Group $\quad \%$ Estrus $\frac{\text { Not Estrus }}{\text { \% Proestrus } \% \text { Other }} \quad \begin{gathered}\text { Palue } \\ \text { vs. Control }\end{gathered}$

Control

65

36

26

9

Adrx 25

25

39

$<0.05$

Adrx day $25+$ injection day 25

\begin{tabular}{|c|c|c|c|c|}
\hline Adrx +011 & 60 & 0 & 40 & \\
\hline Adrx + Al cohol & 40 & 40 & 20 & \\
\hline Adrx + Progesterone- $L$ & 75 & 25 & 0 & N.S. \\
\hline Adrx + Cortlicosterone & 100 & 0 & 0 & N.S. \\
\hline $\begin{array}{c}\text { Adrx + Progesterone-H } \\
(2 \text { times })\end{array}$ & 30 & 20 & 50 & $<0.05$ \\
\hline $\begin{array}{c}\text { Adrx }+ \text { Corticosterone } \\
\text { Progesterone-H }\end{array}$ & +56 & 33 & 11 & N.S. \\
\hline
\end{tabular}


effect on puberty but that on the days and at the doses given the hormones do not effect the onset of puberty in the intact female rat. The slight acceleration in puberty onset seen when the progesterone-L treated group at 22 through 25 days of age, is compared to the oil controls may be due to chance since neither of the groups are different from control. If this effect of progesterone is real, it is supported by the fact that the greatest. difference in the coincidence of the first estrus with vaginal opening is seen at the same treatment age. The lack of any change in organ weights shows that if any immediate changes are taking place due to the injections none are visable by the time of puberty onset. The coincidence of the first estrus with vaginal opening is very good in the controls and most treatment groups but the injections at days 22 through 25 are effective in desynchronizing the first estrus and vaginal opening. Progesterone at both high and low doses causes only a small percentage of the animals to be in estrus at vaginal opening; the majority being in proestrus. Alcohol also had appeared to desynchronize the system but, the corticosterone in alcohol did not. An explanation could be that the alcohol acted as a stress since $100 \%$ alcohol badly burns the animals causing scarring at the injection site one could assume that $75 \%$, although it did not cause any identifiable problems, might have caused a slight irritation. This stress could cause a rise in adrenal output via ACTH secretion but, when corticosterone was given with the alcohol the stress - evoked response was inhibited. Thus, it would seem that alcohol could also be mimicking the action of progesterone since it too would be secreted by the adrenal during stress. ACTH at 
high and low doses had no statistically significant effect but it did move the events apart. This effect may be difficult to mimic with ACTH since the half life of the hormone is very short and being in water is absorbed very quickly causing only a transient rise in ACTH levels.

Thus, it would seem that if any of the hormones administered are involved in the maturation of the reproductive processes from the evidence presented it could be progesterone. It is interesting to note that no effect of the injections was seen when they were administered on days 25 through 28 , or during the period of the stressadvancement (day 26 through day 30 ) where laparotomy causes an advancement of puberty. Here again it might be the dose that is critical to induce the advancement and the doses given did not mimic the effect of stress-surgery.

When animals were adrenalectomized and given hormone injection puberty was no different from the adrenalectomized control animals. Thus, even when injections of progesterone-H were given twice daily the adrenalectomy-induced delay could not be reversed. One effect the injections did have on the adrenalectomized animals was to increase the number of ova per ovulation. In the adrenalectomized animals the number of ova per ovulation was down from control (Table $X$ ). In the adrenalectomized progesterone or corticosterone treated rats the number of ova was not different from control (Table XV). Thus, al though the injections did not reverse the adrenalectomy-induced delay in puberty they do effect the functioning of the system. Another effect of the injections is seen on the colncidence of the first estrus with 
vaginal opening. Progesterone-L and Corticosterone and Progesterone-H plus corticosterone return synchrony to the system while Progesterone-H (twice daily) does not. From the table it would appear that oil also returns the system to normal but in both vehicle groups there are only 5 animals (Table XIV).

Therefore, although the onset of puberty is not affected by hormone injection the total synchrony of the system is affected. This would seem to stress the fact that the effects of adrenal hormones are subtle, affecting the precise timing mechanisms of the animals. If any of the hormones in particular are effective it would seem that progesterone is the most predominant. This is of consequence since the rhythm of corticosterone and progesterone in the adult are shown to be the opposite of one another (130); progesterone at a low when corticosterone is high and the opposite. Thus, as the Corticosterone rhythm is developing it could be assumed that the progesterone rhythm is also developing, and thus influencing the maturation process. It then becomes important to understand if the adrenal is undergoing any changes during development of the reproductive processes.

4. Conclusions

1. None of the hormones administered were effective in mimicking the effects of the stress-induced advancement of puberty onset.

2. None of the hormones replaced succeeded in reversing the adrenalectomy-induced delay in puberty onset as adrenal autotransplantation does. 
3. Injection of alcohol, Progesterone- $L$ and $-\mathrm{H}$ given at 22 through 25 days of age to intact rats desynchronizes vaginal opening and the first ovulation. Hormone replacement of progesterone- $L$, corticosterone, and corticosterone $\mathrm{plus}$ progesterone-H but not progesterone-H (given 2 times) given to adrenalectomized rats on day 25 , the day of adrenalectomy, synchronizes vaginal opening with the first estrus and increases the number of ova per ovulation. Indicating that the synchrony and sensitivity of the system may be dependent upon a specific hormone level about day 25. 
D. Study IV: Development of the System Regulating Adrenal

\section{Corticosterone Secretion}

1. Experimental Design

In a previous study by Allen and Kendall (6) the circadian rhythm of corticosterone was demonstrated to be present at 30-32 days of age and the response to stress present at 15 days of age. The problem with this study was that both males and females were pooled to determine the developmental rhythm and only sampled every five days. In a more recent study by Ader the rhythm in the female rat was shown to be present at 21 days in one experiment and at 25 days In another, but not before. Samplings here were made two to nine days apart. In the light of these studies the following study was designed to more closely examine the development of the corticosterone rhythm.

Animals were autopsied at 45 days of age at 12:30-1:30 AM, 7:30-8:30 AM and 3:30-4:30 PM and 7:30-8:30 PM and blood collected to determine if in our animals a circadian corticosterone rhythm existed in the adult. Once this was determined the next investigation was undertaken to investigate at what age the rhythm arises. Animals were autopsled at 7:30-8:30 AM and 7:30-8:30 PM on days 20, 22, 24, 25, 26,27 and 28 days of age. Only animals at 20 and 22 days of age were pooled ( 2 animals per pool) to make a determination; in all other groups. enough plasma was collected from each animal. Plasma corticosterone levels were determined.

2. Results

Table XVIII presents the results of the circadian study in the 
TABLE XVIII

Dally Variations in Plasma Corticosterone in Adult Rats in Study IV.

\begin{tabular}{lccc}
\hline & \multicolumn{1}{c}{$\begin{array}{c}\text { p Value vs. } \\
\text { Time }\end{array}$} & $\begin{array}{c}\text { P Value vs } \\
12: 30-1: 30 \mathrm{AM} \\
\text { level }\end{array}$ & $\begin{array}{c}7: 30-8: 30 \mathrm{PM} \\
\text { level }\end{array}$ \\
\hline $7: 30-8: 30 \mathrm{AM}$ & $6.4 \pm 1.0(8)^{+}$ & N.S. & $<0.001$ \\
$3: 30-4: 30 \mathrm{PM}$ & $13.8 \pm 1.4(8)$ & N.S. & $<0.001$ \\
$7: 30-8: 30 \mathrm{PM}$ & $37.0 \pm 1.9(18)$ & $<0.001$ & $-\ldots$ \\
$12: 30-1: 30 \mathrm{AM}$ & $8.9 \pm 2.0(9)$ & $-\ldots$ & $<0.001$ \\
\hline
\end{tabular}

${ }^{+}$Mean \pm SEM (number of animals)

All animals autopsied at 45 days of age 
45-day-old animals. It is apparent that a circadian rhythm exists, much like that described by other investigators (157), with a peak rise in the evening at 7:30-8:30 PM (of statistical significance, $p<0.001)$. The development of this rhythm in the prepuberal animal was then examined; Table XIX presents the results of the prepuberal study. In our animals the circadian rhythm is present at 20 days of age where the morning values are significantly lower than the evening values $(p<0.005)$. On each of the days following, the same rhythm appeared of similar magnitude with no noticeable change in the rhythm at 25 and 26 days of age. At any of the prepuberal days examined the peak levels were not as high as those demonstrated in the 45 day old adult female rat. Thus, the circadian rhythm is present at 20 days of age and undergoes no noticeable changes at the times sampled.

\section{Comments}

The results of this study agree well with a study published by Ramaley (157), which came out after this study was in progress. In her study animals were sampled at 8:00 PM and at noon and a circadian rhythm was established by 22 days of age with no noticeable change at 25 and 26 days of age visible. In a more recent study (159), days 22 and 26 were more closely examined; the noon and 4:00 PM corticosterone levels were higher on day 22 than on day 26 but the 8:00 PM peak levels were the same. This may be due to the fact that the 22-day-old animals were received the day before from the breeder and the levels were higher because of the slight stress. In animals raised in the laboratory and weaned at 21 days of age the peak corticosterone plasma level was obtalned at 4:00 AM on day 22 instead of the normal 8:00 PM. This 4:00 AM 
TABLE XIX

Dally Variations in Plasma Corticosterone in Prepuberal Female Rats in Study IV.

\begin{tabular}{|c|c|c|c|}
\hline $\begin{array}{l}\text { Age of Animals } \\
\text { at Autopsy. }\end{array}$ & $\begin{array}{l}\text { Hg corticosterone/ } \\
100 \mathrm{ml} \text { plasma } \\
\text { at } 7: 30-8: 30 \mathrm{AM}\end{array}$ & $\begin{array}{l}\mu \mathrm{gg} \text { corticosterone/ } \\
100 \mathrm{ml} \text { plasma } \\
\text { at } 7: 30-8: 30 \mathrm{PM}\end{array}$ & $\begin{array}{l}\text { P Value } \\
\text { AM Vs. PM }\end{array}$ \\
\hline 20 days & $6.8 \pm 0.4(8)^{+}$ & $14.9 \pm 1.2(9)$ & $<0.005$ \\
\hline 22 days & $6.4+0.8(8)$ & $16.1 \pm 1.2(8)$ & $<0.001$ \\
\hline 24 days & $8.9 \pm 1.3(7)$ & $17.8 \pm 1.3(8)$ & $<0.001$ \\
\hline 25 days & $7.0 \pm 0.7(12)$ & $19.4 \pm 2.1(10)$ & $<0.001$ \\
\hline 26 days & $6.9 \pm 1.0(8)$ & $17.5 \pm 1.0(10)$ & $<0.001$ \\
\hline 27 days & $8.0 \pm 1.0(9)$. & $16.9 \pm 1.4(7)$ & $<0.001$ \\
\hline 28 days & $7.1 \pm 1.2(6)$ & $20.2+4.1(6)$ & $<0.025$ \\
\hline
\end{tabular}

${ }^{+}$Mean \pm SEM (number of determinations) 
peak was not demonstrated in the breeder purchased rats at 22 or 26 days of age which Indicates the dependency of the rhythm upon external factors. Ader has supported this (3) by demonstrating that the rhythm can be induced to begin earlier (20 days of age) if the rats are handled or given electric shock as opposed to being left undisturbed. Therefore the stress of shipping may influence development of the rhythm in Ramaley's study and explain the difference between laboratory bred and purchased rats. Since our rats are weaned and shipped at 18 days of age this process may influence the development of the rhythm, and thus explain the early presence, 20 days of age, of the rhythm. The lower peak values in prepuberal rats as compared to the adult were also demonstrated by Ramaley (157), who showed that adult levels are attained at the time of vaginal opening.

Although the plasma levels of corticosterone appear to remain the same during the days and at the times studied it is possible that changes are occurring in adrenal secretion during these periods but that concurrent changes in clearance rate by the liver and/or steroid binding by blood proteins mask these changes. The results, failing to show any change in corticosterone levels, do not negate the possibility of changes in progesterone levels and the development of the adrenal progesterone rhythm during the prepuberal period. This progesterone rhythm may be later in developing and related to the increased adrenal secretion at the time of puberty.

4. Conclusions

1. A circadian rhythm of corticosterone secretion does exist in the adult rats in our colony. 
2. In the prepuberal rat this rhythm is already present by 20 days of age although its peak level is lower than that of the adult.

3. No change in this rhythm is observed from day 20 through day 28. Thus, the rhythm is well established by the time of the critical day 26 , which marks the transitional day between the adrenalectomy-induced delay period and the sham-induced advancement period. 


\section{CHAPTER IV}

\section{DISCUSSION}

The results of the four studies clearly indicate that the adrenals play a definite role in determining the onset of puberty in the female rat. The perlod of adrenalectomy-induced delay (18-26 days of age) and sham-induced advancement (26-30 days of age) (Study II) occur mostly during the late juvenlle perlod (20 days of age until puberty) in the female when both LH and FSH plasma levels are low and steroid feedback mechanisms are maturing. Rhythmic adrenal secretions have begun by day 20 (Study IV) and the system is al ready capable of responding to stress $(6,157)$. Thus, the periodiclty within the brain-pituitary-adrenal axis has begun well before the termination of the adrenalectomy-induced delay perlod; the sham-induced advancement period appears at least ten days after the system has become responsive to stress. The transitlonal day, day 26 , when the effects of both periods are demonstrable, coincides with the day reported by Ramaley (159) on which the adult pattern of circadlan plasma levels are attained.

The circadian rhythm of adrenal progesterone in the adult is the reciprocal of the corticosterone rhythm (130), the peak of one occurring at the trough of the other. This may be related to adrenal progesterone serving as a precursor for corticosterone synthesis. 
Thus, if this reciprocal relationship is true in the prepuberal female rat, changes in cortlcosterone may reflect changes in progesterone, and development of the adrenal rhythms may be closely related. Progesterone or corticosterone may be the factors responsible for the adrenal effect on puberty since both are cortical hormones (Study I) and both are implicated in the reproductive processes of the adult.

For the most part progesterone and corticosterone have been given the major consideration, but recently estrogen has been shown to be present in the newborn rat with peak levels occurring at 10 and 18 days of age (208). Interestingly enough removal of the ovaries does not lower the levels but adrenalectomy does significantly lower the prepuberal estrogen level. Unfortunately the investigations were only carried out until 24 days of age but, if estrogen continues to be a major product of the adrenal, and thus the major source of estrogen in the prepuberal animal, it could explain the adrenalectomy-induced delay and the sham-induced advancement of puberty. The animals prior to day 25 need the estrogen levels for normal development and puberty onset but after day 25 the ovary may be supplying this tonic level and adrenalectomy thus would no longer be effective in delaying puberty but would still be capable of affecting the fine timing of the system by desynchronizing vaginal opening and the first ovulation. The sham advancement may be due to an increased estrogen output by the adrenal during the sham procedure which influences the maturation process. Estrogen, when given parenterally from five days of age until thirty days of age induces the same advancement of puberty as when given from day 26 through 30 (164), the same days of the sham-advancement period 
(75). Therefore, in the prepuberal rat, adrenal estrogens may be playing an important role in the maturation process.

The mechanism of action of the adrenal hormones may be by a direct action on the ovaries, stimulating growth and development, or by a direct action on the CNS stimulating neural development or facllitating the release of gonadotropin by altering neural thresholds. The hormones may have an indirect action, controlling sensitivity of the ovaries or CNS to different hormones which normally act on these tissues, or possibly by exerting a permissive action on the ovaries or CNS as has been described for hydrocortisone and the pituitarythyrold system (12). Since many hormones are known to have biphasic actions depending on their clrculating level, this may apply to the action of adrenal hormones acting synergistically and antagonistically to affect the reproductive processes.

Different stresses have been shown to affect puberty onset: noise and vibratory stimulation delay puberty (37), handling advances puberty (143), while sham lesioning at the same ages has no effect (24). The action of these non-specific stresses may be through ACTH stimulation and, in light of the above considerations, differing stresses at various ages may lead to opposite effects due to the developmental changes of the adrenal gland itself. The action of stress is compounded by the possible action of adrenal medullary products which may influence the reproductive process.

Adrenalectomy has been shown to affect the sensitivity of immature animals of gonadotropins, adrenalectomy impairing the response to PMS and cortisone returning the response to normal (127). Ramaley 
has shown (158) that animals adrenalectomized prior to day 26 are less responsive to PMS than animals adrenalectomized and tested after day 26. This decreased sensitivity may explain the decreased number of ova per ovulation in the adrenalectomized animals (Study II) and the return to control following hormone replacement of corticosterone of progesterone (Study III). The adrenal hormones, estrogen, progesterone or corticosterone may be acting on the ovary or CNS to affect the sensitivity of the prepuberal animals, with adrenalectomy prior to day 26 having a more profound effect because of the greater dependency on adrenal hormones by the reproductive system.

High levels of ACTH can also inhibit the response to PMS; this adrenal-mediated response has a central site of action (87), and points to an inhibitory effect of high levels of adrenal hormones in the feedback process. The interpretation is difficult since PMS itself can augment the concentrations of progesterone in adrenal vein blood (17) and may play a role in the normal response to PMS as well as the response after high doses of ACTH. Adrenalectomy would then withdraw the facilitatory progesterone from the PMS response.

The synchrony of the reproductive system may depend upon the circulating levels of adrenal hormones (progesterone, corticosterone and/ or estrogen) at differing times of development. Thus, when injections of progesterone or alcohol are given at 22-25 days of age the fine tuning of the system is disturbed and the effect is desynchrony of ovulation and the first estrus. The desynchrony that ascompanies adrenalectomy before day 26 (Study II) may also reflect the importance of specific hormone levels since progesterone or corticosterone 
(Study III) can synchronize the finely tuned system.

In summary, the adrenals have a very definite role in the maturation of the hypothalamic-pituitary-ovarian axis. They not only have a role at the time of ovulation, as demonstrated in the adult (119), but have a developmental role as well, synchronizing the timing mechanisms of puberty and affecting the time of onset of puberty. The two definable periods of adrenal-gonadal interaction, the adrenalectomyinduced delay and the sham-induced advancement periods, demonstrate the profound effect the adrenal have upon the time of onset of puberty, and the precise timing of this interaction. The factor(s) from the adrenal cortex responsible for its effects may be progesterone, corticosterone or estrogen or a host of other factors yet to be inplicated. Whatever the factor(s) and the mechanism, it is clear that the adrenals play an important role in determining the time of onset of puberty in the female rat.

Conclusions:

1. Adrenalectomy at 18 and 25 but not 35 days of age delays puberty onset.

2. Adrenal autotransplantation at 18 but not 25 days of age reverses the adrenalectomy-induced delay in puberty by supplying adrenal cortical hormones to the circulation.

3. A period of adrenalectomy-induced delay in puberty onset in the rat extends from 18 days of age to 1:00 AM at 26 days of age.

4. A period of sham-induced advancement in puberty onset extends from 1:00 AM on day 26 to 30 days of age in the rat.

5. Adrenalectomy also effects the fine tuning of the system and the synchronizing of the first ovulation and the first estrus. 
1. Adams, W.M. and W.C. Wagner. The role of corticoids in parturition. Biol. of Reprod. 3: 223-228, 1970.

2. Addison, T. On the constitutional and local effects of disease of the supra-renal capsules. London, 1855.

3. Ader, R. Early experiences accelerate maturation of the 24-hour adrenocortical rhythm. Science 163: 1225-1226, 1969.

4. Alden, R.H. Implantation of the rat egg II. Alteration of osmiophilic epithelial lipids of the rat uterus under normal and experimental conditions. Anat. Rec. 97: 1-19, 1947.

5. Allen, E. and E.A. Doisy. An ovarian hormone: Preliminary report on its localization, extraction and partial purification, and action in test animals. ‥ Am. Med. Assoc. 81: 819-821, 1923.

6. Allen, C. and J.W. Kendall. Maturation of the circadian rhythm of plasma corticosterone in the rat. Endocr. 88: 926, 1967.

7. Allen, W.M. and 0 . Wintersteiner. Crystalline progestine. Science 80 (2069): 190-191, 1934.

8. Armstrong, D.T., K.A. Knudsen, and L.S. Miller. Effects of prolactin upon cholesterol metabolism and progesterone biosynthes is in corpora lutea of rats hypophysectomized during pseudopregnancy. Endocr. 86: 634-641, 1970.

9. Astwood, E.B. Changes in uterine weight and water content of the uterus of the normal adult rat. Am. J. Physiol. 126: 162-170, 1939.

10. Astwood, E.B. The regulation of corpora lutea function by hypohysial luteotrophin. Endocr. 28: 309, 1941.

11. Aterman, K. and S.M. Greenberg. Cortisone-induced "precocious puberty" in rats. Lancet 1: 545, 1952. 
12. Averill, R.L.W. and J.S. Evans. Is thyrotropin releasing factor (TRF) alone responsible for maintaining thyrotropin (TSH) synthesis in the pituitary gland? The Physiologist 13: $139,1970$.

13. Baker, F.D. and C.L. Kragt. Maturation of the hypothalamicpituitary-gonadal negative feedback system. Endocr. 85: 522-527, 1972.

14. Barnett, S.A. and E.M. Coleman. The effect of low environmental temperature on the reproductive cycle of female mice.

J. Endocr. 19: 232-240, 1959.

15. Barraclough, C.A., R. Collu, R. Massa, and L. Martini. Temporal interrelationships between plasma $L H$, ovarian secretion rates and peripheral plasma progestin concentrations in the rat: effects of nembutal and exogenous gonadotrophins. Endocr. 88: $1437-1447,1971$.

16. Bar-Sela, M.D. and V. Critchlow. Delayed puberty following electrical stimulation of amygdala in female rats. Am. J. Physiol. 211:

17. Bartosik, D., D.H. Szarowski, and D.J. Watson. Influence of functioning ovarian tissue on the secretion of progesterone by the adrenal glands of female rats. Endocr. 88: 1425$1428,1971$.

18. Baxter, J.D. and P.H. Forsham. Tissue effects of glucocorticoids. Am. ‥ Med. 53: $573,1972$.

19. Behrman, A.R., G.P. Orczyk, G.J. MacDonald, and R.0. Greep. Prolactin induction of enzymes controlling luteal cholesterol ester turnover. Endocr. 87: 1251-1256, 1970.

20. Bennett, H.S. The life history and secretion of the cells of the adrenal cortex of the cat. Am. J. Anat. 67: 151-228, 1940.

21. Bennett, H.S. and L. Kilham. The blood vessels of the adrenal gland of the adult cat. Anat. Rec. 77: 447-472, 1940.

22. Blivaiss, B.B., R.0. Hanson, R.E. Rosenzweig, and K. McNiel. Sexual development in female rats treated with cortisone. Proc. Soc. Exp. Biol. E Med. 86: 678-682, 1954.

23. Bloch, E. Fetal adrenal cortex: Function and steriodogenesis. Chapter 19. Function of the Adrenal Cortex, Vol. 2, ed. K.W. McKerns, Appleton-Century-Crofts, New York, 1968. 
24. Bloch, G.J. and W. F. Ganong. Lesions of the brain and the onset of puberty in the female rat. Endocr. 89: 898, 1971.

25. Boling, J.L. Growth and regression of corpora lutea during the normal estrous cycle of the rat. Anat. Rec. 82: 131-145, 1942.

26. Brimblecombe, R.W., I.D.K. Halkerston, and M. Reiss. The effect of various ACTH extracts on the gonads. Endocr. 10: 291301,1954 .

27. Brown-Sequard, C.E. Recherches experimentales sur la physiologie et la Pathologie des capsules surrenales. Compt. Rend. Acad. Scic. 43: $422-425,1856$.

28. Bush, I.E. Species differences in adrenocortical secretion. J. Endocr. 9: $95-100,1953$.

29. Calagaris, L., J.J. Astrada, and S. Taleisnik. Release of luteinizing hormone induced by estrogen injection into ovariectomized rats. Endocr. 88: 810-815, 1971 .

30. Christian, J.J. Actlons of ACTH in intact and corticoid-maintained adrenalectomized female mice with emphasis on the reproductive tract. Endocr. 75: 653-669, 1964.

31. Colby, H.D. and J.1. Kitay. Effects of gonadal hormones on adrenal steroid metabolism in vitro. Steroids 20: 143$157,1972$.

32. Corey, E.L. and S.W. Britton. The induction of precocious sexual maturity by cortico-adrenal extract. Am. ‥ Physiol. 99: $33-43,1931$.

33. Corey, E.L. and S.W. Britton. The ovarian cycle and the adrenal glands. Amer. ‥ Physiol. 107: 207-212, 1934.

34. Coyne, M.D. and J.I. Kitay. Effects of ovarlectomy on pituitary secretion of ACTH. Endocr. 85: 1097, 1969.

35. Coyne, M.D. and J.1. Kitay. Effect of orchiectomy on pituitary secretion of ACTH. Endocr. 89: 1024-1028, 1971.

36. Critchlow, $V$. "The role of lighting in the neuroendocrine system" pp. 377-426 in: Advances in Neuroendocrinology, ed. Andrew Nalbandov, Univ. of Illinois Press, Urbana, 1963.

37. Critchlow, V. and M.E. Bai-Sela. "Control of the onset of puberty" Chapter 20 in: Neuroendocrinology, Vol. 11 , ed. L. Martini and W.F. Ganong. Academic Press, New York, Pp. 101-162, 1967. 
38. Curey, J.T., $I I I$ and L.M. Heim. Brain myelination after neonatal administration of oestradiol. Nature 209: 915, 1966.

39. Dallman, M.F. and M.T. Jones. Corticosteroid feedback control of ACTH secretion: Effect of stress-induced corticosteroid secretion on subsequent stress responses in the rat. Endocr. 22: $1367-1375,1973$.

40. David, L., M.A. Martini, and F. Franschini. Control of LH secretion: Role of a "short" feedback mechanism. Endocr. 78: $55,1966$.

41. Davidson, J.M. and S. Feldman. Cerebral involvement in the inhibition of ACTH secretion by hydrocortisone. Endocr. 72: $936,1963$.

42. Dawson, A.B. and M. McCabe. The interstitial tissue of the ovary In infantile and juvenile rats. J. Morphol. 88: 543-571, 1951.

43. Deane, H.W. and R.0. Greep. Morphological and histochemical study of the rat's adrenal cortex after hypophysectomy with comments on the liver. Am. J. Anat. 79: 117, 1946.

44. Denef, C. and P. DeMoon. Puberty of the rat liver IV: Influences of estrogens upon the differentiation of cortisol metabolism induced by neonatal testosterone. Endocr. 85: 259, 1969.

45. Donovan, B.T. and J.J. Van der Werff ten Bosch. Precocious puberty in rats with hypothalamic lesions. Nature 178: 745, 1956.

46. Donovan, B.T. and J.J. Van der Werff ten Bosch. Physiology of Puberty. Edward Arnold Ltd., London, 1965.

47. Ducommun, P., E. Sakiz, and R. Guillemin. Lability of plasma TSH levels in the rat response to non-specific exteroceptive stimuli. Proc. Soc. Exp. Biol. E Med. 121: 921, 1966.

48. Dupon, C. and N.B. Schwartz. Pituitary LH patterns in prepuberal normal and testosterone-sterilized rats. Neuroendocr. 3: $236-248,1971$.

49. Eguchi, Y., K. Eguchi, and L.J. Wells. Compensatory hypertrophy of right adrenal after left adrenalectomy observation in fetal, newborn and week-old rats. Proc. Soc. Exp. Biol. E Med. 116: 89-92, 1964.

50. Elwers, M. and V. Critchlow. Precocious ovarian stimulation following hypothalamic and amygdaloid lesions in rats. Am. Physiol. 198: $381-385,1960$. 
51. Elwers, M. and V. Critchlow. Precocious ovarian stimulation following interruption of stria terminalis. Am. J. Physiol. 201: $281-284,1961$.

52. Endroczi, E. and K. Lissak. Hormonal feedback regulation of pit-adreno-cortical activity. Acta. physiol. Acad. Sci. Hung. 18: 291, 1961 .

53. Engle, E.T. The effects of daily transplants of the anterior lobe from gonadectomized rats on immature test animals. Am. $\underline{J}$. Physiol. 88: $101,1929$.

54. Evans, H.M. and J.A. Long. Characteristic effects upon growth oestrus, and ovulation induced by the intraperitoneal administration of fresh anterior hypophyseal substance. Proc. Nat. Acad. Sci. 8: $38-39,1922$.

55. Evans, H.M. and M.E. Simpson. A comparison of anterior hypophyseal implants from normal and gonadectomized animals with reference to their capacity to stimulate the immature ovary. Am. ‥ Physiol. 89: 371, 1929.

56. Everett, J.W. Evidence in the normal albino rat that progesterone facilitates ovulation and corpus-luteum formation. Endocr. 41: $364,1947$.

57. Everett, J.W. Progesterone and estrogen in the experimental control of ovulation time and other features of the estrous cycle in the rat. Endocr. 43: 389-405, 1948.

58. Everett, J.W. Central neural control of reproductive functions of the adeno hypohysis. Phys. Rey. 44: 373, 1964.

59. Everett, J.W. and C.H. Sawyer. A 24-hour periodicity in the 'LHrelease apparatus" of female rats, disclosed by barbiturate sedation. Endocr. 47: 198, 1950.

60. Fajer, A.B., M. Holzbauer, and H.M. Newport. The contribution of the adrenal gland to the total amount of progesterone produced in the female rat. J. Physiol. 214: 115-126, 1971.

61. Feder, H.H., K. Brown-Grant, and C.S. Corker. Preovulatory progesterone, the adrenal cortex and the 'critical period' for luteinizing hormone release in rats. J. Endocr. 50: 29-39, 1971.

62. Feder, H.H. and K.B. Ruf. Stimulation of progesterone release and estrous behavior by ACTH in ovariectomized rodents. Endocr. 84: $171-174,1969$. 
63. Feldman, S. Electrophysiological al terations in adrenalectomy. Arch. Neurol. I: 106, 1962.

64. Fiske, V.M. Effect of light on sexual maturation, estrous cycles and anterior pituitary of the rat. Endocr. 29: 187-196, 1941.

65. Florsheim, W.H. and P. Rudko. The development of portal system function in the rat. Neuroendocrinology 3: 89-98, 1969.

66. Forsham, P.H. and K.L. Melon. "The Adrenals" In: Textbook of Endocrinology, ed. Robert H. Willi iams, W.B. Saunders Co., Philadelphia, Pennsylvania, pp. 287-403, 1968.

67. Gala, R.R. and A. Westphal. Corticosteroid-building globulin in the rat: Studies on the sex difference. Endocr. 77: 841-851, 1965.

68. Ganong, W.F. The central nervous system and the synthesis and release of adrenocorticotropic hormone. In: Advances in Neuroendocrinology, ed., A.V. Nalbandov, Univ. Of Illinois Press, Urbana, 111 inois, pp. 92-157, 1963.

69. Gaunt, R. and W.M. Parkins. The alleged interrelationship of the adrenal cortical hormone and the gonads. Am. J. Physiol. 103: $511-516,1933$.

70. Gay, V.L., A.R. Midgley, and G.D. Niswender. Patterns of gonadotrophin secretion associated with ovulation. Fed. Proc. 29: $1880-1887,1970$.

71. Goldman, A.S., A.M. Bongiovanni, W.C. Yakovac, and A. Prader. Study of $\Delta^{5}-3 \beta$-hydroxysteroid dehydrogenase in normal, hyperplastic and neoplastic adrenal cortical tissue. J. clin. Endocr. 24: 894-909, 1964.

72. Goldman, B.D., Y.R. Grazla, I.A. Kamberi, and J.C. Porter. Serum gonadotropin concentrations in intact and castrated neonatal rats. Endocr. 88: $771-776,1971$.

73. Goldman, B.D. and R.A. Gorski. Effects of gonadal steroids on the secretion of LH and FSH in neonatal rats. Endocr. 89: 112, 1971.

74. Gonzaley-Luque, A., M. L'Age, A.P.S. Dhariwal, and F.E. Yates. Stimulation of corticotropin released by CRF or by vasopressin following intrapituitary infusions in unanesthetized dogs: Inhibition of response by dexamethasone. Endocr. 86: 1134, 1970.

75. Gorskl, M.E. and I.E. Lawton. Timing of prepuberal adrenal-ovarian interaction in the rat. Biol. of Reprod. Z: 112, 1972. 
76. Gorski, M.E. and 1.E. Lawton. Adrenal involvement in determining the time of onset of puberty in the rat. Endocr. 23: 1232, 1973.

77. Gorski, R。A. Modification of ovulatory mechanisms by postnatal administration of estrogen in the rat. Am. J. Physiol. 205: $842,1963$.

78. Gorskl, R.A. and C.A. Barraclough. Effects of low dosages of androgen on the differentiation of hypothalamic regulatory control of ovulation in the rat. Endocr. 73: 210-216, 1963.

79. Gray, P. Pituitary-adrenocortical response to stress in the neonatal rat. Endocr. 89: 1126-1128, 1971 .

80. Greene, R.R. and M.W. Burrill. Postnatal treatment of rats with sex hormones - the permanent effects on the ovary. Am. $\mathrm{J}$. Physiol. 133: 302-303, 1941 .

81. Greenwald, G.S. and 1. Rothchild. Formation and maintenance of corpora lutea in laboratory animals. J. Anim. Sci. Suppl. 1, 27: $139-162,1968$.

82. Grönroos, M. and 0. Kauppila. Hormonal-cyclic changes in rats under normal conditions and under stress as revealed by vaginal smears after Shorr Staining. Acta Endocr. 32: $261-271,1959$.

83. Guillemin, R. and R. Burgus. The hormones of the hypothalamus. Sci. Amer. 227: 24-33, 1972.

84. Gulllemin, R., G. Clayton, H.S. Lipscomb, and D. Smith. Fluorometric measurement of rat plasma and adrenal corticosterone concentration. J. Lab E Clin. Med. 53: 830, 1959.

85. Guillemin, R., G.Clayton, J.D. Smith, and H.S. Lipscomb. Measurement of free corticosteroids in rat plasma: Physiological validation of a nethod. Endocr. 63: $349,1958$.

86. Hagino, N. Ovulation and mating behavior in female rats under various environmental stresses or androgen treatment. The Jap. J. of Physiol. 18: $350-355,1968$.

87. Hagino, N., M. Watanabe, and J.W. Goldzieher. Inhibition by adrenocorticotrophin of gonadotrophin-induced ovulation in Immature female rats. Endocr. 84: 308-314, 1969.

88. Haning, R., S.A.S. Tait, and J.F. Tait. In vitro effects of ACTH anglotensin, serotonin and potassium on steroid output and conversion of corticosterone to aldosterone by isolated adrenal cells. Endocr. 87: 1147-1167, 1970. 
89. Harrington, F.E., F.J. Bex, R.L. Elton, and J.B. Roach. The ovulatory effects of follicle-stimulating hormone treated with chymotrypsin in chlorpromazine blocked rats. Acta Endocr. Copenhagen 65: 222-228, 1970.

90. Hartman, F.F. and K.A. Brownell. The hormone of the adrenal cortex. Science 72: 76, 1930.

91. Hayano, M., N. Saba, R.I. Dorfman, and 0. Hechter. Some aspects of the biogenesis of adrenal sterold hormones. Rec. Prog. in Hormone Res. 1: 79-123, 1956.

92. Hiroshige, T. and T. Sato. Postnatal development of circadian rhythm of corticotropin-releasing activity in the rat hypothalamus. Endocrinol. Jap. 17: 1-6, 1970.

93. Hiroshige, $T$. and $T$. Sato. Change in hypothalamic content of corticotropin-releasing activity following stress during neonatal maturation in the rat. Neuroendocr. 7: 257-270, 1971.

94. Hisaw, F.L. Development of the Graafian Follicle and ovulation. Phys. Rev. 27: 95-119, 1947.

95. Hodges, J.R. and J. Vernikos. Circulating corticotrophin in normal and adrenalectomized rats after stress. Acta Endocr. 30: $188-196,1959$.

96. Howard, $E$. The representation of the adrenal $X$ zone in rats in the light of observations on $X$ zone variability in mice. Am. J. Anat. 62: 351-373, 1937-38.

97. Hyyppa, M., M. Motto, and L. Martini. "Ultrashort" feedback control of follicle-stimulating hormone releasing factor-secretion. Neuroendocr. I: 227-235, 1971 .

98. Jacobel, P.W. and C.H. Rodgers. Adrenalectomy: Effects on mating behavior, ovulation, and early gestation in the cycling rat. Hormones E Behavior 2: 201-206, 1971 .

99. Jarrett, B.J. Effects of mode of action of adrenocorticotrophic hormones upon the reproductive tract of the female mouse. Endocr. 76: 434-440, 1965.

100. Josimovich, J.B., A.J. Ladman, and H.W. Deane. A histophysiological. study of the developing adrenal cortex of the rat during fetal and early postnatal stages. Endocr. 54: - 627, 1954. 
101. Kanematsu, S. and C.H. Sawyer. Effects of hypothalamic and hypophyslal estrogen implants on pituitary and plasma LH in ovarlectomized rabbits. Endocr. 75: 579, 1964.

102. Kar, A.B., J.N. Karkun, and S.K. Roy. The effect of adrenocorticotrophic hormone on genital organs of young female rats. Acta Endocr. 15: 101-108, 1954.

103. Kastin, A.J., A.V. Schally, S. Niosca, and M.C. Miller. MSH activity in plasma and pituitaries of rats after various treatments. Endocr. 84: 20, 1967.

104. Kendall, E.C. The adrenal cortex. Arch. Path. 32: 474-501, 1941.

105. Kennedy, G.C. and J. Mirta. Body weight and food intake as indicating factors for puberty in the rat. J. Physiol. 166: $408,1963$.

106. Kitay, J.1. Effect of pinealectomy on ovary weight in immature rats. Endocr. 54: 114-116, 1954.

107. Kitay, J.I. Sex differences in adrenal cortical secretion in the rat. Endocr. 68: 818-824, 1961.

108. Kitay, J.I. Pitultary-adrenal function in the rat after gonadectomy and gonadal hormone replacement. Endocr. 73: 253-260, 1963.

109. Kitay, J.I. "Effect of estrogen and androgen on the adrenal cortex" In: Functions of the Adrenal Cortex, Vol. 2, ed., K.W. Mckerns, pp. 775-827, 1968.

110. Knobil, E. and F.N. Briggs. Mechanlsm of fetal hypertrophy in the adrenalectomized pregnant rat. Fed. Proc. 13: 80, 1954.

111. Kobayashi, F., K. Hara, and T. Miyake. Facilitation of luteinizing hormone release by progesterone in proestrus rat. Endocr. Jap. 17: 149-155, 1970 .

112. Komrad, E.L. and L.C. Wyman. HIstamine tolerance in rats with intramuscular adrenocortical transplants. Endocr. 49: $481,1951$.

113. Kragt, C.L. and J. Dahlgren. Development of neural regulation of follicle stimulating hormone (FSH) secretion. Neuroendocr. 9: 30-40, 1972 .

114. Kragt, C.L. and W.F. Ganong. Pituitary FSH in male rats at varlous ages. Proc. Soc. Exp. Blol. E Med. 128: 965-967, 1968. 
115. Kragt, C.L. and W.F. Ganong. Pituitary FSH content in female rats at various ages. Endocr. 82: 1241-1244, 1968.

116. Kraicer, J. and R.G. Conrad. Clrculating adrenocorticotropin (ACTH) as a controlled variable in the regulation of ACTH secretion. Canadian J. of Physiol. E Pharm. 49: 744-751, 1971.

117. Lane, C.E. The follicular apparatus of the ovary of the immature rat and some of the factors which influence it. Anat. Rec.

61: $141-153,1935$.

118. Lane, C.E. and F.R. Davis. The ovary of the adult rat. I. Changes in growth of the follicle and in the volume and mitotic activity of the granulosa and theca during the estrous cycle. Anat. Rec. 73: 429-442, 1939.

119. Lawton, 1.E. Facilitatory feedback effects of adrenal and ovarian hormones on LH secretion. Endocr. 90: 575-579, 1972.

120. Libertun, C. and C. Lau. Adrenocortical function in prepuberal rats: Neonatal effects of testosterone. J. Endocr. 55: $221-223,1972$.

121. Loeb, R.F. Effect of sodlum chloride in treatment of a patient with Addison's Disease. Proc. Soc. Exp. Biol. E Med. 30: 808-813, 1932-33.

122. Long, J.A. and H.M. Evans. The oestrous cycle in the rat and its associated phenomena. Mem. Univ. Calif. 6: 1-148, 1922.

123. Lostroh, A.J. and R.E. Johnson. Amounts of interstitial-cellstimulating hormone and follicle stimulating hormone required for follicular development, uterine growth and ovulation in the hypophysectomlzed rat. Endocr. 79: 991-996, 1966.

124. MacCorquodale, D.W., S.A. Thayer, and E.A. Doisy. The crystalline ovarian follicular hormone. Proc. Soc. Exp. Blol. E Med. 32: $1182,1935$.

125. MacDonald, G.J. Effect of FSH, prolactin, and LH on serum progesterone levels in the cycling primate. Fed. Proc. 30: $309,1971$.

126. Malven, P.V. and W.R. Hoge. Effect of ergocornine on prolactin secretion by hypophyslal homografts. Endocr. 88: 444-449, 1971 .

127. Mandi, A.M. The sensitivity of adrenalectomized rats to gonadotrophins. J. Endocr. 11: 357-376, 1954. 
128. Mand1, A.M. and S. Zuckerman. Factors influencing the onset of puberty in albino rats. ‥ Endocr. 8: $377,1952$.

129. Manglli, G., M. Motta, and L. Martini. "Control of adrenocorticotropic hormone secretion", Chapter 9, In: Neuroendocrinology Vol. 1, ed., L. Martini and W.F. Ganong, Academic Press, New York, 1966.

130. Mann, D.R. and C.H. Barraclough. Changes In peripheral plasma progesterone during the rat 4-day estrous cycle: An adrenal diurnal rhythm. Proc. Soc. Exp. Blol. E Med. 142: 1226, 1973.

131. Martin, S.J. The effects of complete suprarenalectomy on the oestrual cycle of the white rat with reference to suprarenal-pituitary relationships. Am. ‥ Physiol. 100: 180$191,1931-32$.

132. Martin, S.J. and J.F. Fazekas. Effects of sodium chloride therapy on oestrous cycle and hypophysis of bilaterally suprarenalectomized rats. Proc. Soc. Exp. Biol. E Med. 37: 369-372, 1937.

133. McCann, S.M. and J.R. Brobeck. Evidence for a role of the supraopticohypophyseal system in the regulation of adrenocorticotrophin secretion. Proc. Soc. Exp. Blol. E Med. 87: 318, 1954.

134. McCormack, C.E. and R.K. Meyer. Minimal age for Induction of ovulation with progesterone in rats: Evidence for neural control. Endocr. 74: 793, 1964.

135. Mckeown, T. and W.R. Spurrell. The results of adrenalectomy in the pregnant albino rat. J. Physlol. 98: 255-262, 1940.

136. Meijs-Roelofs, H.M.A. Effect of electrical stimulation of the hypothalamus on gonadotrophin release on the onset of puberty. J. Endocr. 54: 277, 1972.

137. Meyer, R.K., S.J. Leonard, F.L. Hisaw, and S.J. Martin. Effect of estrin on the gonad stimulating power of the hypophysis. Proc. Soc. Exp. Biol. E Med. 27: 702-704, 1930.

138. Meyer, V. and E. Knobil. Growth hormone secretion in the unanesthetized Rhesus Monkey in response to noxious stimull. Endocr: 80: $163-171,1967$.

139. Milkovic, K. and S. Milkovic. "Adrenocorticotroplc hormone secretion in the fetus and infant", Chapter 10, In: Neuroendocrinology, Vol. 1, ed., Martini and Ganong, pp. 371-405, 1965. 
140. Miyachi, Y., E. Nieschlag, and M.B. Lipsett. The secretion of gonadotropins and testosterone by the neonatal male rat. Endocr. 92: 1-5, 1973.

141. Moon, H.D. Effect of adrenocorticotropic hormone on sexual development of spayed rats. Proc. Soc. Exp. Biol. E Med. 37: 36,1937 .

142. Moore, C.R. Adrenal cortical secretions in relation to the reproductive system of rats. J. Clin. Endocr. 13: 330-368, 1953.

143. Morton, J.R.C., V.H. Denenberg, and.M.X. Yarrow. Modification of sexual development through stimulation in Infancy. Endocr. 72: 439-442, 1963.

144. Nallar, R. and S.M. McCann. Luteinizing hormone-releasing activity in plasma of hypophysectomized rats. Endocr. 76: $272,1965$.

145. Nel11, J.D. Effect of 'stress' on serum prolactin and lutelnizing hormone levels during the estrous cycle of the rat. Endocr. 87: 1192-1197, 1970.

146. Neill, J.D. and L.E. Reichert, Jr. Development of radioimmunoassay for rat prolactin and evaluation in the NIAMD rat prolactin radioimmunoassay. Endocr. 88: 548-555, 1971.

147. Nelson, D.H. "Some effects of estrogens on the metabolic action and secretion of adrenal steroids", In: Functions of the Adrenal Cortex, Vol. 2, ed. by McKerns, pp. 813-827,

148. Nequin, L.G. and N.B. Schwartz. Adrenal participation in the timing of mating and $L H$ release in the cyclic rat. Endocr. 88: $325-331,1971$.

149. Nishikawa, M., I. Murone, and T. Sato. Electron microscopic examination of the adrenal cortex. Endocr. 72: 197-209, 1963.

150. Noumura, T. Development of the hypophyseal-adrenocortical system in the rat embryo in relation to the maternal system. Jap. J. Zool. 12: 279-299, 1959.

151. Ojeda, S.R. and V.D. Ramirez. Plasma levels of LH and FSH in maturing rats: Response to hemigonadectomy. Endocr. 90: $466-472,1972$.

152. Parkes, A.S. The adrenal-gonad relationship. Phys. Rev. 25: 203-254, 1945. 
153. Parlow, A.F. Differential action of small doses of estradiol on gonadotrophins in the rat. Endocr. 75: 1, 1964.

154. Pfeiffer, C.A. Sexual differences of the hypophyses and their determination by the gonads. Am. J. Anat. 58: 195-225, 1936.

155. Pfeiffner, J.J. The adrenal cortical hormones. Adv. In Enzymology 2: $325-356,1942$.

156. Ramaley, J.A. Steroid binding to serum proteins in maturing male and female rats. Endocr. 89: 545-552, 1971.

157. Ramaley, J.A. Changes in dally serum corticosterone values in maturing male and female rats. Steroids 20: 185, 1972.

158. Ramaley, J.A. Role of the adrenal PMS-induced ovulation before puberty: Effect of adrenalectomy. Endocr. 92: 881, 1972.

159. Ramaley, J.A. The development of dally changes in serum cortlcosterone in pre-weaning rats. Steroids 21: 433, 1973.

160. Ramaley, J.A. and E.L. Burn. Seasonal varlation in the onset of puberty in rats. Endocr. 91: 611, 1972.

161. Ramirez, V.D., R.M. Abrams, and S.M. McCann. Effect of estradiol implants in the hypothtlamo-hypophysial region of the rat on the secretion of luteinizing hormone. Endocr. 75: 243, 1964.

162. Ramirez, V.D. and S.M. McCann. Comparison of the regulation of luteinizing hormone (LH) secretion in immature and adult rats. Endocr. 72 : $452-464 ; 1963$.

163. Ramirez, V.D. and S.M. McCann. Fluctuations in plasma LH concentration during the estrous cycle of the rat. Endocr. 74: $814,1964$.

164. Ramlrez, V.D. and C.H. Sawyer. Advancement of puberty in the female rat by estrogen. Endocr. 76: 1158-1168, 1965.

165. Raps, D., P.L. Barthe, and P.A. Desaulles. Plasma and adrenal corticosterone levels during the different phases of the sexual cycle in normal female rats. Experentia 27: 399, 1971.

166. Reichstein, T. and C.W. Shoppee. "The hormones of the adrenal cortex", In: Vitamins and Hormones, Pp. 346-414, 1943.

167. Reiter, E.O., R.L. Goldenberg, J.L. Valtukitis, and G.F. Ross. A role for endogenous estrogen in normal ovarian development in the neonatal rat. Endocr. 91: 1537-1539, 1972. 
168. Relkin, R. Relative efficacy of pinealectomy, hypothalamic and amygdalold lesions in advancing puberty. Endocr. 88: 415, 1971.

169. Relkin, R. Absence of alteration in puberal onset in male rats following amygdaloid lesioning. Endocr. 88: 1272, 1971.

170. Resko, J.S., H.H. Feder, and R.W. Goy. Androgen concentrations in plasma and testis of developing rats. J. Endocr. 40: 485-491, 1968.

171. Rothchild, 1. Interrelations between progesterone and the ovary, pitultary, and the central nervous system, in the control of ovulation and the regulation of progesterone secretions. vitam. Horm. , New York 23: 209-237, 1965.

172. Schaberg, A., C.A. deGroot, and S. Sollewin Gelpke. Corticotrophic activity of the foetal and neonatal anterior hypophysis in vitro. Acta Physlol. Pharmacol Neurl. 8: $447-456,1959$.

173. Schapiro, S., J. Marmorston, and H. Sobel. Steroid feedback mechanisms. Am. ‥ Physiol. 192: $58-62,1958$.

174. Schiavi, R.C. Effect of anterior and posterior hypothalamic lesions on precoclous sexual maturity. Am. J. Physiol. 206: 805-810, 1964.

175. Schmidt, A.L.C. and A.P.L. Christiaans. An oestrogenic effect as a component of the stress syndrome. Acta Endocr. 46: $421-439,1964$.

176. Schwartz, N.B. Acute effects of ovariectomy on pituitary LH uterine weight and vaginal cornification. Am. J. Physiol. 207: $1251,1964$.

177. Schwartz, N.B. A model for the regulation of ovulation in the rat. Recent Prog. In Hormone Res. 25: 1-55, 1969.

178. Schwartz, N.B. The role of FSH and LH and their antibodies on follicle growth and ovulation. Symposium on Mechanism of Ovulation: Soclety for the Study of Reproduction, Aug. $14-16,1973$.

179. Schwartz, N.B. and D. Caldarelli. Plasma LH in cyclic female rats. Proc. Soc. Exp. Biol. E Med. 119: 16,1965.

180. Schwartz, N.B. and C.A. Ely. Comparison of effects of hypophysectomy, antiserum to ovine LH and ovarlectomy on estrogen secretion during the rat estrous cycle. Endocr. 86: 1420$1435,1970$. 
181. Schwartz, N.B. and C.E. McCormack. Reproduction: Gonadal function and its regulation. Ann. Rev. of Physiol. 34: 425-472, 1972.

182. Seiden, G. and A. Brodish. Physiological evidence for 'shortToop' feedback effects of ACTH on hypothalamic CRF. Neuroendocr. 8: $154-164,1971$.

183. Seiden, G. and A. Grodish. Persistence of a diurnal rhythm in hypothalamic corticotrophin-releasing factor (CRF) in the absence of hormone feedback. Endocr. 90: 1401-1403, 1972.

184. Selye, H. Studies on adaptation. Endocr. 21: 169-188, 1937.

185. Selye, H. The gereral adaptation syndrome and the diseases of adaptation. J. Clin. Endocr. 6: 117-234, 1946.

186. Seperstein, E.R. and K.J. Miller. Further cytophysiologic evidence for identity of the cells that produce adrenocorticotrophin hormone. Endocr. 86: 461-486, 1969.

187. Silber, R.H., R.D. Busch, and R.0slapas. Practical procedure for estimation of corticosterone or hydrocortisone. Clin. Chem. 4: 278, 1958.

188. Singer, S. and G. Litwack. Effect of age and sex on ${ }^{3} H$-cortisol uptake, binding and metabolism in liver and on enzyme induction capacity. Endocr. 88: 1448-1455, 1971.

189. Slusher, M.A. Dissociation of adrenal ascorbic acid and cortisone responses to stress with hypothalamic lesions. Endocr. 63: 412, 1958.

190. Slusher, M.A. Effect of chronic hypothalamin lesions of diurnal and stress corticosteroid levels. Am. J. Physiol. 206: 1161-1164, 1964.

191. Smith, E.K. The interrelationship of the anterior pituitary and the adrenal cortex in the rat ovarian hyperemia reaction. Endocr. 56: 567-574, 1955.

192. Smith, E.K., J. Johnson, R.F. Werck, S. Levine, and J.M. Davidson. Inhibition of the reproductive system in immature rats by intracerebral implantation of cortisol. Neuroendocr. 94-106, 1971.

193. Smith, P.E. The disabilities caused by hypophysectomy and their repair: The tuberal (hypothalamic) syndrome in the rat. ‥ Am. Med. Assoc. 88: 158-161, 1927. 
194. Swanson, H.E. and J.J. Van Der Werff Ten Bosch. Sex differences in growth of rats, and their modification by a single injection of testosterone proplonate shortly after birth. J. Endocr. 26: $197-207,1963$.

195. Swingle, W.W., J.J. Pfelffner, N.H. Vars, P.A. Bott, and H.M. Parkins. The function of the adrenal cortical hormone and the cause of death from adrenal insufficiency. Science 77 : 58-64, 1933.

196. Swingle, W.W. and J.J. Pfelffner. Experiments with an active extract of the suprarenal cortex. Anat. Rec. 44: 225-226, 1929.

197. Swingle, W.W. and J.W. Remengton. The role of the adrenal cortex in physiological processes. Phys. Rev. 24: 89-127, 1944.

198. Takebe, K., M. Sakakura, and K. Mashimo. Continuance of diurnal rhythmicity of CRF activity in hypophysectomlzed rats. Endocr. 90: 1515-1519, 1972.

199. Taleisnik, S., L. Caligaris, and J.J. Astrada. Positive feedback of progesterone on the release of FSH and the influence of sex in rats. J. Reprod. Fert. 22: 89-98, 1970.

200. Thoman, E.B., M. Spiroul, B. Seeler, and S. Levine. Influence of adrenalectomy in female rats on reproductive processes including effects on the foetus and offspring. J. Endocr. 46: $297-303,1970$.

201. Tyler, F.H. and C.D. West. Laboratory evaluation of disorders of the adrenal cortex. The Am. J. Med. 53: 664, 1972.

202. Van Dorp, A.W.V. and H.W. Deane. A morphological and cytochemical study of the postnatal development of the rats adrenal cortex. Anat. Rec. 107: 265-274, 1950.

203. Vincent, W.S. and E.J. Dornfield. Locallization and the role of nucleic acid in the developing rat ovary. Am. J. Anat. 83: $437,1948$.

204. Wade, N.J. and L.A. Haselwood. Effect of removal of ovaries and adrenals on opening of the vagina in the albino rat. Endocr. 28: 624,1941 .

205. Weaver, J.A. Changes induced in the thymus and lymph nodes of the rat by the administration of cortisone and sex hormones and by other procedures. J. Path. Bacteriol. 69: 133, 1955. 
206. Weick, R.F. and J.M. Davidson. Locallzation of the stimulatory feedback effect of estrogen on ovulation in the rat. Endocr. 87: 693-700, 1970.

207. Weick, R.F., E.R. Smith, R. Domiquez, A. D'Hariwal, and J.M. Davidson. Mechanism of stimulatory feedback effect of estradiol benzoate on the pituitary. Endocr. 88: 293$301,1971$.

208. Weisz, J. and P. Gunsalus. Estrogen levels in immature female rats: True or Spurious--Ovarian or adrenal. Endocr. 93 1057-1065, 1973.

209. Whalen, R.E. and W.G. Luttge. Role of the adrenal in the preferential accumulation of progestin by mesencephalic structures. Steroids 18: 141-146, 1971 .

210. Wintersteiner, 0 . and W.M. Allen. Crystallin progestin. J. Biol. Chem. 107: $321-336,1934$.

211. Wurtman, R.J., J. Axelrod, and E.W. Chu. Melatonin, a pineal substance: Effect on the rat ovary. Sclence 141: 277$278,1963$.

212. Wuttke, W., E. Cassell, and J. Meltes. Effect of ergocornine on serum prolactin and $L H$ and on hypothalamic content of PIF and LRF. Endocr. 88: 737-741, 1971.

213. Yates, F.E. and J. Urquhart. Control of plasma concentrations of adrenocortical hormones. Phys. Rev. 42: 359, 1962.

214. Yates, F.E., S.E. Leeman, D.W. Glenlster, and M.F. Dallman. Interaction between plasma corticosterone concentration and adrenocorticotroplc releasing stimuli in the rat: Evidence for reset of an endocrine feedback control. Endocr. 69: $67-80,1961$.

215. Ying, S.Y. and R.K. Meyer. Facilitation of ovulation by steroids in immature rats primed with pregnant mare serum gonadotropin. Steroids 20: 237-245, 1972.

216. Young, W.C. Sex and Internal Secretions, Chapter 19, "The hormones and mating behavior"'. W.C. Young, ed., Wllliams \& Wilkins Co., Baltimore, 1961.

217. Zimmermann, E. and V. Critchlow. Suppression of pltuitary-adrenal function with physiological levels of corticosterone. Neuroendocr. 5: 183-192, 1962. 
206. Weick, R.F. and J.M. Davidson. Locallzation of the stimulatory feedback effect of estrogen on ovulation in the rat. Endocr. 87: 693-700, 1970.

207. Weick, R.F., E.R. Smith, R. Domiquez, A. D'Hariwal, and J.M. Davidson. Mechanism of stimulatory feedback effect of estradiol benzoate on the pituitary. Endocr. 88: 293$301,1971$.

208. Weisz, J. and P. Gunsalus. Estrogen levels in immature female rats: True or Spurious--Ovarian or adrenal. Endocr. 93 1057-1065, 1973.

209. Whalen, R.E. and W.G. Luttge. Role of the adrenal in the preferential accumulation of progestin by mesencephalic structures. Steroids 18: 141-146, 1971 .

210. Wintersteiner, 0 . and W.M. Allen. Crystallin progestin. J. Biol. Chem. 107: $321-336,1934$.

211. Wurtman, R.J., J. Axelrod, and E.W. Chu. Melatonin, a pineal substance: Effect on the rat ovary. Sclence 141: 277$278,1963$.

212. Wuttke, W., E. Cassèll, and J. Meites. Effect of ergocornine on serum prolactin and $L H$ and on hypothalamic content of PIF and LRF. Endocr. 88: 737-741, 1971.

213. Yates, F.E. and J. Urquhart. Control of plasma concentrations of adrenocortical hormones. Phys. Rev. 42: 359, 1962.

214. Yates, F.E., S.E. Leeman, D.W. Glenlster, and M.F. Dallman. Interaction between plasma corticosterone concentration and adrenocorticotropic releasing stimuli in the rat: Evidence for reset of an endocrine feedback control. Endocr. 69: $67-80,1961$.

2.15. Ying, S.Y. and R.K. Meyer. Facllitation of ovulation by steroids in immature rats primed with pregnant mare serum gonadotropin. Steroids 20: 237-245, 1972.

216. Young, W.C. Sex and Internal Secretions, Chapter 19, "The hormones and mating behavior". W.C. Young, ed., Williams E Wilkins Co., Baltimore, 1961 .

217. Zimmermann, E. and V. Critchlow. Suppression of pltuitary-adrenal function with physiological levels of corticosterone. Neuroendocr. 5: 183-192, 1962. 
218. Zimmermann, E., R. Smyzl, and V. Critchlow. Suppression of pitultary-adrenal response to stress with physiological plasma levels of corticosterone in the female rat.

Neuroendocr. 10: 246-256, 1972.

219. Zwemer, R.L. An experimental study in the adrenal cortex.

Am. J. Physiol. 79: 645-665, 1927. 
The dissertation submited by Marianne Gorski Firlit has been read and approved by the following five members of the dissertation committee:

Irene E. Lawton, Ph.D., Honorary Chairman

Northwestern University Medical School

Clarence N. Peiss, Ph.D., Chaiman

Professor, Physiology and Associate Dean, Gractuate School

Loyola, Stritch School of Medicine

Robert Hadek, Ph.D., D.V.M.

Associate Professor, Anatomy

Loyola, Stritch School of Medicine

WaIter C. Randall, Ph.D.

Professor and Chairman, Physiology

Loyola, Stritch School of Medicine

Neena B. Schwartz, Ph.D.

Professor, Phystology

Northwestern University Medical School

The final copies have been examined by the director of the

dissertation and the signiture which appears below verifies the fact that any necessary changes have been incorporated and that the dissertation is now given final approval by the Committee with reference to content and form.

The dissertation is therefore accepted in partial fulfillment of the requirements for the degree of Doctor of Philosophy.

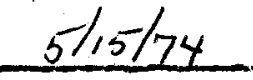

Date

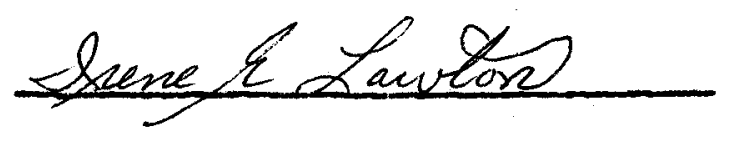

Signature of Advisor

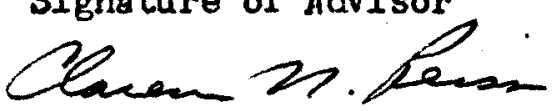

